THALES PIRES DIAS GALUCHI

\title{
MONTAGEM E CARACTERIZAÇÃO DE UNIDADE DE ELETRODIÁLISE EM ESCALA DE LABORATÓRIO PARA TRATAMENTO DE SOLUÇÕES SALINAS
}

Dissertação apresentada à Escola

Politécnica da Universidade de São

Paulo para obtenção de título de Mestre em Engenharia. 
THALES PIRES DIAS GALUCHI

\section{MONTAGEM E CARACTERIZAÇÃO DE UNIDADE DE ELETRODIÁLISE EM ESCALA DE LABORATÓRIO PARA TRATAMENTO DE SOLUÇÕES SALINAS}

Dissertação apresentada à Escola

Politécnica da Universidade de São

Paulo para obtenção de título de Mestre em Engenharia.

Área de concentração:

Engenharia Química

Orientador:

Prof. Dr. Roberto Guardani 
A meus pais Pedro e Roseli e minha "Garoutha" Sabrina 


\section{AGRADECIMENTOS}

Aos meus familiares que tanto me incentivaram e apoiaram na realização do Mestrado.

Ao Prof. Roberto Guardani pela confiança e dedicação dispensada na evolução do trabalho.

Aos companheiros do laboratório do Departamento de Engenharia Química da USP.

Ao Conselho Nacional de Desenvolvimento Científico e Tecnológico (CNPq) pelo apoio financeiro. 


\section{RESUMO}

A escassez de água nos grandes centros urbanos deve se agravar nos próximos anos. Novas fontes de água são necessárias para suprir a demanda. Nas cidades não há disponibilidade de terrenos para construção de estações de tratamento de águas e esgotos convencionais. Por isso, são necessários novos processos de tratamento. Processos de separação por membranas como osmose reversa e eletrodiálise são usados na dessalinização de águas e efluentes.

Para a realização do estudo foi montada unidade de eletrodiálise em escala de laboratório. Na montagem selecionaram-se equipamentos que fossem resistentes à salinidade das soluções. As bombas magnéticas deveriam, ainda, superar a perda de cargas causada pelas membranas. As membranas foram adquiridas no exterior; os equipamentos, no mercado local.

Os experimentos foram realizados em duas etapas: exploratória e comparativa. Eles seguiram os planejamentos de fatorial e do tipo Doehlert, respectivamente. Estudou-se a dessalinização de soluções aquosas unitárias $(\mathrm{NaCl}$, $\mathrm{Na}_{2} \mathrm{SO}_{4}, \mathrm{MgCl}_{2}$ e $\left.\mathrm{KCl}\right)$, com salinidade similar à água marinha (3,5\%).

Obtiveram-se como respostas os fluxos de sal, de água e consumo de energia em função dos fatores envolvidos no processo. Análises estatísticas propiciaram relacionar os fatores estudados com os resultados empíricos.

Os fluxos salinos são proporcionais às densidade de corrente aplicadas e não apresentaram diferenças significativas entre si. Observou-se que o fluxo de água é relevante pelo mecanismo de solvatação de íons removidos e pela osmose. $O$ consumo de energia é proporcional à densidade de corrente e maior para os sais bivalentes.

Palavras-chave: eletrodiálise (tratamento de água); membranas de separação; dessalinização; processos de separação. 


\section{ABSTRACT}

Water shortage in urban centers is expected to get worse in the next years. New water sources are necessary to meet demand. At urban area there are no available lands to build conventional water and sewage treatment plants. Therefore, new treatment processes are needed. Membrane processes like reverse osmosis and electrodialysis are used in water and wastewater desalination.

A lab-scale electrodialysis unit was assembled for the study, based on a stack of electrodialysis membranes and support components that are capable of resisting solution salinity. The membrane stack was imported; the other equipment, obtained locally.

The experiments were divided in two phases: exploratory and comparative. The experiments followed factorial and Doehlert designs, respectively. The desalination of aqueous solutions containing different inorganic salts $\left(\mathrm{NaCl}, \mathrm{Na}_{2} \mathrm{SO}_{4}\right.$, $\mathrm{MgCl}_{2}$ e $\mathrm{KCl}$ ) in seawater salinity (3.5\% mass) was studied.

The responses were the salt and water fluxes and energy consumption in function of the processes variables selected. By means of a statistical analysis, it was possible to obtain the correlations for the studied factors based on the experimental results.

The salt fluxes are proportional to the applied current density and they are not significantlydifferent for the salts included in the study. It was observed that the water fluxes are relevant due to solvation of removed ions and osmosis. The energy consumption is proportional to current density and is larger for bivalent salts.

Key-words: electrodialysis (water treatment); membrane separation; desalination; separation process. 


\section{LISTA DE FIGURAS}

Figura 1.1.Esquema do pré-tratamento de efluente por ED ................................ 6

Figura 3.1.Esquema da estrutura da membrana trocadora de cátions

(Strathmann,2004).

Figura 3.2.Perfis de concentração e potencial elétrico no empilhamento de membranas em processo contínuo (adap. Baker, 2004) 13

Figura 3.3.Esquema do transporte de massa na superfície da membrana trocadora de íons (Strathmann, 2004)

Figura 3.4.Densidade de corrente para potencial aplicado sobre o empilhamento ... 18

Figura 3.5.Diferença de potencial e corrente elétrica aplicada sobre o empilhamento no processo batelada obtidas em experimento qualquer 22

Figura 4.1.Fluxograma de processo do equipamento de ED. 24

Figura 4.2.Unidade de eletrodiálise (acima) e empilhamento de membranas (abaixo). 26

Figura 4.3.Curva proposta por Cowan \& Brown, 1959. 28

Figura 4.4.Esquema de um planejamento experimental com 3 fatores em 2 níveis com ponto central.

Figura 4.5.Esquema de um planejamento Doehlert com 2 fatores em 2 níveis com ponto central

Figura 5.1.Evolução da condutividade dos tanques alimentação e água obtidas em um experimento qualquer.

Figura 5.2 Curva obtida para solução de $\mathrm{NaCl}$ na aplicação do método de Cowan \& Brown, 1959.

Figura 5.3.Gráfico do resíduo de Js para ajuste linear em papel de probabilidade normal.

Figura 5.4.Gráfico da distribuição dos erros de $J_{S}$ para os respectivos ajustes lineares

Figura 5.5.Pontos experimentais e modelo da regressão com bandas de confiança (95\%).

Figura 5.6.Distribuição dos resíduos de $\mathrm{J}_{\mathrm{V}}$ de $\mathrm{NaCl}$ 
Figura 5.7.Distribuição dos resíduos de $\mathrm{J}_{V}$ de $\mathrm{NaCl}$ no gráfico de probabilidade

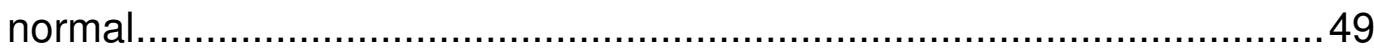

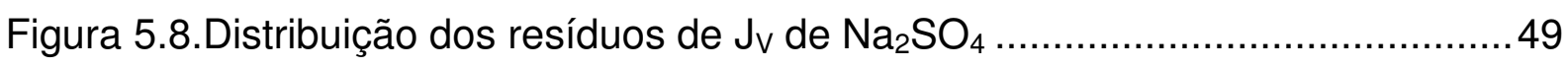

Figura 5.9.Distribuição dos resíduos de $\mathrm{J}_{V}$ de $\mathrm{Na}_{2} \mathrm{SO}_{4}$ no gráfico de

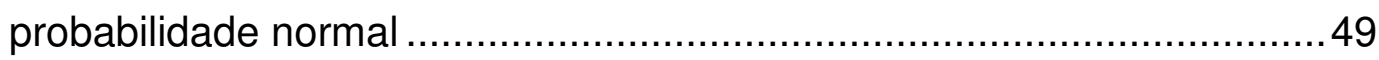

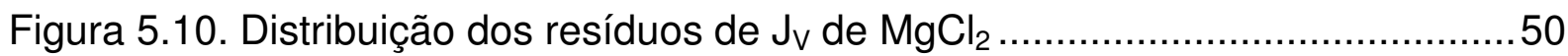

Figura 5.11.Distribuição dos resíduos de $\mathrm{JV}_{V}$ de $\mathrm{MgCl}_{2}$ no gráfico de

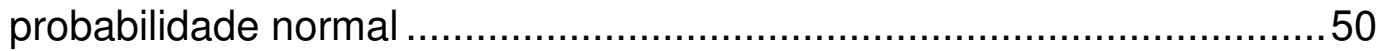

Figura 5.12.Distribuição dos resíduos de $\mathrm{JV}_{\mathrm{V}}$ de $\mathrm{KCl}$.............................................50

Figura 5.13.Distribuição dos resíduos de $J_{V}$ de $\mathrm{KCl}$ no gráfico de probabilidade

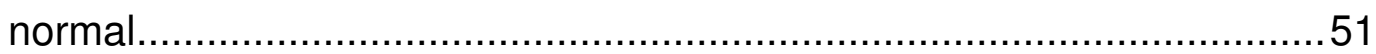

Figura 5.14.Superfície de resposta e pontos experimentais para $\mathrm{J}_{\mathrm{V}}$ de $\mathrm{NaCl}$...........53

Figura 5.15.Superfície de resposta e pontos experimentais para $\mathrm{J}_{\mathrm{V}}$ de $\mathrm{Na}_{2} \mathrm{SO}_{4} \ldots \ldots . .53$

Figura 5.16.Superfície de resposta e pontos experimentais para $\mathrm{J}_{\mathrm{V}}$ de $\mathrm{MgCl}_{2} \ldots \ldots . .53$

Figura 5.17.Superfície de resposta e pontos experimentais para $\mathrm{J}_{\mathrm{V}}$ de $\mathrm{KCl}$............54

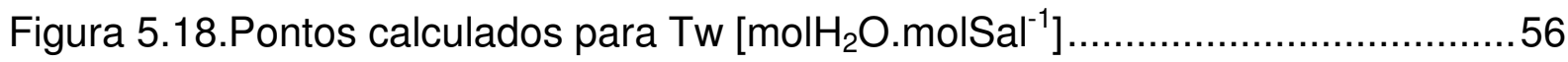

Figura 5.19. Superfície de resposta do consumo energético na remoção de sais ...58

Figura 5.20. Distribuição dos resíduos de energia consumida por equivalente

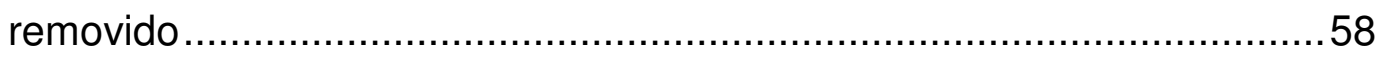

Figura 5.21. Gráfico de probabilidade normal dos resíduos de energia consumida por equivalente removido 59

Figura 5.22. Pontos experimentais e curvas obtidas com as bandas de confiança em $95 \%$ para consumo energético para remoção de sais. .....60

Figura A.1. Curvas de calibração dos sais.........................................................66 


\section{LISTA DE TABELAS}

Tabela 3.1.Cargas fixas usadas em membranas trocadoras de íons.......................11

Tabela 3.2.Mobilidade iônica em água a $25^{\circ} \mathrm{C}$ em solução diluída (Atkins, 1999) ....15

Tabela 4.1.Características fisico-químicas das membranas usadas........................26

Tabela 4.2.Componentes da unidade experimental de ED.................................27

Tabela 4.3.Planejamento experimental exploratório ..............................................33

Tabela 4.4.Planejamento experimental comparativo..............................................34

Tabela 4.5.Típico planejamento de um fator fixos em a níveis ................................36

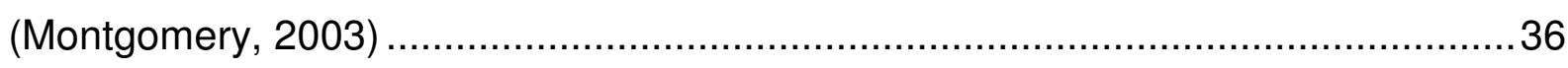

Tabela 5.1.Fluxos médios de sal (Js) obtidos nos experimentos exploratórios..........41

Tabela 5.2.Análise de variância do fluxo de sal $\left(\mathrm{J}_{\mathrm{s}} \cdot 10^{3}\right)$ dos experimentos

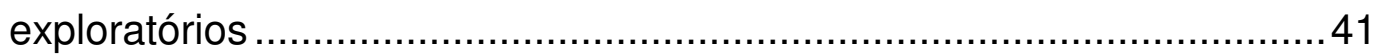

Tabela 5.3.Análise de variância dos fatores sobre o fluxo de sal $\left(\mathrm{Js} .10^{3}\right)$ nos experimentos exploratórios............................................................... 42

Tabela 5.4. Densidade de corrente limite $(\mathrm{i}$ lim) .................................................... 43

Tabela 5.5. Fluxos de sal $\left(\mathrm{J}_{\mathrm{S}}\right)$ obtidos nos experimento comparativos .....................44

Tabela 5.6. Análise de variância para o modelo de Js de $\mathrm{NaCl}$...............................46

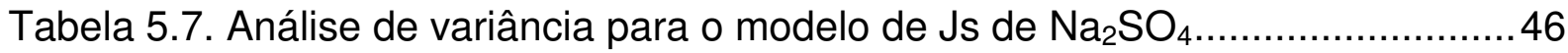

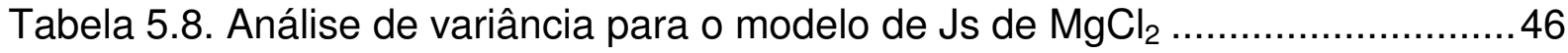

Tabela 5.9. Análise de variância para o modelo de Js de $\mathrm{KCl}$................................46

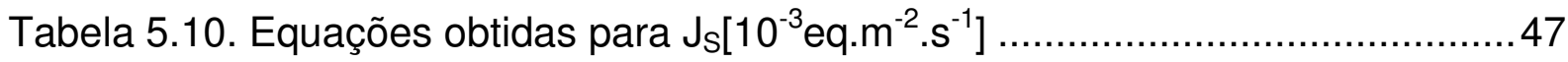

Tabela 5.11. Análise de variância para o modelo de $\mathrm{J}_{\mathrm{V}}$ de $\mathrm{NaCl}$.............................51

Tabela 5.12. Análise de variância para o modelo de $\mathrm{JV}_{\mathrm{V}}$ de $\mathrm{Na}_{2} \mathrm{SO}_{4} \ldots \ldots \ldots \ldots \ldots \ldots \ldots \ldots . . . . . . . . . . .52$

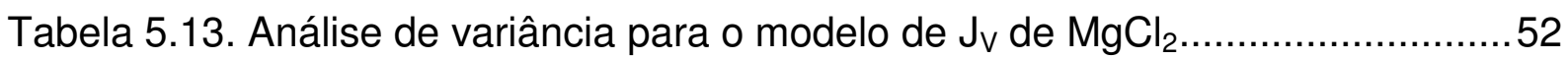

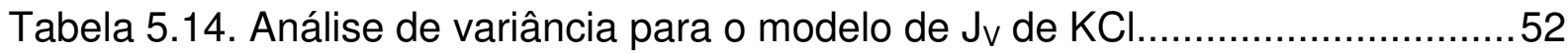

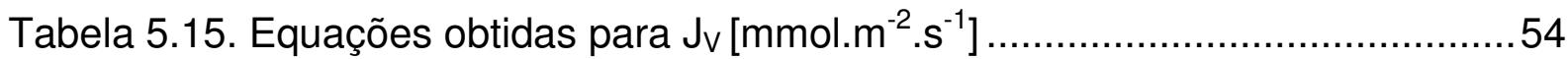

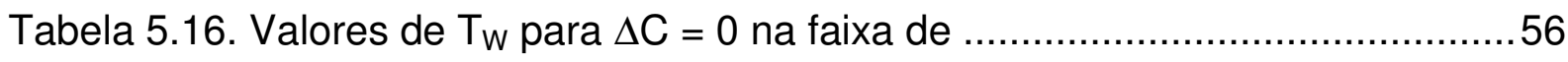

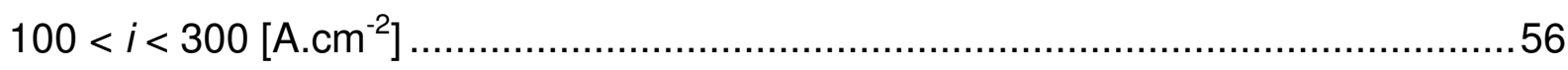

Tabela 5.17. Consumo energético por massa removida .......................................57

Tabela 5.18. Consumo energético por equivalente químico ..................................57

Tabela A.1 Equações das curvas de calibração..................................................67 


\section{LISTA DE ABREVIATURAS E SIGLAS}

$\begin{array}{ll}\text { ANOVA } & \text { Análise de variância } \\ \text { ED } & \text { Eletrodiálise } \\ \text { EDR } & \text { Eletrodiálise reversível } \\ \text { ETE } & \text { Estação de Tratamento de Efluentes } \\ \text { LSCP-DEQ } & \text { Laboratório de Simulação e Controle de Processos / } \\ & \text { Departamento de Engenharia Química } \\ \text { MF } & \text { Microfiltração } \\ \text { MTA } & \text { Membrana Trocadora de Ânions } \\ \text { MTC } & \text { Membrana Trocadora de Cátions } \\ \text { MTI } & \text { Membrana Trocadora de Íons } \\ \text { NF } & \text { Nanofiltração } \\ \text { OR } & \text { Osmose Reversa } \\ \text { POA } & \text { Processo Oxidativo Avançado } \\ \text { PV } & \text { Pervaporação } \\ \text { UF } & \text { Ultrafiltração } \\ \text { XL50 } & \text { Condutivímetro Accumet Excel XL50, Fisher Scientific }\end{array}$




\section{LISTA DE SÍMBOLOS}

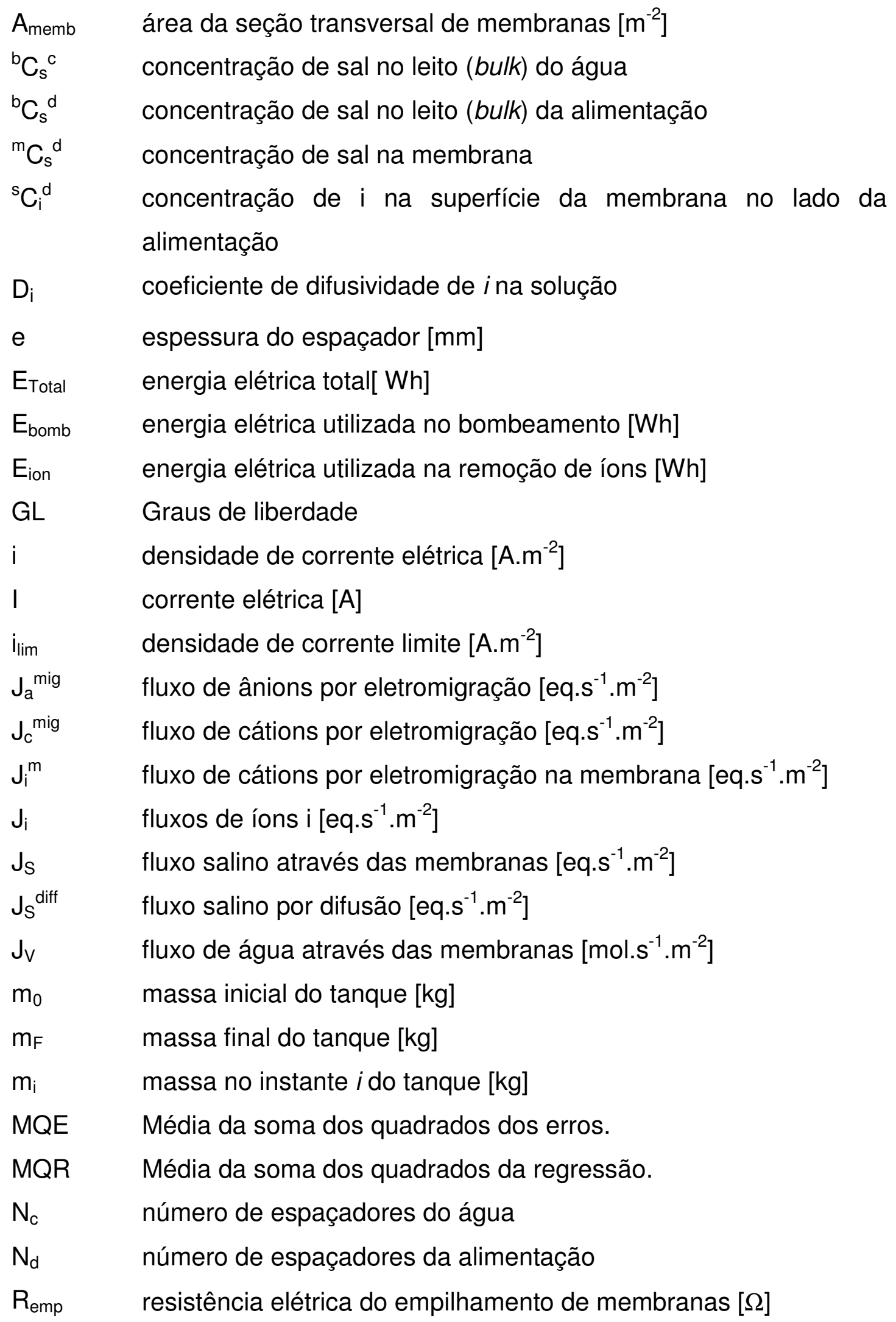




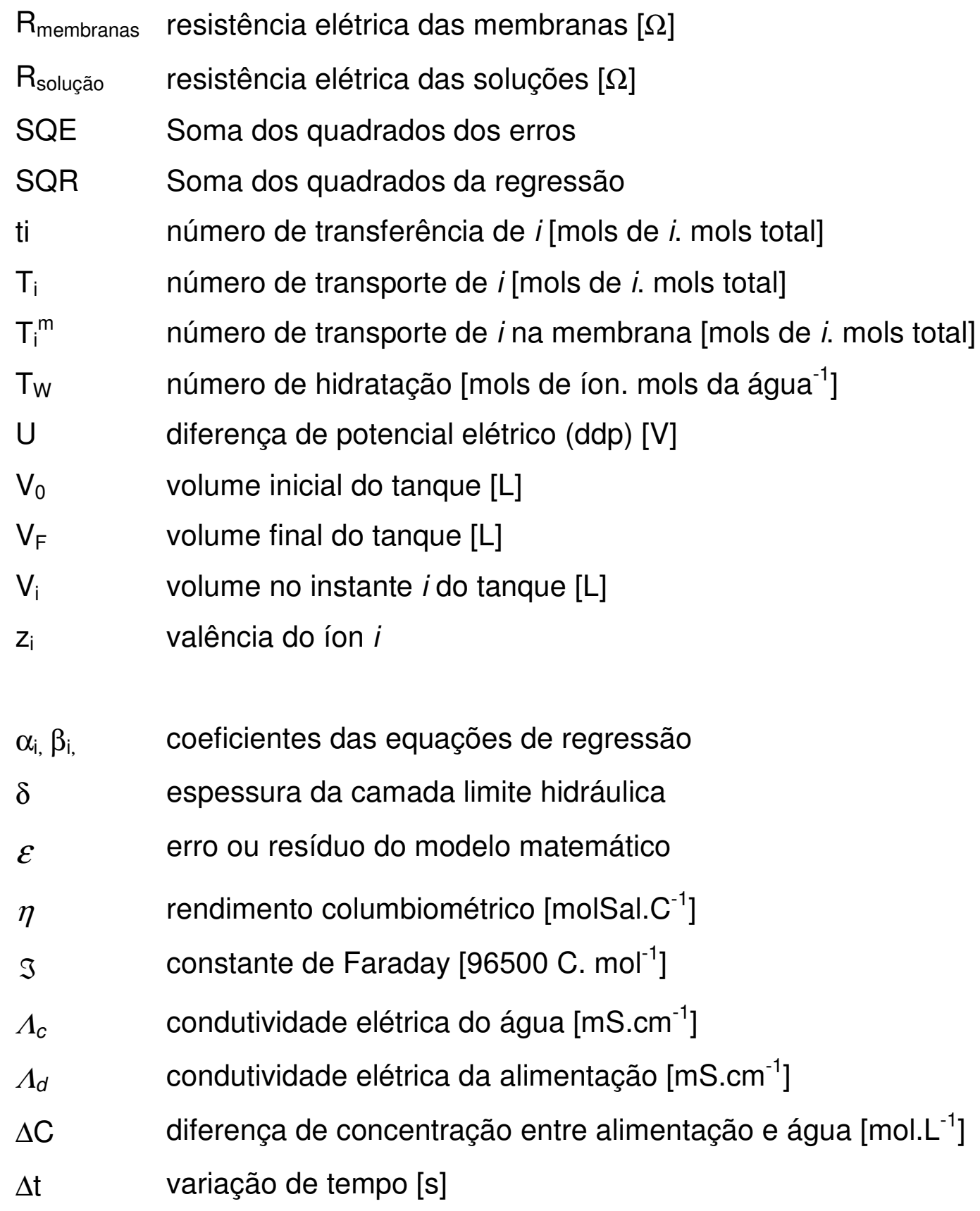




\section{SUMÁRIO}

1. INTRODUÇÃO

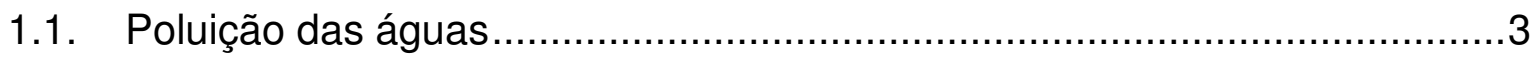

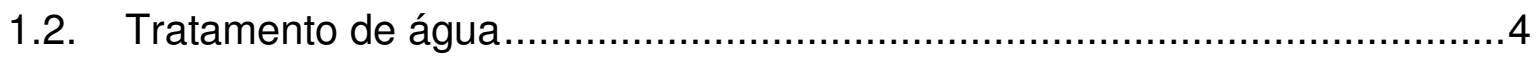

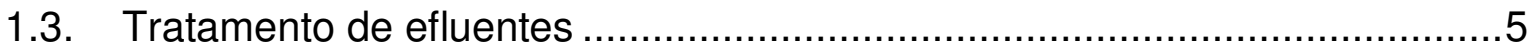

1.4. Integração de processos de tratamento ....................................................

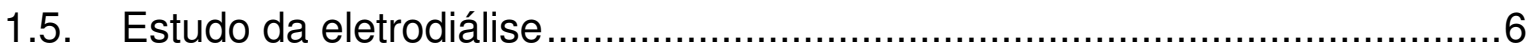

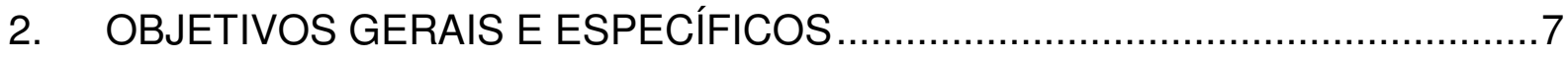

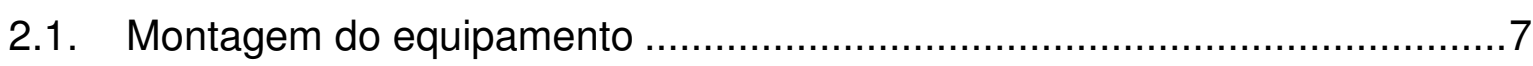

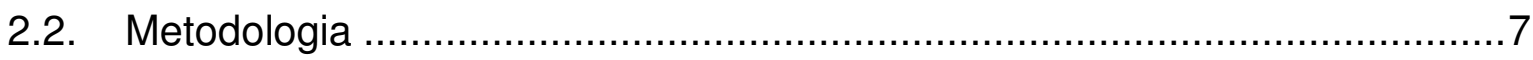

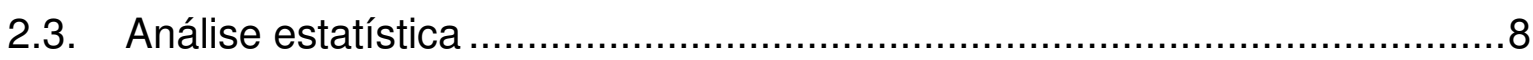

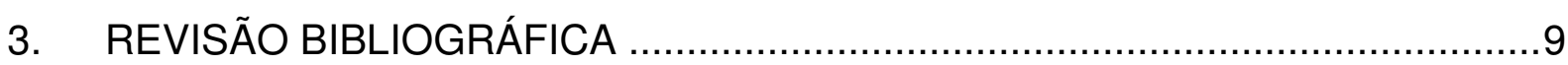

3.1. Processos de separação por membranas..............................................

3.2. Membrana trocadora de íons e exclusão de Donnan....................................10

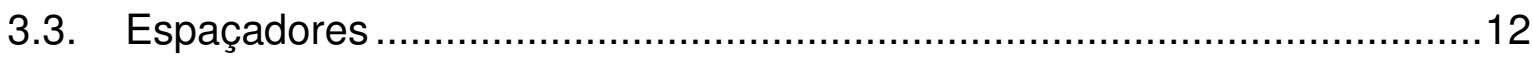

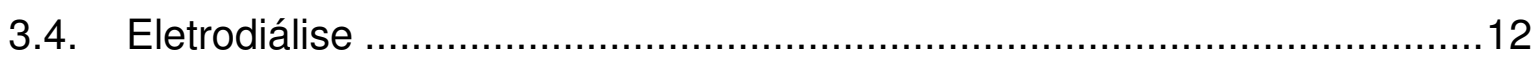

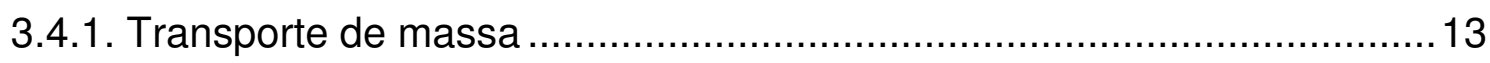

3.4.1.1. Mecanismos de transporte de massa ...................................13

3.4.1.2. Fluxo de íons e densidade de corrente elétrica.......................14

3.4.1.3. Modelo para transporte de massa.........................................19

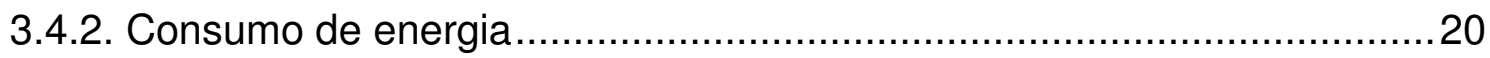

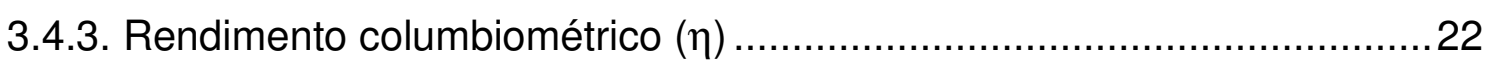

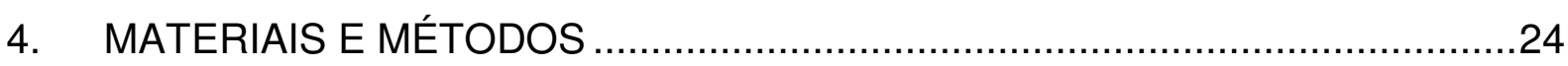

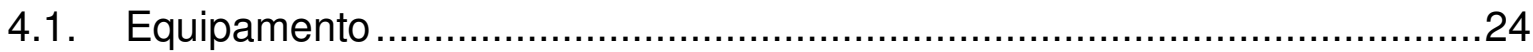

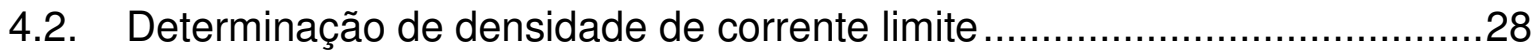

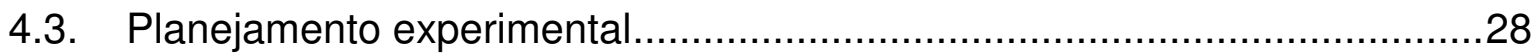

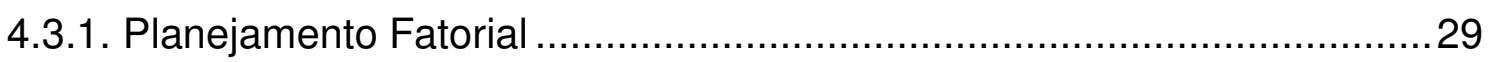

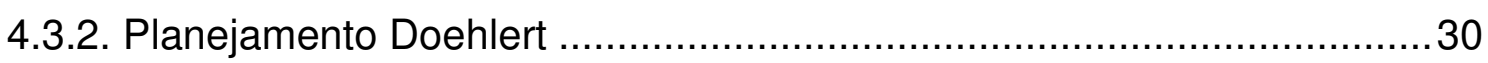

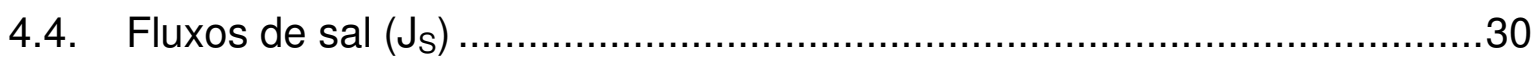

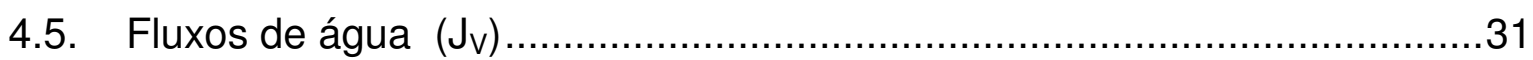

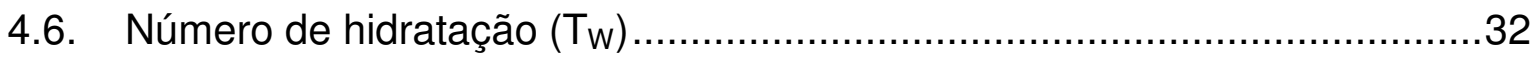

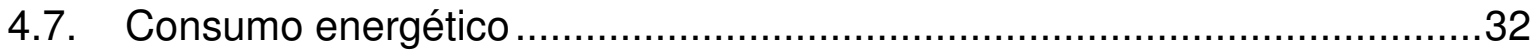




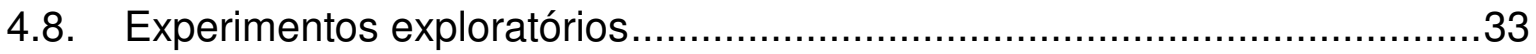

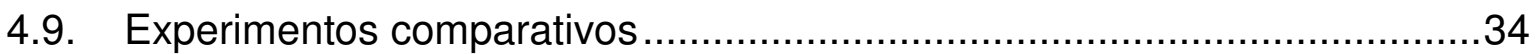

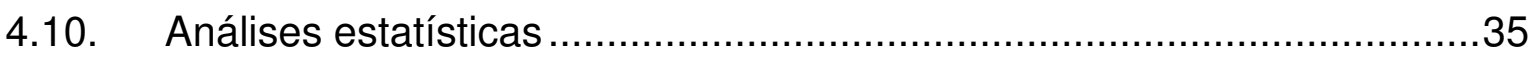

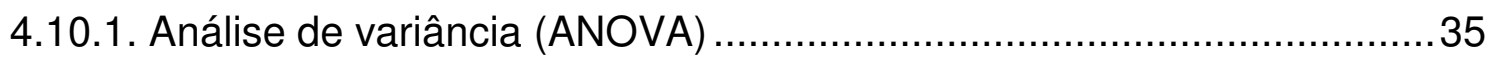

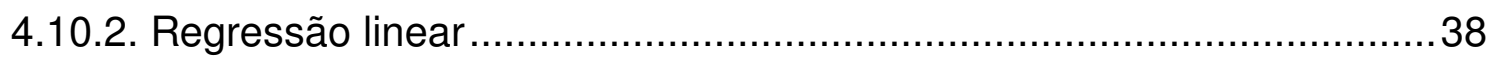

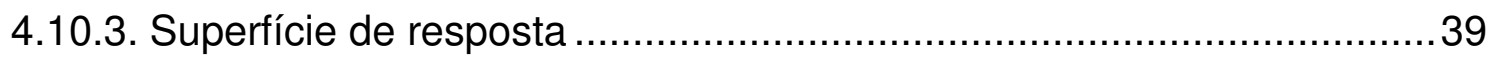

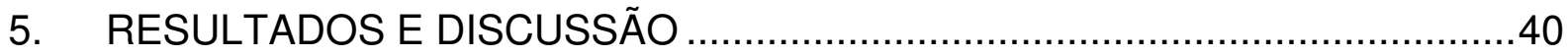

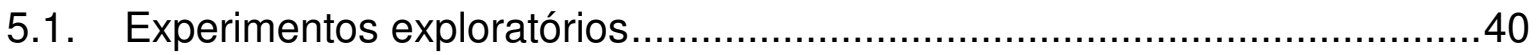

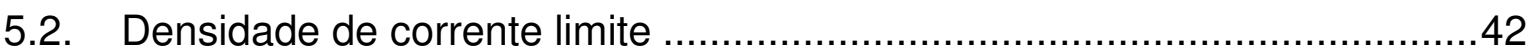

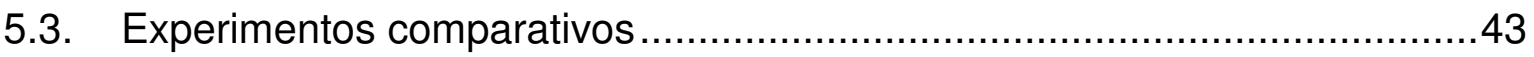

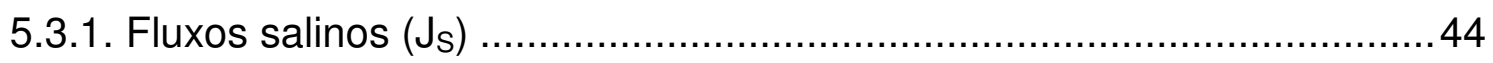

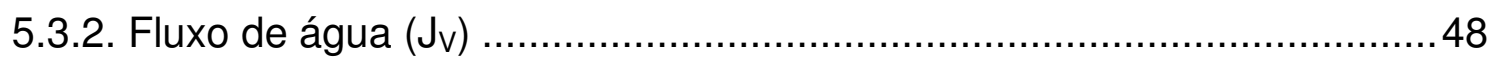

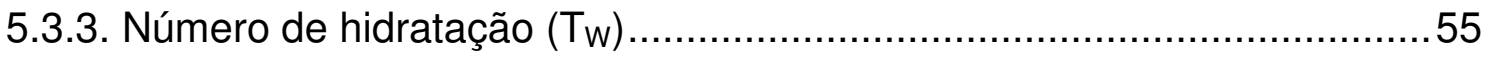

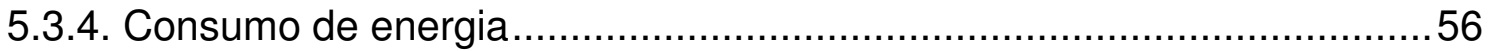

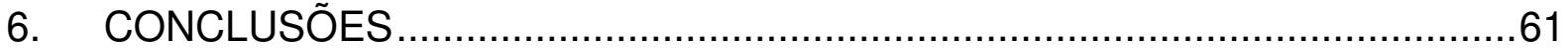

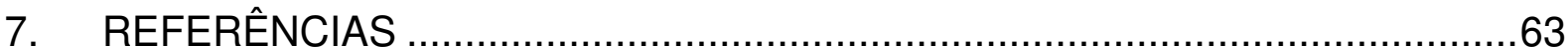

ANEXO A. CURVAS DE CALIBRAÇÃO DE CONDUTIVIDADE DAS SOLUÇÕES..66 


\section{INTRODUÇÃO}

\subsection{Poluição das águas}

A escassez de água deve afetar a vida do ser humano nos próximos anos. Não é mais possível resolver um problema ambiental transferindo-o para outras regiões, tamanha interdependência que se tem atualmente.

É necessário compreender a degradação ambiental para resolvê-la.

$\mathrm{Na}$ Antiguidade, o Homem era nômade. Migrava segundo as condições naturais. A partir da Revolução Neolítica os seres humanos fixaram-se em locais onde podia obter os recursos para viver. Esses recursos naturais, como a água, deviam estar próximos de sua morada. Os cursos de água eram (e ainda são) essenciais para a manutenção da vida sedentária. Sem água não haveria como manter a agricultura, a pecuária, entre outras atividades humanas.

Assim como nós, o homem primitivo sedentário gerava dejetos que eram dispostos na natureza segundo as possibilidades de cada região. Os dejetos sanitários eram lançados nos cursos de água, onde os resíduos eram degradados. Esses cursos de água eram "infinitos" diante das pequenas quantidades de dejetos. Sem se dar conta, o ser humano começou a poluir.

Sob esse modelo a civilização evoluiu. A poluição dos dias atuais funciona como a daquele tempo, ressalvadas quantidades e qualidade dos dejetos. A explosão populacional escasseou os antes abundantes cursos de água. $\mathrm{O}$ avanço científico e tecnológico "criou" incontáveis compostos químicos artificiais.

Desse ponto de vista, a degradação ambiental é um ciclo vicioso que ocorre em dois momentos: na busca por recursos naturais e na disposição de resíduos na natureza. A água está presente nas duas situações. O Homem capta a água para sua sobrevivência do mesmo local em que outro lançou seus resíduos.

Assim, evitar a total degradação das fontes de água limpa depende de uma série de esforços coletivos, dentre eles o uso racional da água e o tratamento dos efluentes industriais e domésticos, todos visando à quebra desse ciclo. 


\subsection{Tratamento de água}

A água é um recurso natural essencial para manutenção da vida. Para abastecer centros urbanos, novas fontes de água são usadas. Novas formas de tratamento são estudadas para substituir as convencionais.

Para abastecimento das grandes cidades a água limpa vem sendo buscada em locais cada vez mais distantes. Esse fato encarece os custos de captação e prejudica outras cidades que dependem dessa água. Para abastecer cerca de metade dos 19 milhões de habitantes, a região metropolitana de São Paulo, por exemplo, já capta água da Bacia do Piracicaba-Capivari-Jundiaí, localizada a mais de $100 \mathrm{~km}$ do centro da capital. (www.sabesp.com.br acessado em 01/06/2010). Segundo dados do IBGE de 2000, apenas $35 \%$ do esgoto coletado é tratado no Brasil.

O uso de águas salobras e marinhas já foi objeto de estudo em abastecimento de cidades como, por exemplo, Adelaide na Austrália, onde há escassez de recursos hídricos (Wittholz, 2008). As tecnologias de dessalinização das águas consideradas nesse estudo foram: osmose reversa, evaporação flash em múltiplos estágios (multi-stage flash distillation), evaporação por múltiplos efeitos (multiple-effect distillation), compressão de vapor (vapour compression) e eletrodiálise. Todas essas tecnologias já são estabelecidas e podem vir a ser usadas em escala comercial. Dentre elas, as duas primeiras apresentam maior capacidade de produção instalada em nível mundial (Wangnick, 1991).

Nesse contexto, a captação e o tratamento da água por métodos convencionais tornam-se custosos. Assim, as novas tecnologias no tratamento de água tornam-se competitivas economicamente se comparados aos processos convencionais. Processos oxidativos avançados (POA) e separação por membranas são algumas dessas novas tecnologias avançadas.

Portanto, o acesso à água para consumo humano requer mudanças nos sistemas atuais de captação, tratamento e disposição de esgotos. As fontes de água já não são próximas, nem abundantes dos consumidores. Novas tecnologias podem ser adotadas. 


\subsection{Tratamento de efluentes}

Tradicionalmente, os efluentes gerados nas grandes cidades são captados através de uma rede coletora, que os leva até uma estação de tratamento de esgoto (ETE). Na estação, o esgoto "in natura" é tratado por processos físico-químicos e biológicos a fim de limpar a água. A água tratada é, então, despejada num curso de água, como um rio.

Já os efluentes industriais requerem tratamentos específicos, pois têm compostos químicos com diferentes características em sua composição. O tratamento deve ser feito internamente, ao invés de lançá-los no ambiente ou na rede pública misturando-o aos dejetos residenciais. A dessalinização de efluentes pode funcionar, ainda, como pré-tratamento para a aplicação de outros processos, como o foto-Fenton, em que o íon cloreto pode atuar como inibidor (Machulek, 2007).

No tratamento de efluentes, a dessalinização aplica-se a efluentes industriais salinos que permitem o reaproveitamento de água ou adequação aos limites legais do despejo de efluentes. Por outro lado, outra solução terá os contaminantes em concentração mais elevada. Logo, não se resolve a contaminação, mas a concentra.

\subsection{Integração de processos de tratamento}

Os tratamentos de água gerada em processos industriais são complexos e específicos por sua composição. A tendência para tratamento de efluentes é o tratamento específicopróximo dos pontos de contaminação. Essa descontaminação requer novas tecnologias de tratamento, como o tratamento com membranas e processos oxidativos avançados (POAs). A integração de processos possibilita utilização de processos de forma complementar, resultando em redução de tamanhos de equipamentos e, possivelmente, de custos.

Embora esse trabalho não tenha por objetivo a integração de processos, a ED possibilita o pré-tratamento de um efluente para um tratamento posterior por processos como os POAs. As reações químicas de compostos orgânicos envolvidas 
nos POAs podem ser inibidas pela presença de compostos inorgânicos (como cloreto e sulfato) no meio reativo. Deste modo, a retirada de íons dos efluentes a serem tratados pode resultar em melhores rendimentos das reações oxidativas.

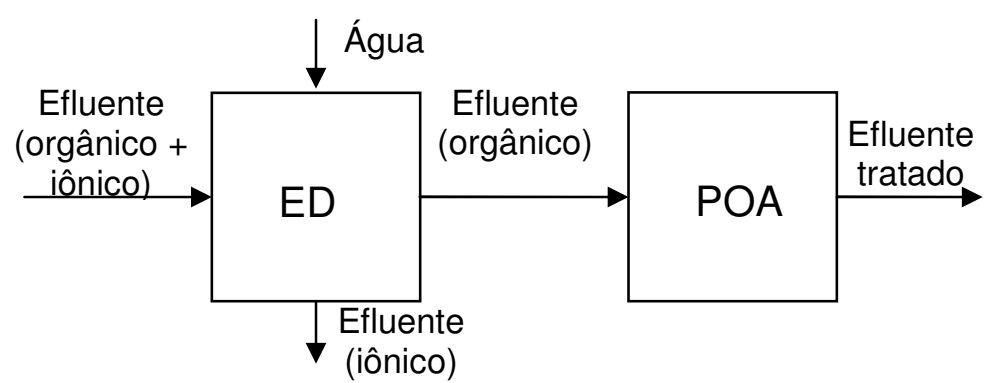

Figura 1.1.Esquema do pré-tratamento de efluente por ED.

Nesse cenário, uma outra aplicação para a eletrodiálise é comom prétratamento de efluentes onde houver íons, mantendo o composto orgânico no efluente a ser tratado (Figura 1.1). Apesar de a eletrodiálise não ser projetada para esse fim, ela já foi objeto de estudo para a remoção de compostos orgânicos (Borges, 2009).

Em suma, a ED pode ampliar o campo de atuação para novos usos além dos convencionais de dessalinização.

\subsection{Estudo da eletrodiálise}

O transporte de íons por eletrodiálise requer a aplicação de corrente contínua sobre o empilhamento de membranas. Em termos práticos, esse tipo de corrente elétrica é uma dificuldade para o processo. Comparativamente com outros processos de membranas como a osmose reversa, isso torna a eletrodiálise mais complexa. Por outro lado, a ED requer menor rigor no pré-tratamento das soluções.

No trabalho, será apresentado o estudo dos fatores que influenciam o transporte transmembrânico. A densidade de corrente é o principal fator que influencia o processo de dessalinização. Outros fatores como concentração e vazão serão analisados igualmente. 


\section{OBJETIVOS GERAIS E ESPECÍFICOS}

Os objetivos do trabalho são:

a) elaborar o projeto, montagem e caracterização de planta de eletrodiálise em escala laboratorial, para dessalinização de solução salina aquosas;

b) realizar estudo experimental dos fluxos de sal e de água através das membranas e da energia consumida para a dessalinização;

c) desenvolver modelos matemáticos do processo de dessalinização nas condições estudadas, com base no tratamento estatístico dos dados experimentais.

Cada um dos objetivos é descrito com maiores detalhes a seguir

\subsection{Montagem do equipamento}

As membranas e seu sistema de empilhamento (descritos mais à frente) foram adquiridos de um fornecedor específico e o projeto elaborado a partir das características desse sistema de membranas.

Para montagem do equipamento, elaborou-se um projeto baseado nas informações do manual do fabricante do sistema de eletrodiálise. Dele foram retiradas informações como vazões e pressão de trabalho, dimensões de tubulação, soluções de trabalho e dados da fonte elétrica de corrente contínua.

A unidade de eletrodiálise está montada no laboratório de Simulações e Controle de Processos no Departamento de Engenharia Química (LSCP-DEQ) da Escola Politécnica da Universidade de São Paulo, em São Paulo.

\subsection{Metodologia}

A fase experimental do trabalho dividiu-se em duas etapas: exploratória e comparativa.

$\mathrm{Na}$ etapa exploratória, utilizaram-se soluções de $\mathrm{NaCl}$ a fim de avaliar as influências de densidade de corrente elétrica, concentração inicial da alimentação e 
vazão volumétrica no fluxo salino. Os resultados dos experimentos exploratórios serviram de referência para o planejamento para os experimentos comparativos.

A etapa comparativa seguiu o planejamento experimental Doehlert e foi realizada com quatro sais: $\mathrm{NaCl}, \mathrm{Na}_{2} \mathrm{SO}_{4}, \mathrm{MgCl}_{2}$ e $\mathrm{KCl}$. De acordo com os exploratórios, a influência da densidade de corrente e da concentração inicial da alimentação no fluxo salino foram estudados.

\subsection{Análise estatística}

Os resultados experimentais podem ser comparados estatisticamente através de modelos matemáticos. Utilizando ferramentas estatísticas, os modelos são obtidos e depois apresentados de forma que se permita a comparação dos fenômenos de transporte para os diferentes sais utilizados. 


\section{REVISÃO BIBLIOGRÁFICA}

\subsection{Processos de separação por membranas}

A membrana é uma região de descontinuidade entre duas fases, cuja seletividade permite a separação de componentes presentes da solução a partir de propriedades físico-químicas. Seletividade é a capacidade de permitir a passagem, através da membrana, de determinadas espécies e impedir a de outras. As membranas devem apresentar características físico-químicas de acordo com sua aplicação. As principais aplicações dos processos por membranas são separações.

Os processos mais comuns por membrana em uso industrial são: microfiltração (MF), ultrafiltração (UF), nanofiltração (NF), osmose reversa (OR), pervaporação (PV) e eletrodiálise (ED).

As membranas usadas nos quatro primeiros (MF, UF, NF e OR) têm por característica principal o tamanho do poro, sendo o maior poro a MF e o menor a OR As duas primeiras são flexíveis; as últimas, sólidas. A força motriz desses processos é a pressão hidráulica.

Já a PV é um sistema mais complexo que os demais. Sua membrana é sólida e a separação acontece entre líquidos. Ela trabalha com líquidos aquecidos e a separação acontece em razão da diferença da pressão de vapor dos compostos envolvidos e suas difusividades preferenciais no meio poroso.

A ED alia a eletro-seletividade das membranas com a aplicação de um campo elétrico sobre um empilhamento de membranas. Logo, é usada na remoção de íons em solução.

A eletrodiálise reversa (EDR) é variação da ED que possibilita a redução da polarização por concentração. As mesmas membranas são usadas. Durante o processo de separação, os eletrodos têm, periodicamente, as polaridades invertidas. Simultaneamente, uma manobra com válvulas faz com que as soluções troquem de compartimentos dentro do empilhamento. A inversão de polaridade provoca um fluxo de massa inverso através das membranas entre os compartimentos. Com isso parte 
do depósito sobre as superfícies das membranas é removido. Logo, o rendimento da separação melhora em relação à ED convencional (Baker,2004).

Originalmente, a eletrodiálise foi concebida como sistema de dessalinização de água salobra ou concentrador de água marinha ou salobra para produção de sal (Rautenbach,1989). Na Europa e nos EUA, a ED é usada, principalmente, na dessalinização de água salobra para produzir água potável. (Strathmann, 2004)

Nas últimas décadas outras aplicações vêm sendo desenvolvidas, como o controle de impurezas iônicas em efluentes salinos e dessalga de soro de leite (Baker, 2004). Existem estudos do uso para separar compostos orgânicos de iônicos (Zhang et al, 2009).

\subsection{Membrana trocadora de íons e exclusão de Donnan}

As membranas trocadoras de íons usadas na ED possuem cargas elétricas fixas. Isso proporciona a propriedade da seletividade iônica, permitindo a separação eletro-química dos íons presentes na solução.

As membranas são compostas de uma matriz polimérica contendo íons fixados em sua estrutura. Normalmente, são planas.

$\mathrm{Na} E D$, são dois os tipos de membranas:

a) membrana trocadora de cátions (MTC) negativamente carregada.

b) membrana trocadora de ânions (MTA) positivamente carregada.

Na MTC, as cargas negativas fixas ficam em equilíbrio elétrico com os cátions móveis (contra-íons) presentes nos interstícios da matriz. Nos interstícios também estão presentes ânions (co-íons) que, repelidos pelas cargas fixas, são excluídos da estrutura da membrana, conforme a figura 3.1. 


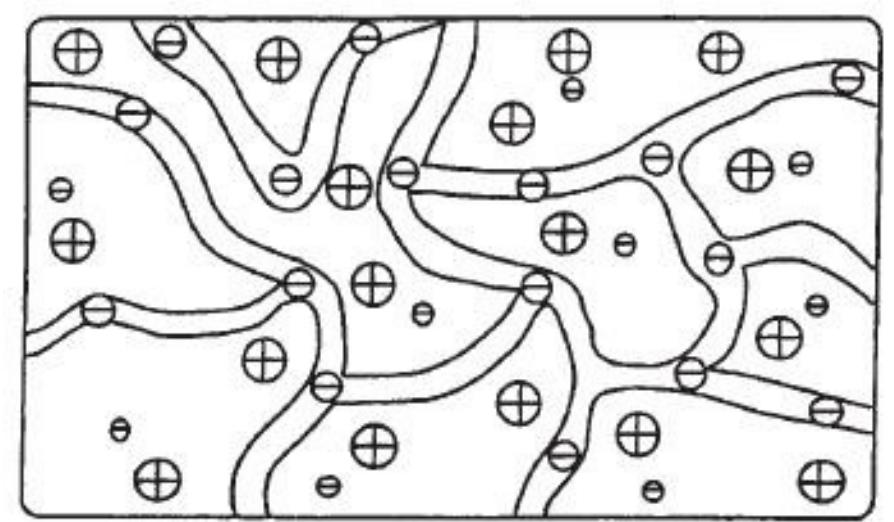

$\theta$ íon negativo fixo $\theta$ co-íon negativo $\oplus$ contra-íon positivo

Figura 3.1.Esquema da estrutura da membrana trocadora de cátions (Strathmann,2004)

Portanto, numa MTC ideal, todos os ânions da solução seriam excluídos de sua estrutura, permitindo apenas a passagem de cátions. Esse mecanismo é denominado Exclusão de Donnan (Strathmann, 2004).

As MTAs funcionam de maneira análoga, apenas com sinais opostos.

As principais características físico-químicas desejadas desses tipos de membranas são: alta seletividade, baixa resistência elétrica, resistência mecânica, térmica e química.

Tais propriedades serão determinadas pela matriz polimérica e o tipo e concentração do íon fixo. Para isso, utilizam-se polímeros hidrofóbicos como poliestireno, polietileno e poli-sulfona. No entanto, a adição de íons aumenta a solubilidade em água dos polímeros. Esse efeito é reduzido com ligações cruzadas na matriz polimérica. A quantidade dessas ligações determinará a estabilidade química e térmica, além de afetar a resistência elétrica e seletividade da membrana. Os íons fixos determinam seletividade e resistência elétrica da membrana, mas têm efeito significativo nas propriedades mecânicas das membranas (Strathmann, 2004).

Tabela 3.1.Cargas fixas usadas em membranas trocadoras de íons

\begin{tabular}{lccc}
\hline Tipo de Membrana & \multicolumn{3}{c}{ Tipos de íons fixos } \\
\hline MTC & $\mathrm{SO}_{3}^{-}$ & $-\mathrm{COO}^{-}$ & $-\mathrm{HPO}_{2}^{-}$ \\
MTA & $-\mathrm{NH}_{3}$ & $-\mathrm{R}_{3} \mathrm{~N}^{+}$ & $-\mathrm{R}_{3} \mathrm{P}^{+}$ \\
\hline
\end{tabular}




\subsection{Espaçadores}

As correntes da alimentação e de água circulam pelo empilhamento através dos espaçadores. Com eles, mantém-se a distância entre as membranas, o que permite que as soluções circulem no interior do empilhamento de membranas através dos espaçadores..

Os espaçadores são feitos de materiais poliméricos e apresentam diversos formatos. Seu formato altera a turbulência do sistema e apresentam espessura de 0,5 a 2,0 mm. Pelos espaçadores passam as duas correntes de fluído: alimentação (diluate) e água (concentrate).

\subsection{Eletrodiálise}

A eletrodiálise $(E D)$ é um processo de separação que utiliza membranas e potencial elétrico.

A unidade elementar da ED é o par de células (cell pair) que consiste na justaposição de uma membrana trocadora de cátions (MTC), um espaçador da alimentação, uma membrana trocadora de ânions (MTA) e um espaçador de água. No equipamento, os pares de células são colocados um após o outro, como em uma pilha. Por isso é denominado empilhamento (stack). É a ordem de colocação dos pares dentro do empilhamento que permite a separação.

Os eletrodos são colocados nas extremidades do empilhamento. Por fim, todo o sistema é prensado (figura 3.2). Nos compartimentos dos eletrodos circula uma solução salina (eletrólito). O eletrólito não se mistura com as outras duas, logo, não é necessário usar as mesmas espécies iônicas removidas da alimentação. Devemse evitar sais com $\mathrm{Cl}^{-}$, para que evitar a formação de gás cloro $\left(\mathrm{Cl}_{2}\right)$. 


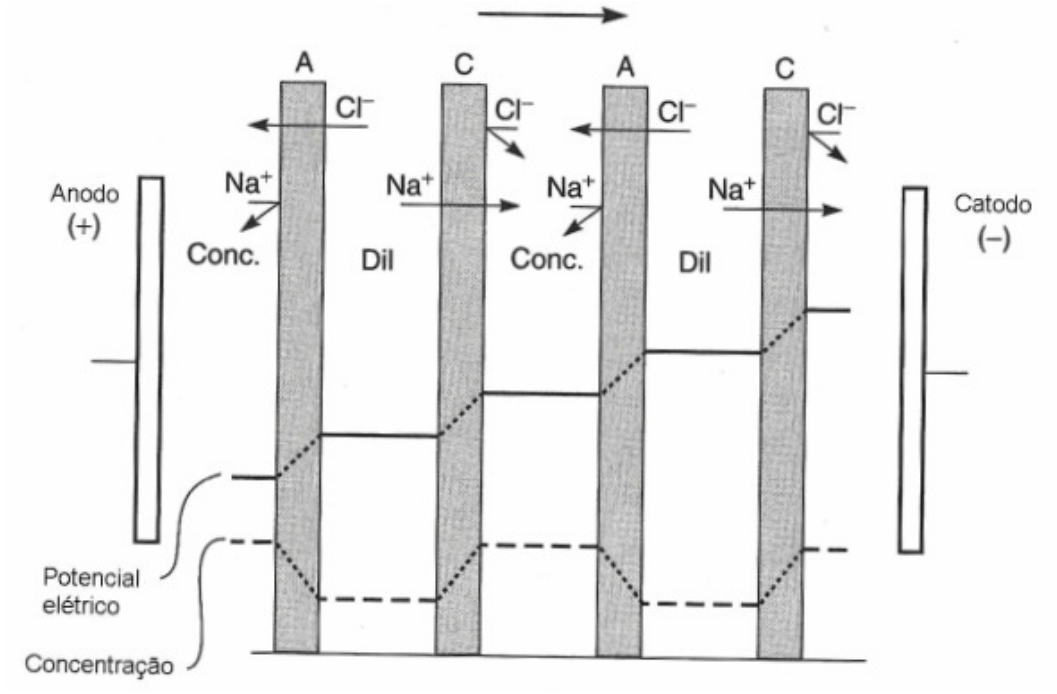

Figura 3.2.Perfis de concentração e potencial elétrico no empilhamento de membranas em processo contínuo (adap. Baker, 2004)

Dentro do empilhamento, as concentrações das correntes de alimentação e água que passam pelos espaçadores têm o mesmo perfil em todo empilhamento, pois o fluxo das soluções é paralelo às membranas. A diferença de potencial elétrico é constante sobre todo o empilhamento conforme visto na figura 3.2.

\subsubsection{Transporte de massa}

\subsubsection{Mecanismos de transporte de massa}

A eletrodiálise remove íons de uma solução (alimentação) para outra (água), através do fluxo de íons através das membranas trocadoras de íons (MTI). O transporte de massa iônico ocorre nos espaçadores por onde fluem as soluções e através das membranas trocadores de cátions e ânions.

As forças-motrizes do transporte de massa iônico no empilhamento de ED são três: convecção, eletro-difusão (migração) e difusão.

A convecção dá-se por força mecânica, geralmente por diferença de pressão hidrostática. Dentro das MTI, a convecção é desprezível. Já nas soluções, é significativo. Quanto maior a turbulência nos espaçadores, melhor o transporte 
convectivo iônico, pois a turbulência reduz a camada limite de massa na superfície das membranas. Alguns formatos de espaçadores são aplicados para melhorar, justamente, esse tipo de fenômeno de transporte.

A eletrodifusão dos íons é resultado do gradiente de potencial elétrico sobre o empilhamento. Os íons migrarão em direção aos eletrodos de acordo com suas cargas. Esse é o tipo de transporte através das membranas.

O transporte difusivo ocorre devido ao gradiente de potencial químico, que é causado por diferença de concentração ou de pressão dentro da solução. Nesse caso, o gradiente concentração é predominante nas MTI. Mesmo com gradiente, a eletroneutralidade mantém-se, ou seja, os íons difundem na mesma direção e, localmente, a carga da solução é nula. A difusão é desprezível na eletrodiálise.

Assim como os íons, o solvente também apresenta fluxo através das membranas. Esse fluxo é resultante da soma de três fatores:

a) eletro-osmótico resultante do gradiente de potencial elétrico, ou seja, os íons $\mathrm{H}^{+}$e $\mathrm{OH}^{-}$são sujeitado à densidade de corrente. Logo, só irá ocorrer nas regiões II e III da figura 3.4;

b) pela solvatação dos íons que atravessam as membranas, isto é, pelas moléculas de água que se ligam aos íns;

c) osmótico devido ao gradiente de potencial químico.

Em geral, o solvente usado é a água. Os dois primeiros fatores sobrepõem-se ao último na eletrodiálise.

Dessa forma, a densidade de corrente elétrica aplicada sobre o empilhamento é a principal responsável pelos dois fluxos mássicos.

\subsubsection{Fluxo de íons e densidade de corrente elétrica}

Para o transporte de corrente elétrica dentro do empilhamento assume-se que toda ela, através das membranas, é carregada pelos íons. Entretanto, os cátions e ânions transportam cargas proporcionais a suas valências, o que é expresso pelo número de transporte (equação 3.1). O número de transferência (equação 3.2) indica a quantidade de mols de $i$ transportados com um mol de elétrons fornecidos (Strathmann, 2004) 


$$
\begin{aligned}
& T_{i}=\frac{z_{i} J_{i}}{\sum_{n} z_{i} J_{i}} \\
& t_{i}=\frac{T_{i}}{\left|z_{i}\right|}=\frac{\left|J_{i}\right|}{\sum_{n} z_{i} J_{i}}
\end{aligned}
$$

sendo: $z_{i}$ - valência do íon $\mathrm{i} ; \quad J_{i}-$ fluxo do íon i [eq. $\mathrm{s}^{-1} \cdot \mathrm{m}^{-2}$ ].

A somatória dos números de transporte dos íons presentes na solução é 1 . Para espécies monovalentes dissociados em solução como $\mathrm{NaCl}$, os números serão iguais. Consequentemente, $\mathrm{Na}^{+}$e $\mathrm{Cl}^{-}$transportam quantidades iguais de carga na solução (Strathmann, 2004).

As membranas possuem íons fixos em sua matriz polimérica, que não transportam carga. Ali todo o fluxo de corrente elétrica ocorre somente pelos contraíons. Logo, os íons fixos e os co-íons têm número de transporte 0 e os contra-íons 1.

A quantidade de carga elétrica transportada pelos íons é proporcional à concentração de cada espécie na solução e nas membranas. Isso porque a mobilidade iônica de diferentes espécies tem mesmas ordens de grandeza (tabela 3.2).

Enquanto os íons difundem através da solução, os íons $\mathrm{H}^{+} \mathrm{e} \mathrm{OH}^{-}$são transportados por substituição nas moléculas de água, em uma sequência rápida de ligações e separações químicas. Por isso, a maior mobilidade.

Tabela 3.2.Mobilidade iônica em água a $25^{\circ} \mathrm{C}$ em solução diluída (Atkins, 1999)

\begin{tabular}{lclc}
\hline Cátions & $\begin{array}{c}\text { Mobilidade } \\
{\left[10^{-8} \cdot \mathrm{m}^{2} \cdot \mathrm{s}^{-1} \cdot \mathrm{V}^{-1}\right]}\end{array}$ & Ânions & $\begin{array}{c}\text { Mobilidade } \\
{\left[10^{-8} \cdot \mathrm{m}^{2} \cdot \mathrm{s}^{-1} \cdot \mathrm{V}^{-1}\right]}\end{array}$ \\
\hline $\mathrm{Li}^{+}$ & 4,01 & $\mathrm{~F}^{-}$ & 5,70 \\
$\mathrm{Na}^{+}$ & 5,19 & $\mathrm{Cl}^{-}$ & 7,91 \\
$\mathrm{~K}^{+}$ & 7,62 & $\mathrm{Br}$ & 8,09 \\
$\mathrm{NH}_{4}^{+}$ & 7,63 & $\mathrm{NO}_{3}{ }^{-}$ & 7,40 \\
$\mathrm{Ca}^{++}$ & 6,17 & $\mathrm{SO}_{4}^{-}$ & 8,29 \\
$\mathrm{H}^{+}$ & 36,23 & $\mathrm{OH}^{-}$ & 20,64 \\
\hline
\end{tabular}


Dentro do empilhamento, o fluxo de cátions dá-se pela MTC; o de ânions, pela MTA. Os cátions presentes na alimentação, ao entrarem no empilhamento de membranas, são submetidos ao campo elétrico e migram em direção a superfície das MTC por eletrodifusão ( $\left.\mathrm{J}_{S}^{\text {diff }}\right)$.

Dali penetram e atravessam as membranas e alcançam o água $\left(\mathrm{J}_{C}{ }^{\mathrm{mig}}\right)$. De acordo com a relação entre $J_{S}{ }^{\text {diff }}$ e $J_{C}{ }^{m i g}$, haverá excesso ou escassez de íons na superfície das membranas no lado do dliluente. O mesmo ocorre com os ânions nas MTA.

Nerst propôs um modelo de escoamento dividido em duas regiões: o leito do escoamento (bulk) e a camada limite (boundary layer). Nesta, a velocidade de escoamento é menor, geralmente, em regime laminar. A espessura da camada limite é menor para escoamento turbulento, ou seja, os espaçadores têm, também, a função de reduzir a espessura da camda limite. Na eletrodiálise, a maior turbulência e a consequente redução da camada limite, ocorre nas regiões entre membranas (Taky, 1992).

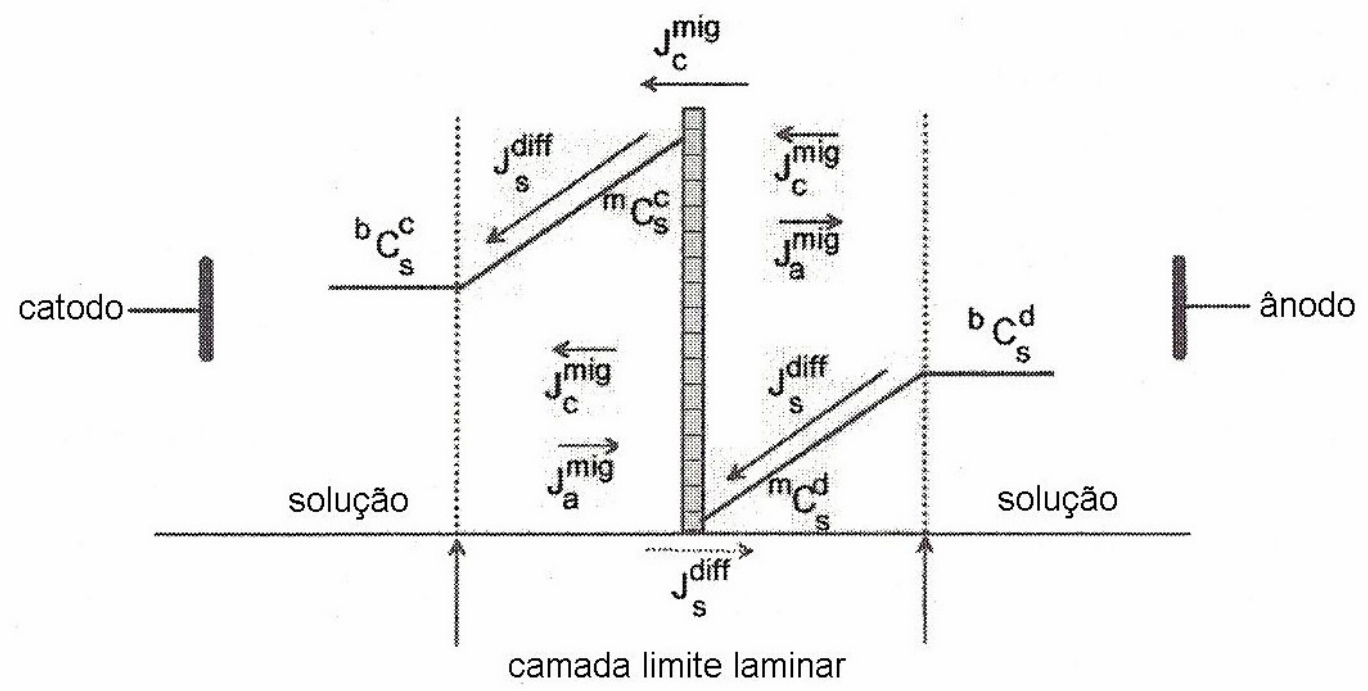

Figura 3.3.Esquema do transporte de massa na superfície da membrana trocadora de íons (Strathmann, 2004)

Para condição ideal, o fluxo iônico dependerá dos íons atravessarem a camada limite e a membrana. Nas membranas o fluxo de contra-íons $\left(\mathrm{J}_{i}^{\mathrm{m}}\right)$ será dado por (3.4). A aproximação da superfície das membranas segue a equação (3.5). 


$$
\begin{aligned}
& J_{i}^{m}=J_{i}^{m i g}+J_{i}^{\text {diff }} \\
& J_{i}^{m}=T_{i}^{m} \cdot \frac{i}{\left|z_{i}\right| \cdot \mathfrak{I}} \\
& J_{i}^{m i g}+J_{i}^{d i f f}=-D_{i} \cdot \frac{d C_{i}^{d}}{d z}+T_{i}^{m} \cdot \frac{i}{\left|z_{i}\right| \cdot \mathfrak{I}}
\end{aligned}
$$

onde $T_{i}^{m}$ é o número de transporte do contra-íons na membrana; $z_{i}$ a valência do íon.

Substituindo-se as equações, tem-se a densidade de corrente.

$$
i=\frac{\mathfrak{I} D_{i}}{\left|z_{i}\right| \cdot\left(T_{i}^{m}-T_{i}\right)} \cdot \frac{d C_{i}^{d}}{d z}
$$

sendo $D_{i}$ é o coeficiente de difusividade e $z$ eixo de coordenadas perpendicular às membranas.

A densidede de corrente limite ( $\mathrm{i}_{\text {lim }}$ ) ocorre quando a concentração de íons na superfície das membranas do lado da alimentação $\left({ }^{\mathrm{s}} \mathrm{C}_{\mathrm{i}}{ }^{\mathrm{d}}\right)$ tende a zero.

Logo, a equação (3.7) define a i lim.

$$
i_{\lim }=\frac{\Im D_{i}}{\left|z_{i}\right| \cdot\left(T_{i}^{m}-T_{i}\right)} \cdot \frac{{ }^{s} C_{i}^{d}}{\delta}
$$

onde $\delta$ é a espessura da camada limite $e{ }^{s} \mathrm{C}_{\mathrm{i}}{ }^{\mathrm{d}}$ a concentração de íons na superfície do lado da alimentação.

A escassez de íons na superfície da membrana provoca aumento brusco na queda de tensão na região da camada limite. Fenômeno conhecido por polarização por concentração (concentration polarization). Quanto maior a turbulência, menor será a polarização. Diferentes formas dos espaçadores causam variações na turbulência das correntes e, consequentemente, amenizam a polarização.

A curva de densidade de corrente pelo potencial elétrico aplicado apresenta três regiões bem definidas que são resultantes da relação entre o transporte convectivo na solução e do transporte através das membranas (figura 3.4). 


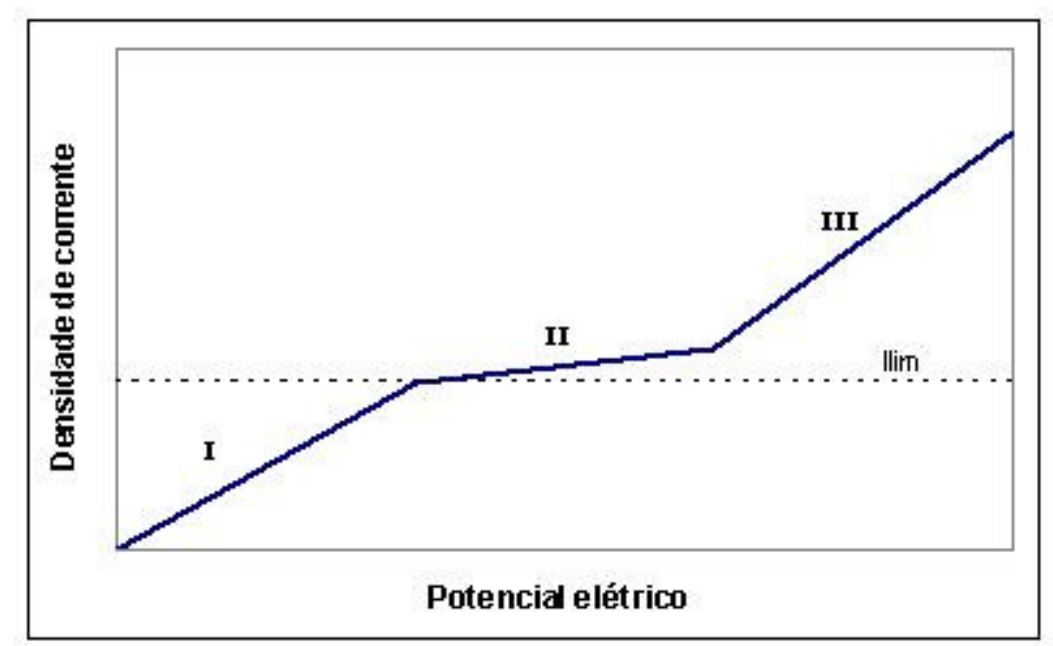

Figura 3.4.Densidade de corrente para potencial aplicado sobre o empilhamento

A explicação abaixo, feita para o fluxo de cátions, é similar ao fluxo de ânions. I. $J_{S}^{\text {diff }}>J_{C}^{\text {mig }}$, há acúmulo de íons na superfície da membrana (comportamento ôhmico)

II. $J_{S}^{\text {diff }}=J_{C}^{\text {mig }}$, os fluxos difusivo e transmembrânico são iguais. (densidade de corrente limite - $I_{\text {lim) }}$

III. $J_{S}^{\text {diff }}<J_{C}^{m i g}$, faltam íons na superfícies das membranas (dissociação da água)

Na região I os íons chegam à superfície da membrana em maior quantidade que atravessam a membrana. Há excesso de íons na superfície. As plantas de ED devem operar nessa região. Para garantir a operação de uma planta de eletrodiálise fique na região I, recomenda-se aplicar, no máximo, 80\% de $I_{\lim }$ (Strathmann, 2004). Nessa região, ocorre a polarização por concentração, embora não afete perceptivelmente o potencial elétrico que age sobre o sistema, isto é, não há falta de íons na superfície das membranas.

Aumentando-se a densidade de corrente sobre o empilhamento, aumenta o fluxo iônico através das membranas até o momento em que os fluxos difusivos e transmembrânicos são iguais (região II). Esse ponto é denominado densidade de corrente limite $\left(l_{\lim }\right), I_{\lim }$ é obtida, experimentalmente, pelo método proposto por Cowan e Brown em 1959.

Na região III (Figura 3.4) acontece, mais intensamente, a polarização por concentração. Qualquer aumento de potencial sobre o empilhamento não resultará 
em aumento de fluxo iônico, mas na hidrólise. O fenômeno controla a performance dos sistemas de eletrodiálise práticos (Baker, 2004).

A partir da região III, ocorrem reações paralelas para compensar a falta de íons como a dissociação da água, pois os íons $\mathrm{H}^{+}$e $\mathrm{OH}^{-}$passam a transportar a corrente elétrica no lugar dos íons do soluto. Consequentemente, há variação de $\mathrm{pH}$. Embora a dissociação da água tenha sido objeto de vários estudos, seu mecanismos ainda não é claro. A diferença da dissociação entre as MTC e MTA foi reconhecida por Rosenberg e Tirrel em 1957.

No caso de experimento na presença de íons alcalinos terrosos, como o $\mathrm{Mg}^{++}$, há um problema de deposição nas regiões II e III. O aumento de $\mathrm{pH}$, na presença de $\mathrm{Mg}^{++}$, resulta em deposição de $\mathrm{Mg}(\mathrm{OH})_{2}$ na superfície das MTC's próximas ao cátodo. (Oda e Yawataya,1967). Foi observado durante os experimentos que a aplicação de correntes mais elevadas contribuem para o depósito de $\mathrm{Mg}(\mathrm{OH})_{2}$.

$$
\mathrm{MgCl}_{2}+2 \mathrm{OH}^{-} \rightarrow \mathrm{Mg}(\mathrm{OH})_{2}+2 \mathrm{Cl}^{-}
$$

Portanto, dentre todos os fatores acima abordados, a densidade de corrente é da maior relevância na remoção iônica por eletrodiálise e o funcionamento da unidade.

\subsubsection{Modelo para transporte de massa}

O modelo matemático permitirá obter equações para os fluxos de sal $\left(\mathrm{J}_{\mathrm{s}}\right)$ e de água $\left(J_{v}\right)$ através das membranas, baseando-se em equações de transporte de massa. Após definido, simulações computacionais verificarão a adequação do modelo aos dados experimentais obtidos.

Os experimentos comparativos visaram obter os coeficientes para a equação (3.9) geral do transporte de sal (Js).

$$
J_{S}=\alpha_{1} \cdot i+\alpha_{2} \cdot C+\varepsilon
$$


onde $\alpha_{i}$ são coeficientes obtidos pela regressão linear, $i$ é a densidade de corrente $\left[A \cdot m^{-2}\right], C$ a concentração inicial da alimentação [eq. $\left.L^{-1}\right]$ e $\varepsilon$, o erro.

Da mesma forma estimou-se o fluxo de água $\left(J_{V}\right)$ para uma equação geral (3.10).

$$
J_{V}=\beta_{1} \cdot i+\beta_{2} \cdot \Delta C+\varepsilon
$$

onde $\beta_{\mathrm{i}}$ são coeficientes obtidos pela regressão linear, $i$ é a densidade de corrente $\left[\mathrm{A} \cdot \mathrm{m}^{-2}\right.$ ] e $\Delta C$ a diferença de concentração entre as soluções [mol. $\mathrm{L}^{-1}$ ].

\subsubsection{Consumo de energia}

$\mathrm{Na}$ região de operação da eletrodiálise o empilhamento de membranas, quando submetido a um potencial elétrico, apresenta comportamento ôhmico (região I da figura 3.4).

A resistência elétrica do empilhamento $\left(R_{e m p}\right)$ é a resultante das resistências oferecidas pelas soluções e pelas membranas (3.11). Seguindo a Lei de Ohm, aplicado um potencial elétrico, tem-se a densidade de corrente. Se for imposta densidade de corrente, haverá um potencial elétrico resultante e vice-versa.

$$
\begin{aligned}
& R_{\text {emp }}=\frac{U}{\frac{I}{A_{\text {memb }}}}=\frac{U}{i}=R_{\text {membranas }}+R_{\text {solução }} \approx R_{\text {solução }} \\
& R_{\text {solução }}=\left(\Lambda_{d} \cdot e \cdot N_{d}\right)^{-1}+\left(\Lambda_{c} \cdot \text { e. } N_{c}\right)^{-1}
\end{aligned}
$$

Onde $R_{\text {emp }}[\Omega]$, $R_{\text {solução }}[\Omega]$ e $R_{\text {membrana }}[\Omega]$ são as resistências elétricas do empilhamento, das soluções e das membranas $U[V], I[A]$ e i[A.m $\left.{ }^{-2}\right]$ é potencial, corrente e densidade de corrente elétricos. $A_{m e m b}\left[m^{2}\right]$ a secção transversal do empilhamento, $\Lambda\left[\mathrm{mS} . \mathrm{cm}^{-1}\right]$ é a condutividade da solução, e[cm] é a espessura dos espaçadores e $\mathrm{N}$ a quantidade de espaçadores. 
A resistência $R_{e m p}$ é determinada pelas concentrações da alimentação e da

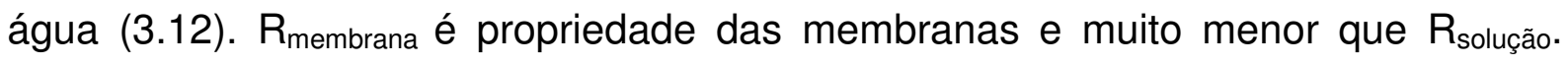
Assim, existem diferenças quanto ao comportamento de potencial e densidade de corrente entre um sistema contínuo e um batelada:

a) no contínuo, os perfis de concentração iônica das soluções são constantes, ou seja, o processo acontece em estado estacionário. Logo, não há variação de $R_{\text {emp }}$, o que implica em $U$ e $i$ constantes durante todo processo.

b) na batelada, a alimentação reduz sua concentração iônica enquanto o água aumenta. O perfil de concentração de íons varia com o tempo de remoção, bem como o valor de $R_{\text {solução. }}$ Por isso, $R_{\text {emp }}$ varia com o tempo de experimento. Logo, se $U$ é constante, $i$ varia, e vice-versa.

Apenas como exemplo, a figura 3.5 apresenta como os dados de diferença de potencial e corrente comportam-se durante um experimento qualquer. Nela, observa-se que ao início dos experimentos, o potencial é elevado e decrescente. A causa desse fenômeno é a ausência de íons na solução de água inicial. Com a evolução do processo, essa solução passa a receber íons e aumentar sua condutividade elétrica.

No processo batelada estudado, a partir do momento que as duas correntes de solução igualam-se, a resistividade da solução de alimentação passa a elevar-se, pois continua perdendo íons. Daí em diante, a resistência do empilhamento aumenta. Como a densidade de corrente permanece constante, o potencial elétrico torna-se crescente a partir da metade do experimento. 


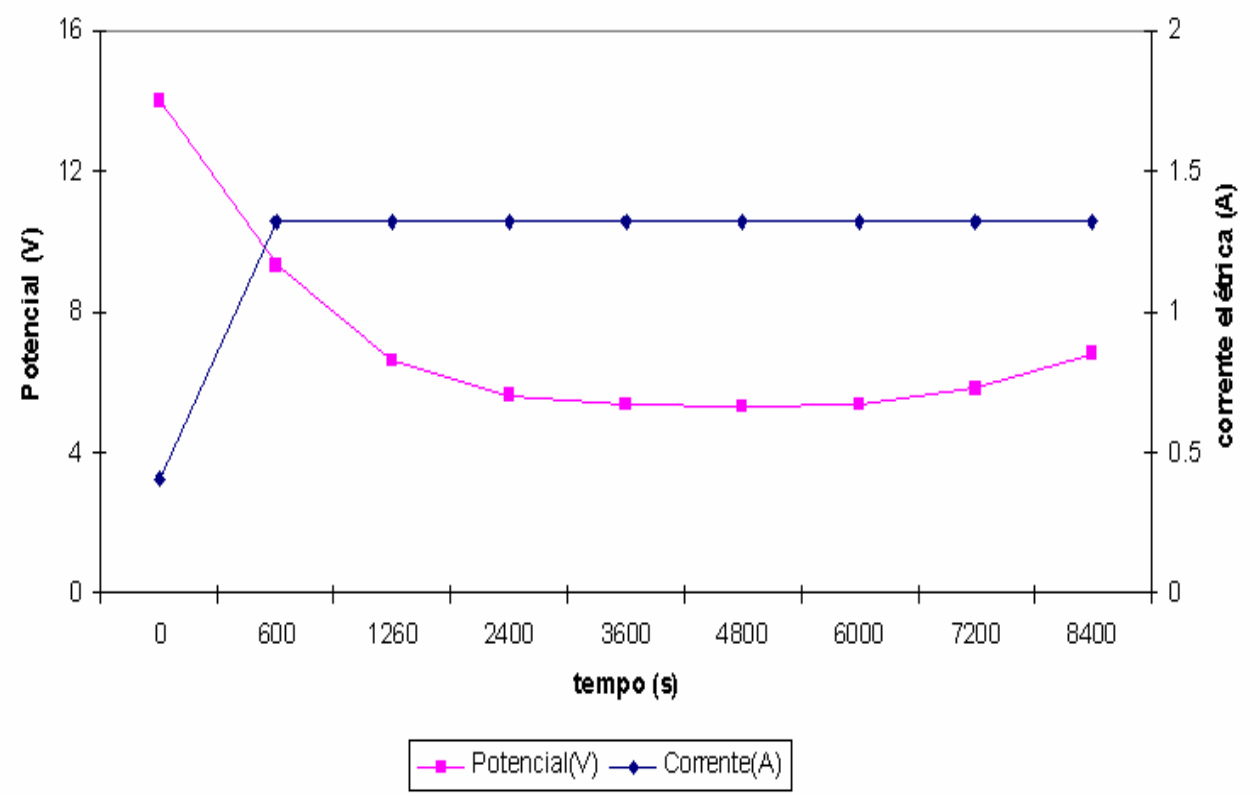

Figura 3.5.Diferença de potencial e corrente elétrica aplicada sobre o empilhamento no processo batelada obtidas em experimento qualquer.

O consumo energético na ED é o somatório da energia de bombeamento $\left(E_{\text {bomb }}\right)$, a de remoção de íons $\left(E_{i o n}\right)$ e as perdas (3.13).

$$
E_{\text {TOTAL }}=E_{\text {bomb }}+E_{\text {ion }}+\text { perdas }
$$

O consumo energético de remoção específico $\left(E_{i o n}\right)$ é dado pela potência elétrica utilizada para remover uma dada quantidade de sal (Turek, 2002). A energia é obtida pela integração numérica da curva V.i por tempo. A energia por massa é a divisão numérica desse valor pela massa removida no mesmo período.

\subsubsection{Rendimento columbiométrico $(\eta)$}

Rendimento columbiométrico (ou de Faraday) é a fração da corrente elétrica aplicada sobre o empilhamento que, efetivamente, participa do transporte de íons da alimentação para a água (Roux-de Balmann e Casemond). Numericamente, é a relação entre o fluxo molar de sal e a quantidade de carga elétrica, em mols de 
Coulomb (C) aplicados sobre o empilhamento (3.14), isto é, quantos equivalentesgrama de íons são removidos por mol de elétrons fornecido

$$
\eta=\frac{J_{S}}{i / \mathfrak{I}}(\text { Tanaka,2006) }
$$

sendo $\mathrm{J}_{\mathrm{S}}$ - fluxo molar de sal $\left[\mathrm{mol} . \mathrm{s}^{-1} \cdot \mathrm{cm}^{-2}\right]$, i - densidade de corrente aplicada $\left[\right.$ A.cm ${ }^{-2}=$ C.S $^{-1} \cdot \mathrm{cm}^{-2}$ ] e $\mathfrak{I}$ - constante de Faraday [96480 C.eq ${ }^{-1}$ ]

$\mathrm{O}$ valor de $\eta$ varia entre 0 e 1 . Em equipamentos de laboratório, aproxima-se da unidade. Nas instalações industriais ficam entre 0,7 e 0,9 (Roux-de Balmann e Casemond).

Com base nos fundamentos teóricos acima apresentados, o estudo foi realizado. 


\section{MATERIAIS E MÉTODOS}

\subsection{Equipamento}

A unidade de ED foi dimensionada a partir do empilhamento de membranas. Dessa forma, o sistema foi projetado às avessas, ou seja, os demais componentes da unidade deveriam adaptar-se ao empilhamento. Com isso em mente, dimensionaram-se os acessórios como os tanques de solução, a fonte elétrica de corrente contínua, os medidores de vazão, a balança, as válvulas e as bombas. $O$ fluxograma do processo é representado na Figura 4.1, baseando-se, principalmente, no manual fornecido pelo fabricante do sistema de membranas.

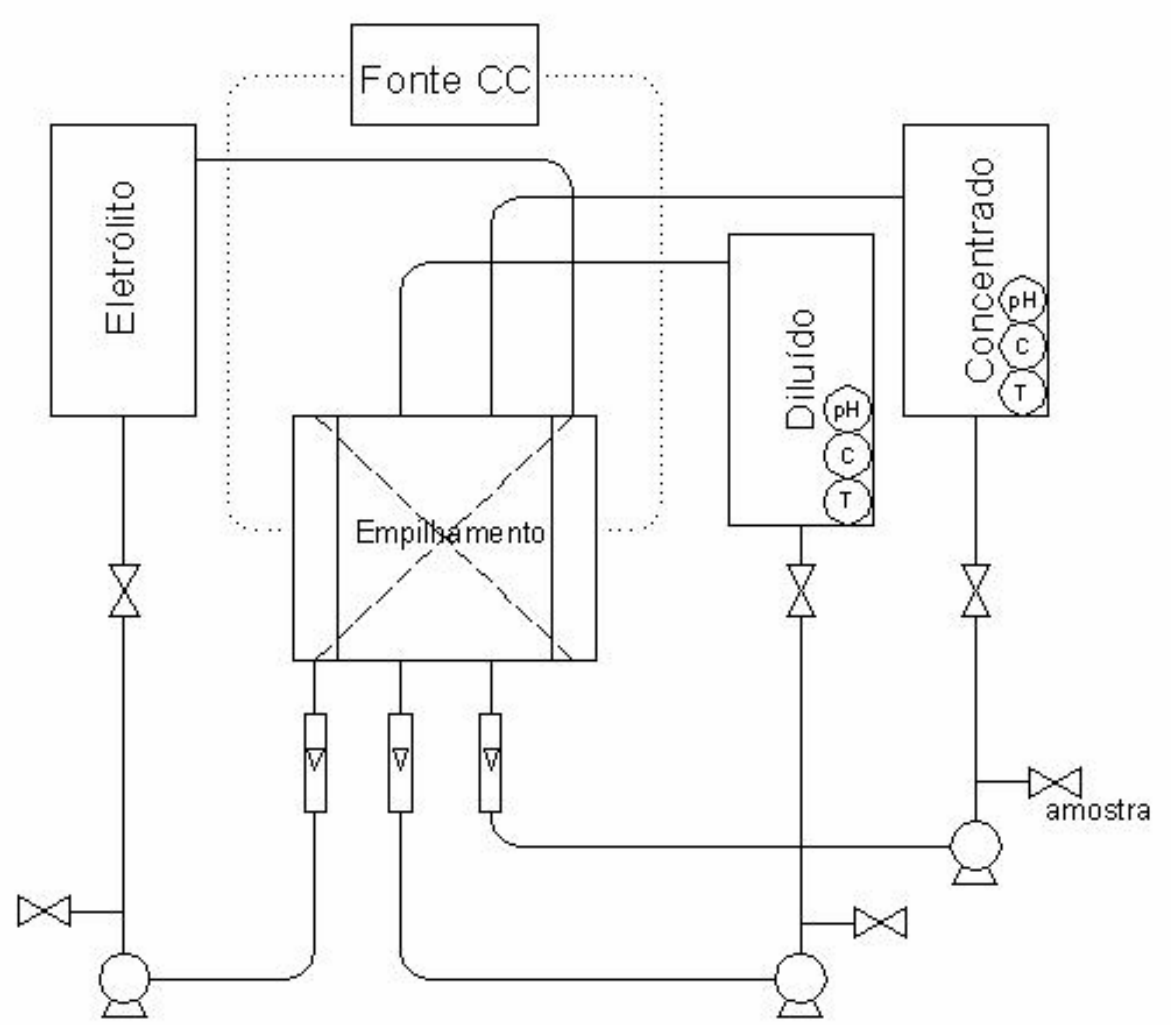

Figura 4.1.Fluxograma de processo do equipamento de ED. 
O equipamento pronto deve fornecer uma vazão de 4 a $8 \mathrm{~L} / \mathrm{h} / \mathrm{par}$ de membrana, utilizando equipamentos resistentes à corrosão causada pelas soluções salinas. O máximo potencial elétrico aplicável é de $2 \mathrm{~V}$ por par de membrana até $20 \mathrm{~V}$ e até $5 \mathrm{~A}$ de corrente elétrica contínua.

Devido à salinidade, alguns componentes testados na montagem, foram danificados. As bombas centrífugas, as válvulas de aço e os manômetros de linha tiverem partes oxidadas pela corrosão. Além disso, os componentes metálicos poderiam interferir nas medições de condutividade elétrica.

As bombas foram substituídas por bombas magnéticas com rotor plástico; as válvulas, por outras de aço INOX 316 tipo agulha. Os manômetros foram retirados do projeto. Os demais componentes são de plásticos, como os tanques, as tubulações e os rotâmetros (medidores de vazão). A fonte elétrica fornece corrente contínua até $6 \mathrm{~A}$ e potencial até $30 \mathrm{~V}$.

Além da operação, foram necessários equipamentos para medição. Medidores de condutividade elétrica (condutivímetros), de $\mathrm{pH}$ (pH-metros) e uma balança analítica foram utilizados.

Os medidores conectados ao equipamento tinham suas leituras transmitidas ao computador, através de cabos conectados às portas seriais RS232 dos próprios medidores. Os dados eram recebidos e gravados com auxílio de programa desenvolvido com o software LabView.

Com outro condutivímetro de bancada (Excell XL50) mediram-se os dados de condutividade. Essas medidas eram feitas a partir de amostras, que foram devolvidas ao tanque em seguida, mostraram-se mais confiáveis e precisas, que as tomadas diretamente nos tanques.

A balança analítica tem precisão de $10 \mathrm{~g}$ com capacidade máxima de $4 \mathrm{~kg}$.

Para os experimentos, o equipamento consistiu de empilhamento (stack) de membranas, sistema hidráulico e fonte de corrente elétrica, além do sistema de aquisição de dados de condutividade e $\mathrm{pH}$. Três bombas magnéticas (Bomax PX-50) circulação das soluções; uma fonte de corrente contínua (ICEL PS-6100).

Os experimentos foram realizados nessa planta de laboratório com o sistema de membranas PCCell 640 02, da PCCell GmbH, com 7 pares de membranas (PCSA/PC-SK), cada uma com área ativa de $64 \mathrm{~cm}^{2}$ (total de $0,13 \mathrm{~m}^{2}$ ). $\mathrm{O}$ anodo é de $\mathrm{Pt} / \mathrm{rr}$-revestido com $\mathrm{Ti}$ e o catodo de aço inox V4A. A tabela 4.1 traz as características fisico-químicas das membranas. 
A unidade pode ser vista na Figura 4.2 e a Tabela 4.2 apresenta o rol de componentes adquiridos. Para a aquisição de dados on-line, é preciso também um computador com o software LabView instalado.
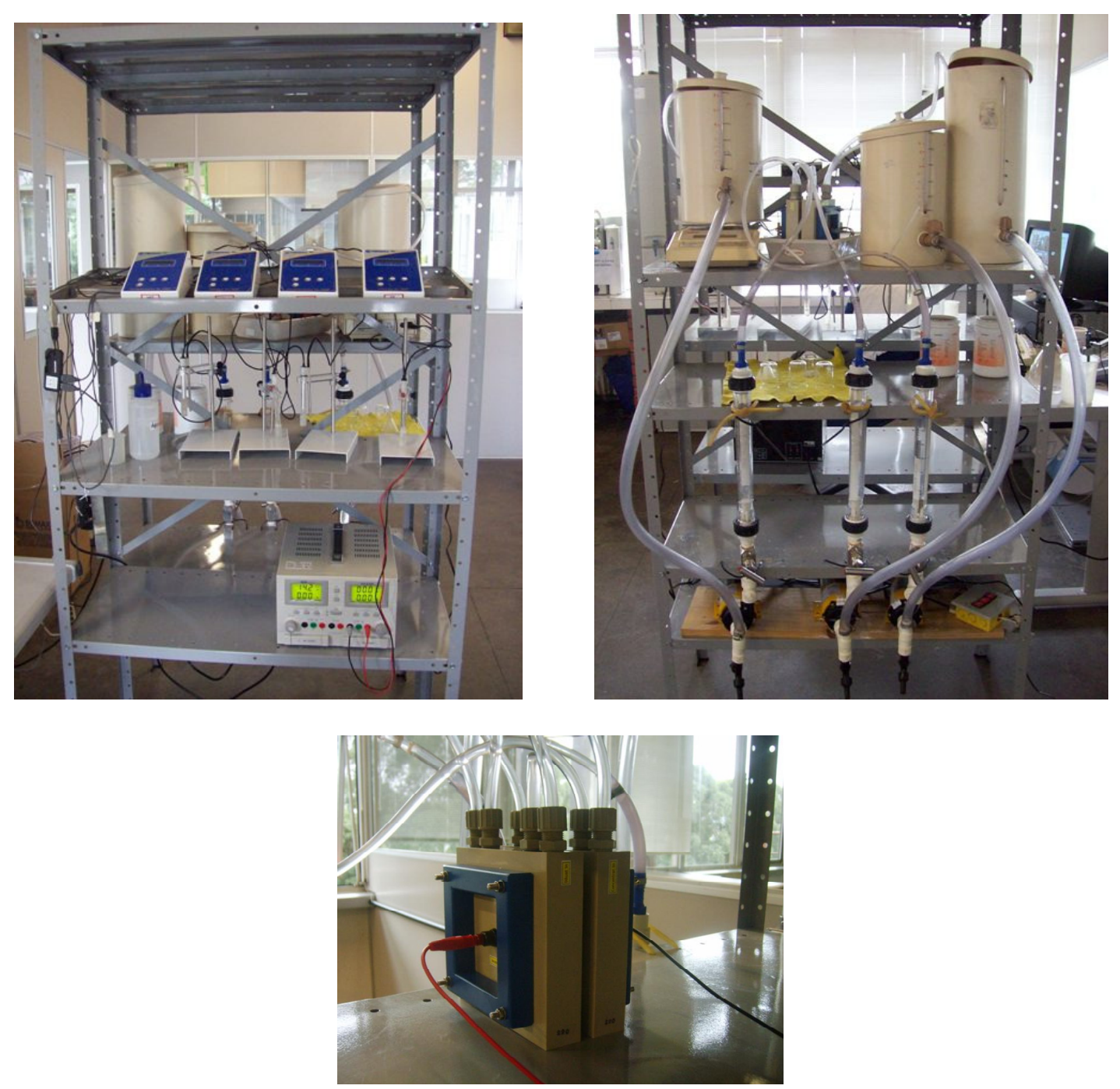

Figura 4.2.Unidade de eletrodiálise (acima) e empilhamento de membranas (abaixo).

Tabela 4.1.Características fisico-químicas das membranas usadas

\begin{tabular}{ccccccc}
\hline Membrana & $\begin{array}{c}\text { Espessura } \\
(\mu \mathrm{m})\end{array}$ & $\begin{array}{c}\text { Capacidade } \\
\text { de troca } \\
\left(\mathrm{meq} \cdot \mathrm{g}^{-1}\right)\end{array}$ & $\begin{array}{c}\text { Estabilidade } \\
\text { química } \\
(\mathrm{pH})\end{array}$ & Seletividade & $\begin{array}{c}\text { Grupo } \\
\text { funcional }\end{array}$ & Resistividade \\
\hline PC-SK & 130 & $\sim 1$ & $0-11$ & $>0.93$ & $-\mathrm{SO}_{3}^{-}$ & $0.75-3$ \\
PC-SA & $90-130$ & $\sim 1.5$ & $0-9$ & $>0.96$ & $-\mathrm{NR}_{4}{ }^{+}$ & $1-1.5$ \\
\hline
\end{tabular}


Tabela 4.2.Componentes da unidade experimental de ED.

\begin{tabular}{|c|c|}
\hline Equipamento & Descrição \\
\hline $\begin{array}{lrr}\text { Fonte } \quad \text { ajustável } & \text { de } \\
\text { energia } & \text { elétrica } & \text { em } \\
\text { corrente contínua } & \end{array}$ & $\begin{array}{l}\text { Com possibilidade de controle de corrente ou tensão, na } \\
\text { faixa de } 0 \text { a } 6 \mathrm{~A}, 0 \text { a } 30 \mathrm{~V} \text {. }\end{array}$ \\
\hline Bombas de circulação & $\begin{array}{l}\text { Bomax PX50 Centrífugas magnéticas, vazão nominal de até } \\
200 \mathrm{l} / \mathrm{h} \text { sem desnível. }\end{array}$ \\
\hline Válvulas & Tipo agulha com internos feitos de aço inox 316 \\
\hline $\begin{array}{l}\text { Rotâmetros } \\
\text { (Água e Alimentação) }\end{array}$ & $\begin{array}{l}\text { Applitech Série AP 300, corpo externo de policarbonato e } \\
\text { flutuador de teflon. Faixa de operação: } 0 \text { a } 80 \mathrm{l} / \mathrm{h} \text {. }\end{array}$ \\
\hline Rotâmetros (Eletrodos) & $\begin{array}{l}\text { Applitech Série AP 300, corpo externo de policarbonato e } \\
\text { flutuador de aço inox } 316 \text {. Faixa de operação: } 0 \text { a } 300 \mathrm{l} / \mathrm{h} \text {. }\end{array}$ \\
\hline Tanques (barriletes) & $\begin{array}{l}\text { Mogiglass, capacidade de } 10 \mathrm{~L} \text {, em PVC, com visor de nível, } \\
\text { válvulas de dreno e tampa. }\end{array}$ \\
\hline $\begin{array}{l}\text { Medidores de } \mathrm{pH}(\mathrm{pH}- \\
\text { metro) }\end{array}$ & $\begin{array}{l}\text { Medidor de bancada Tecnal, com ajuste automático de } \\
\text { temperatura e saída para computador. }\end{array}$ \\
\hline $\begin{array}{lr}\text { Medidores } & \text { de } \\
\text { Condutividade } & \text { Elétrica } \\
\text { (condutivímetro) } & \end{array}$ & $\begin{array}{l}\text { Medidor de bancada Tecnal, com ajuste automático de } \\
\text { temperatura e saída para computador. }\end{array}$ \\
\hline $\begin{array}{l}\text { Cabos de transmissão de } \\
\text { dados }\end{array}$ & $\begin{array}{l}\text { Cabos para transmissão e conversão de dados RS232 - } \\
\text { USB, conectados entre o computador e os medidores. }\end{array}$ \\
\hline
\end{tabular}

Durante os experimentos, observou-se que $\mathrm{pH}$-metros e condutivímetros interferem nas medidas um do outro, sendo feita apenas uma das medidas no tanque. Visto que, para efeito precisão de cálculos, os valores de condutividade são mais relevantes que os de $\mathrm{pH}$, optou-se por medir o $\mathrm{pH}$ no tanque e a condutividade por amostragem no medidor de bancada. As medidas de $\mathrm{pH}$ foram apenas utilizadas durante os experimentos para verificação de variações significativas.

Os condutivímetros medem as resistividades elétricas da solução e a converte em condutividade, afinal um é o inverso do outro. Para isso, mantém uma ddp entre seus eletrodos no sensor do equipamento. $O$ sensor do pHmetro é sensível a essa ddp. Portanto, esse fenômeno pode ser interpretado como uma interferência causada no $\mathrm{pH}$-metro resultante dos impulsos elétricos emitidos pelo condutivímetro. 


\subsection{Determinação de densidade de corrente limite}

Como foi explicado na seção 3.4.1.2., a densidade de corrente limite (ilim) é um parâmetro fundamental para o sistema de eletrodiálise. O método utilizado foi aquele desenvolvido por Cowan e Brown em 1959. Para melhor eficiência do sistema, recomenda-se aplicar um valor máximo de $80 \%$ de $\mathrm{i}_{\text {lim, }}$, o que garante estar na região ôhmica do processo (seção 3.4.1.2).

O experimento foi realizado na própria unidade nas condições de menor concentração inicial de alimentação. Considera-se que esse é o maior valor em todo o planejamento. Para cada sal foi obtido apenas um valor de $\mathrm{i}_{\text {lim. }}$.

Os experimentos consistiam em circular uma mesma solução, com a menor concentração encontrada no planejamento experimental, através dos dois compartimentos no empilhamento. Logo após, são aplicados potenciais elétricos (V) sobre o empilhamento e medidos valores de corrente elétrica (I). O potencial é aumentado em passos de $0,5 \mathrm{~V}$ e aguardando-se a estabilização da leitura de corrente. Levanta-se o gráfico de $\mathrm{V} / \mathrm{I}$ por $\mathrm{I}^{-1}$, como na figura 4.3. A inflexão da curva indica $\mathrm{i}_{\mathrm{lim}}$.

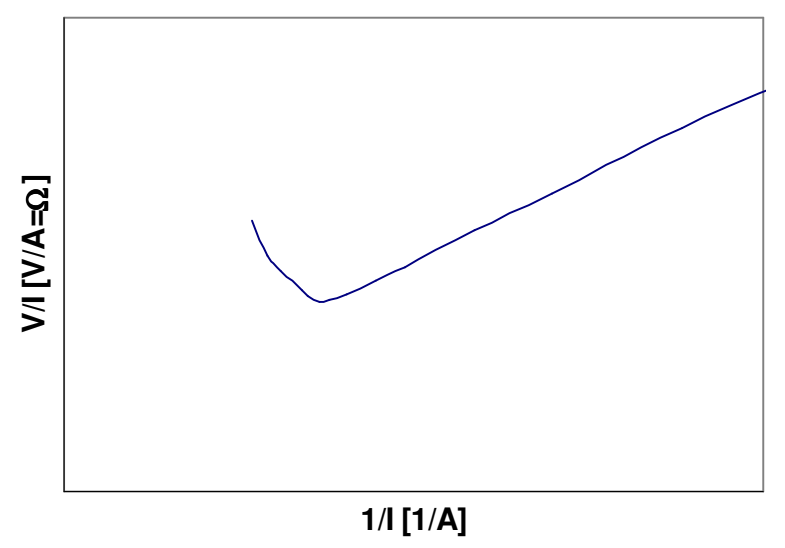

Figura 4.3.Curva proposta por Cowan \& Brown, 1959.

\subsection{Planejamento experimental}

Os experimentos seguiram os planejamentos experimentais de acordo com valores de densidade de corrente elétrica (i), concentração inicial de equivalentes na 
alimentação $(C)$ e vazão $(\mathrm{Q})$. Durante os experimentos, tomaram-se os dados de condutividade elétrica, $\mathrm{pH}$ e temperatura das soluções por meio de amostras, que eram devolvidas após as medições. A fonte elétrica informava a corrente e potencial elétricos aplicados no empilhamento.

A condutividade elétrica foi convertida para concentração por meio de curvas de calibração obtidas previamente apresentadas no ANEXO A.

\subsubsection{Planejamento Fatorial}

O planejamento experimental do tipo fatorial coloca os fatores em diferentes níveis. Combinando os diferentes níveis de fatores são realizados experimentos. Analisam-se, estatisticamente, os resultados experimentais a fim de verificar a significância de cada um dos fatores nas respostas. A quantidade de experimentos é dada por (4.1)

N.exerimentos $=k_{\text {exp }} . N i^{f}+k_{P C}$

onde $k_{\exp }$ e $k_{P C}$ são as repetições dos experimentos do planejamento e dos pontos centrais; $\mathrm{N}_{\mathrm{i}}$ é a quantidade de níveis; f são os fatores.

Foi utilizado o planejamento com três fatores e dois níveis nos experimentos exploratórios. Ele pode ser visualizado, esquematicamente, na figura 4.4. Os vértices simbolizam os experimentos. Ao centro do cubo o ponto central.

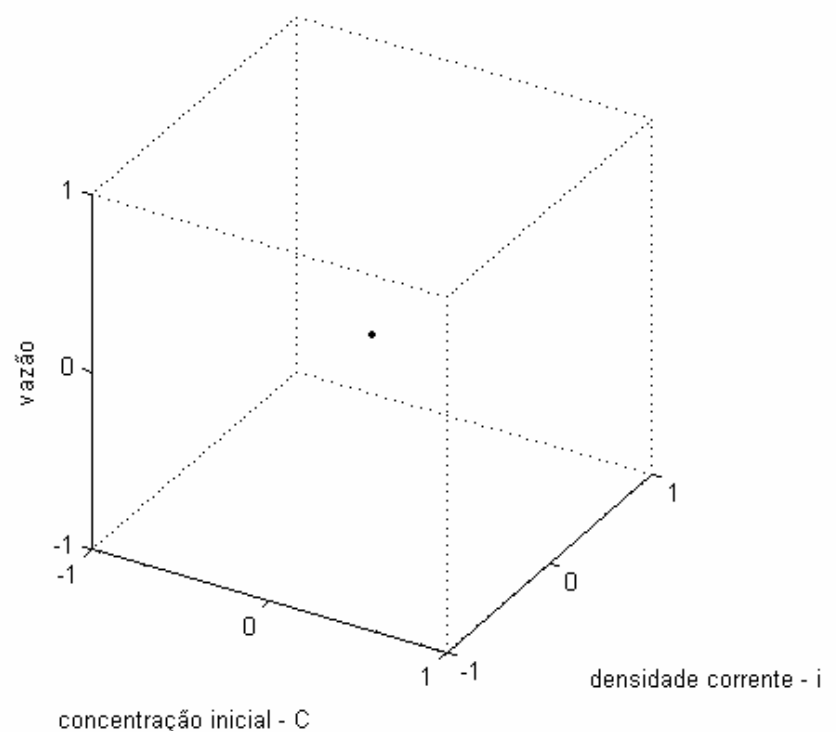

Figura 4.4.Esquema de um planejamento experimental com 3 fatores em 2 níveis com ponto central 
Mais a frente (seção 4.10) os métodos estatísticos utilizados na análise serão explicados em maiores detalhes.

\subsubsection{Planejamento Doehlert}

O planejamento Doehlert é uma variação do planejamento fatorial (Doehlert, 1970). Os pontos do planejamento experimental são posicionados conforme um hexágono, como na figura 4.5.

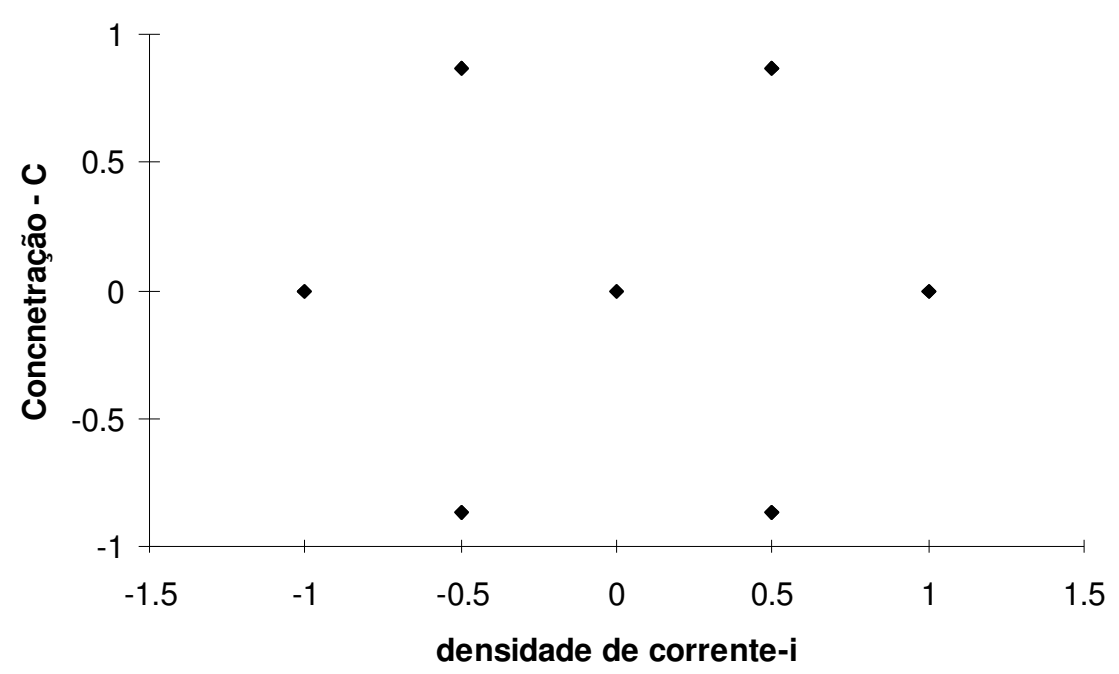

Figura 4.5.Esquema de um planejamento Doehlert com 2 fatores em 2 níveis com ponto central

A partir desse planejamento, pode-se obter uma equação geral (3.9 e 3.10) para os resultados experimentais numa região maior que a fornecida pelo planejamento fatorial.

\subsection{Fluxos de sal $\left(J_{s}\right)$}

Existem dois fluxos de massa no processo de eletrodiálise: o fluxo de sal $\left(\mathrm{J}_{\mathrm{S}}\right)$ e o fluxo de água $\left(J_{\mathrm{v}}\right)$. Os fluxos foram calculados de forma indireta a partir dos 
dados de condutividade e da variação da massa da solução de no tanque de água, medidas pela balança.

Primeiro foi preciso obter os volumes a cada instante. São conhecidos os volumes iniciais $\left(V_{0}\right)$ das duas soluções e os finais $\left(V_{F}\right)$ eram medidos. Esses volumes foram relacionados com a massa de solução no tanque $\left(m_{0}\right.$ e $\left.m_{F}\right)$. Os volumes intermediários $\left(\mathrm{V}_{\mathrm{i}}\right)$ são calculados proporcionalmente ao peso medido $\left(\mathrm{m}_{\mathrm{i}}\right)$ no água, como em (4.2).

$$
\frac{V_{i}-V_{0}}{V_{F}-V_{0}}=\frac{m_{i}-m_{0}}{m_{F}-m_{0}} \Leftrightarrow V_{i}=V_{0}+\left(V_{F}-V_{0}\right) \cdot\left(\frac{m_{i}-m_{0}}{m_{F}-m_{0}}\right)
$$

Para determinar $J_{S}$ usaram-se a condutividade e o volume instantâneo no água. Com os dados aplicava-se a equação (4.3)

$$
J_{S}=\frac{C_{i+1} \cdot V_{i+1}-C_{i} \cdot V_{i}}{\Delta t \cdot N \cdot A_{m e m b}}
$$

Onde $J_{S}$ é o fluxo de equivalentes de sal [eq... ${ }^{-1} . m^{-2}$; $C_{i}$ e $C_{i+1}$, as concentrações de sal no água nos instantes; $i$ e $i+1$ [eq. $\mathrm{L}^{-1}$ ]; $\mathrm{V}_{\mathrm{i}}$ e $\mathrm{V}_{\mathrm{i}+1}$, volumes de água nos instantes $i$ e $i+1[\mathrm{~L}]$; $\Delta \mathrm{t}$, variação temporal [s]; $\mathrm{N}$, número de pares de membranas e $A_{m}$, a área de membrana $\left[\mathrm{m}^{2}\right]$.

\subsection{Fluxos de água $\left(J_{V}\right)$}

O fluxo de água $\left(J_{V}\right)$ é causado pela diferença de concentração entre as soluções $(\Delta \mathrm{C})$ e pela densidade de corrente elétrica (i). Durante os experimentos, $\Delta \mathrm{C}$ varia com o tempo, enquanto i é constante.

Para obter a equação de $J_{V}$, calculou-se $J_{V}$ entre duas medições através de (4.4). A água atravessa pelos dois tipos de membranas, os íons por apenas um. Por isso, Jv é calculado sobre o dobro de área em relação à Js. 


$$
J_{V}=\frac{m_{i+1}-m_{i}}{2 \cdot \Delta t \cdot N \cdot A_{m}}
$$

Onde $J_{V}$ é o fluxo de água $\left[\mathrm{g} . . \mathrm{s}^{-1} \cdot \mathrm{m}^{-2}\right] ; \mathrm{m}_{\mathrm{i}}$ e $\mathrm{m}_{\mathrm{i}+1}$, as massas do tanque alimentação nos instantes; i e $i+1$ [g]; $\Delta$ t, variação temporal [s]; $N$, número de pares de membranas e $A_{m}$, a área de membrana $\left[\mathrm{m}^{2}\right]$.

Os coeficientes da equação geral (3.10) foram obtidos por regressão linear de uma tabela com todos os valores de $J_{V}$ dos experimentos com um sal.

\subsection{Número de hidratação $\left(T_{\mathrm{W}}\right)$}

A quantidade de moléculas de água que acompanham os íons denomina-se número de hidratação $\left(\mathrm{T}_{\mathrm{W}}\right)$. Quanto maior o número de hidratação, maior a quantidade de água transportada por eletro-migração, ou seja, solvatando os íons.

$$
T_{W}=\frac{J_{V}}{J_{S}}
$$

Calculou-se $T_{w}$ pela equação (4.5), com as equações obtidas de $J_{V}$ e $J_{s}$., nas faixas de i e $\Delta C$ usadas nos experimentos.

A equação descrita considera que todo fluxo de água seja provocado pelos íons solvatados que atravessam as membranas.

\subsection{Consumo energético}

O consumo de energia para a separação foi obtido pela divisão da quantidade de energia (Wh) pela quantidade de massa (g) removida da alimentação. Calculouse a energia integrando-se numericamente a curva potência em função do tempo de experimento. Em seguida, o valor é dividido pela massa de sal removida da alimentação no tempo de cada experimento. 


$$
E_{\text {ion }}=\frac{U . I . \Delta t}{\Delta m \cdot 3600}
$$

Sendo: $E_{\text {ion }}$ é energia elétrica [Wh]; U, potencial elétrico [V]; I, corrente elétrica [A]; $\Delta \mathrm{t}$, variação de tempo [s], $\Delta \mathrm{m}$, variação de massa [g]

A energia usada nesse cálculo é apenas a relativa à corrente elétrica aplicada sobre o empilhamento, desprezando-se a energia de bombeamento.

\subsection{Experimentos exploratórios}

Nos experimentos exploratórios, três fatores foram analisados: a concentração de sal inicial da alimentação $(C)$, a densidade de corrente elétrica aplicada (i) e as vazões na alimentação e água (Q). O planejamento experimental adotado foi o fatorial com três fatores em dois níveis, apresentado na Tabela 4.3. Foram realizados $\left(2^{n}=2^{3}=\right) 8$ experimentos mais três pontos centrais, totalizando $(8+3=) 11$ experimentos. Foi usado apenas o cloreto de sódio $(\mathrm{NaCl})$.

Tabela 4.3.Planejamento experimental exploratório

\begin{tabular}{ccccccc}
\hline \multirow{2}{*}{ Experimento } & \multicolumn{3}{c}{ Fatores codificados } & \multicolumn{3}{c}{ Fatores Não codificados } \\
& $\mathrm{C}$ & $\mathrm{i}$ & $\mathrm{Q}$ & $\begin{array}{c}\left.\mathrm{C} . \mathrm{L}^{-1}\right) \\
\left(\text { A. } \mathrm{m}^{-2}\right)\end{array}$ & $\begin{array}{c}\text { (L.s } \\
\text { (-1) }\end{array}$ \\
\hline 1 & - & - & - & 25 & 200 & 45 \\
2 & + & - & - & 45 & 200 & 45 \\
3 & - & + & - & 25 & 350 & 45 \\
4 & + & + & - & 45 & 350 & 45 \\
5 & - & - & + & 25 & 200 & 75 \\
6 & + & - & + & 45 & 200 & 75 \\
7 & - & + & + & 25 & 350 & 75 \\
8 & + & + & + & 45 & 350 & 75 \\
9,10 e 11 & 0 & 0 & 0 & 35 & 275 & 60 \\
\hline
\end{tabular}

Durante os experimentos exploratórios mediram-se a condutividade e $\mathrm{pH}$ das soluções e os níveis de solução nos tanques. A concentração de sal é obtida a partir da curva de calibração levantada previamente (ANEXO A).

Tanto os experimentos exploratórios como os comparativos foram iniciados com 2L de cada uma das soluções (alimentação e água). Usou-se água eletro- 
deionizada na alimentação. Como eletrólito foi usado 4L. de $\mathrm{Na}_{2} \mathrm{SO}_{4}$ a $0,25 \mathrm{M}$, de acordo com o manual do fabricante. Os experimentos foram realizados sem controle de temperatura.

\subsection{Experimentos comparativos}

Encerrados os experimentos exploratórios, o trabalho foi direcionado para o estudo comparativo dos comportamentos com diferentes soluções salinas. A primeira comparação foi feita entre as soluções de $\mathrm{NaCl}, \mathrm{Na}_{2} \mathrm{SO}_{4}, \mathrm{MgCl}_{2}$ e $\mathrm{KCl}$. Para melhor comparação, o planejamento experimental baseou-se em soluções iguais em base de equivalentes químicos, tomando como base a salinidade marinha $\left(35 \mathrm{gNaCl} . \mathrm{L}^{-1}\right)$. São concentrações mais elevadas que as normalmente encontradas na literatura (van der Bruggen, 2004; Demircoiglu, 2002).

O planejamento utilizado (Tabela 4.3) seguiu o planejamento Doehlert, com duas repetições de cada experimento, totalizando 14 experimentos por sal.

Tabela 4.4.Planejamento experimental comparativo

\begin{tabular}{ccccc}
\hline & \multicolumn{2}{c}{ Fatores } & \multicolumn{2}{c}{ Fatores } \\
Experimento & \multicolumn{2}{c}{ Codificados } & \multicolumn{2}{c}{$\begin{array}{c}\text { não-codificados } \\
\text { i }\end{array}$} \\
& $\mathrm{i}$ & $\mathrm{C}$ & $\begin{array}{c}\mathrm{C} \\
\left(\mathrm{A} \cdot \mathrm{m}^{-2}\right)\end{array}$ & $\left(\mathrm{eq} \mathrm{L}^{-1}\right)$ \\
\hline 1 & 0 & 0 & 200 & 0,45 \\
2 & 1 & 0 & 300 & 0,45 \\
3 & 0,5 & 0,86 & 250 & 0,58 \\
4 & -1 & 0 & 100 & 0,45 \\
5 & $-0,5$ & $-0,86$ & 150 & 0,32 \\
6 & 0,5 & $-0,86$ & 250 & 0,32 \\
7 & $-0,5$ & 0,86 & 150 & 0,58 \\
\hline
\end{tabular}

A partir dos resultados de fluxo de sal $\left(J_{S}\right)$, fluxo de água $\left(J_{V}\right)$ e energia específica de remoção de íon ( $\left.E_{i o n}\right)$, foram conduzidas as análises estatísticas.

Não foi feito controle de temperatura. Os experimentos foram realizados com temperaturas entre 23 e $30^{\circ} \mathrm{C}$. No decorrer dos experimentos a temperatura aumentava entre 1 e $2^{\circ} \mathrm{C}$ por hora, resultado da energia dissipada pelas bombas e pela queda de potencial sobre o empilhamento. Para o estudo, essa variação de temperatura não interfere significativamente nos resultados obtidos. 


\subsection{Análises estatísticas}

O planejamento experimental permite avaliar como os fatores (e as interações entre eles) participam das respostas. As respostas foram analisadas estatisticamente por análise de variância, regressão linear e superfície de resposta. A metodologia e as hipóteses adotadas são descritas a seguir.

\subsubsection{Análise de variância ( $\left.A N O V A^{1}\right)$}

Duas médias podem ser comparadas por meio de testes estatísticos. Quando se tem mais de duas médias, esses métodos tornam-se demasiados trabalhosos. Usa-se, então, a análise de variância (Box, 1978).

Num planejamento com um só fator, cada nível é chamado de tratamento. Um tratamento pode ser aproximado para um modelo estatístico linear (4.7)

$$
\begin{aligned}
& Y_{i t}=\eta+\tau_{t}+\varepsilon_{i t}\left\{\begin{array}{l}
i=1,2, \ldots, a \\
t=1,2, \ldots, n
\end{array}\right. \\
& Y_{i t}=\eta_{t}+\varepsilon_{i t}
\end{aligned}
$$

onde $Y_{i t}$ é a variável aleatória da it-ésima observação, $\eta$ é a média global dos tratamentos, $\tau_{t}$ é o efeito incremental do tratamento $t$ na média global e $\varepsilon_{\mathrm{t}} \mathrm{O}$ erro. Simplificando a equação (4.7), tem-se (4.8) adotando $\eta_{\mathrm{t}}=\eta+\tau_{\mathrm{t}}$.

Assume-se que os erros são independentes e normalmente distribuídos com média zero e variância fixa e desconhecida $\sigma^{2}$. Desprezam-se os resíduos, assumese média $\mu_{t}$ para cada tratamento e testam-se as hipóteses (4.9) e (4.10).

$$
\begin{aligned}
& H_{0}: \tau_{1}=\tau_{2}=\ldots=\tau_{a}=0 \\
& H_{1}: \tau_{i} \neq 0, \text { para pelo menos um } i
\end{aligned}
$$

${ }^{1}$ Analysis of Variance 
Se a hipótese nula $\left(H_{0}\right)$ for verdadeira, não há "efeito incremental" de nenhum tratamento.

A ANOVA divide a variabilidade da amostra em dois componentes. $O$ teste de hipótese baseia-se na comparação das duas estimativas independentes das variâncias da população: a variância dos tratamentos e a do erro. A variabilidade total dos dados é descrita pela soma total dos quadrados $S Q_{T}$ (Montgomery,2003).

O cálculo envolvido no teste de hipótese parte de um planejamento experimental típico apresentado na tabela 4.5. Esse tipo de planejamento é equilibrado, pois tem o mesmo número de repetições $n$ para cada tratamento.

Tabela 4.5.Típico planejamento de um fator fixos em a níveis (Montgomery, 2003)

\begin{tabular}{|c|c|c|c|c|c|c|}
\hline \multicolumn{2}{|l|}{ Tratamento } & \multicolumn{3}{|c|}{ Observações } & \multirow{2}{*}{$\begin{array}{l}\text { Totais } \\
\mathrm{y}_{1} .\end{array}$} & \multirow{2}{*}{$\begin{array}{l}\text { Médias } \\
\hat{y}_{1} .\end{array}$} \\
\hline 1 & $y_{11}$ & $y_{12}$ & $\ldots$ & $\mathrm{y}_{1 \mathrm{n}}$ & & \\
\hline 2 & $y_{21}$ & $y_{22}$ & $\ldots$ & $y_{2 n}$ & $y_{2}$ & $\hat{y}_{2}$. \\
\hline$\vdots$ & $\vdots$ & $\vdots$ & & $\vdots$ & $\vdots$ & $\vdots$ \\
\hline \multirow[t]{2}{*}{$a$} & $\mathrm{y}_{\mathrm{a} 1}$ & $\mathrm{y}_{\mathrm{a} 2}$ & $\ldots$ & $y_{a n}$ & $\mathrm{y}_{\mathrm{a}}$ & $\hat{y}_{\mathrm{a}}$ \\
\hline & & & & & y.. & $\hat{\mathrm{y}}$. \\
\hline
\end{tabular}

As estimativas das variâncias são obtidas pelas somas dos quadrados dos tratamentos $\left(\mathrm{SQ}_{\mathrm{t}}\right)$ e do erro $\left(\mathrm{SQ}_{\mathrm{e}}\right)$. Para o planejamento equilibrado, as estimativas são dadas por (4.11), (4.12) e (4.13) e as médias quadradas (MQ) de (4.14).

Finalmente, a hipótese é testada a partir de $F_{0}$ confrontando-se com a distribuição $F$ com (a-1) e a.(n-1) graus de liberdade. Se $F_{0}>F_{(a-1), a .(n-1)}, H_{0}$ é aceita, ou seja, há diferença estatística entre os tratamentos.

$$
\begin{aligned}
& S Q_{T}=\sum_{t=1}^{a} \sum_{j=1}^{n} y_{t j}^{2}-\frac{y_{. .}^{2}}{a . n} \\
& S Q_{t}=\sum_{t=1}^{a} \frac{y_{t}^{2}}{n}-\frac{y_{.2}^{2}}{a . n}
\end{aligned}
$$




$$
\begin{gathered}
\mathrm{SQ}_{\mathrm{e}}=\mathrm{SQ}_{\mathrm{T}}-\mathrm{SQ}_{\mathrm{t}} \\
M Q=\frac{S Q}{G . L .}
\end{gathered}
$$

Tabela 4.6.ANOVA para planejamento de um fator com a níveis (Montgomery, 2003)

\begin{tabular}{lcccc}
\hline $\begin{array}{r}\text { Fonte de } \\
\text { variação }\end{array}$ & $\begin{array}{c}\text { Soma dos } \\
\text { quadrados }\end{array}$ & $\begin{array}{c}\text { Graus de } \\
\text { liberdade (G.L.) }\end{array}$ & Média & $F_{0}$ \\
\hline Tratamento & $\mathrm{SQ}_{\mathrm{t}}$ & $\mathrm{a}-1$ & $\mathrm{MQ}_{\mathrm{t}}$ & $\mathrm{MQ}_{\mathrm{t}} / \mathrm{MQ}_{\mathrm{e}}$ \\
Erro & $\mathrm{SQ}_{\mathrm{e}}$ & a.(n-1) & $\mathrm{MQ}_{\mathrm{e}}$ & \\
Total & $\mathrm{SQ}_{\mathrm{T}}$ & a.n-1 & & \\
\hline
\end{tabular}

No planejamento com dois fatores (A e B), o cálculo é semelhante. O modelo linear estatístico (4.7-A) considera as contribuições dos fatores $\left(\beta_{\mathrm{i}} \mathrm{e} \tau_{\mathrm{j}}\right)$, suas interações $\left(\beta \tau_{\mathrm{ij}}\right)$ nas respostas $\left(\mathrm{Y}_{\mathrm{ijk},},\right)$ em $k$ repetições.

$$
Y_{i j k}=\eta+\beta_{i}+\tau_{j}+(\beta \tau)_{i j}+\varepsilon_{i t k}\left\{\begin{array}{l}
i=1,2, \ldots, a \\
j=1,2, \ldots, b \\
k=1,2, \ldots, n
\end{array}\right.
$$

A tabela da ANOVA é apresentada na tabela 4.6-A, que é obtida de maneira análoga à tabela 4.6 e é testada pela distribuição $F$.

Tabela 4.6-A.ANOVA para planejamento com dois fatores (Montgomery, 2003)

\begin{tabular}{lcccc}
\hline $\begin{array}{c}\text { Fonte de } \\
\text { variação }\end{array}$ & $\begin{array}{c}\text { Soma dos } \\
\text { quadrados }\end{array}$ & $\begin{array}{c}\text { Graus de } \\
\text { liberdade (G.L.) }\end{array}$ & Média & $F_{0}$ \\
\hline Fator $\mathrm{A}$ & $\mathrm{SQ}_{\mathrm{A}}$ & $\mathrm{a}-1$ & $\mathrm{MQ}_{\mathrm{A}}$ & $\mathrm{MQ}_{\mathrm{A}} / \mathrm{MQ}_{\mathrm{e}}$ \\
Fator $\mathrm{B}$ & $\mathrm{SQ}_{\mathrm{B}}$ & $\mathrm{b}-1$ & $\mathrm{MQ}_{\mathrm{B}}$ & $\mathrm{MQ}_{\mathrm{B}} / \mathrm{MQ}_{\mathrm{e}}$ \\
Interação $\mathrm{AB}$ & $\mathrm{SQ}_{\mathrm{AB}}$ & $(\mathrm{a}-1) \cdot(\mathrm{b}-1)$ & $\mathrm{MQ}_{\mathrm{AB}}$ & $\mathrm{MQ}_{\mathrm{AB}} / \mathrm{MQ}_{\mathrm{e}}$ \\
Erro & $\mathrm{SQ}_{\mathrm{e}}$ & ab.(n-1) & $\mathrm{MQ}_{\mathrm{e}}$ & \\
Total & $\mathrm{SQ}$ & abn-1 & & \\
\hline
\end{tabular}




\subsubsection{Regressão linear}

A regressão linear é a ferramenta estatística que permite obter modelos matemáticos que se aproximem das respostas experimentais obtidas. A equação (4.15) é o modelo mais simples para regressão linear, aproximar dados empíricos para uma reta.

$$
Y=\beta_{0}+\beta_{1} x+\varepsilon
$$

Onde $\beta_{0}$ e $\beta_{1}$ são os coeficientes linear e angular e $\varepsilon$ o erro do modelo. Considerando a distribuição do erro $\varepsilon$ normal, podemos assumir $\varepsilon$ nulo com variância $\sigma^{2}$.

Obtêm-se os coeficientes pelo método dos mínimos quadrados, que minimiza a somatória das distâncias dos pontos experimentais da reta do modelo. Há variações da regressão linear com termos de segunda ordem ou interações entre termos. Esses modelos geram gráficos em 3D denominados superfície de resposta.

Conforme visto, o $J_{S}$ é proporcional à densidade de corrente elétrica. Quando $\mathrm{i}=0, \mathrm{~J}_{\mathrm{S}}=0$. Logo, pode-se assumir (4.16), isto é, uma reta que passa pela origem. O coeficiente $\beta 1$ é obtido por (4.17).

$$
\begin{aligned}
& \hat{J}_{S i}=\beta_{1} . i \\
& \beta_{1}=\frac{\sum i_{i} \cdot J_{S i}}{\sum i_{i}{ }^{2}} \\
& \left.\hat{s}_{\left\{J_{S i}\right.}\right\}=\frac{S Q_{e}}{n-2}=\frac{\sum\left(J_{S i}-\beta_{1} . i\right)^{2}}{n-2}
\end{aligned}
$$

onde $s\left\{\hat{J_{S i}}\right\}$ é estimativa da desvio-padrão e n os graus de liberdade

As bandas de confiança permitem visualizar a região que a regressão abrange. Os pontos experimentais devem estar dentro dela para que o modelo seja 
adequado. Para obter as bandas, utiliza-se o fator Working-Hotteling (W) e os valores limites calculam-se por (4.19) e (4.20), de acordo com (Kutner, 2004).

$$
\begin{aligned}
& W^{2}=2 . F(1-\alpha ; 2 ; n-2) \\
& \hat{J}_{S_{i}} \pm W . s\left\{\hat{J}_{S_{i}}\right\}
\end{aligned}
$$

Os limites das bandas são obtidos pra cada ponto experimental, mas foram extrapolados para toda a faixa de i.

\subsubsection{Superfície de resposta}

A superfície de resposta engloba uma série de técnicas para relacionar a resposta obtida com as variáveis (ou fatores) de entrada (Box, 1978). Os gráficos levantados, a partir das equações obtidas por meio dessa técnica, permitem visualizar a influência dos fatores nas respostas.

As equações devem ser do tipo que apresente boa aproximação dos pontos experimentais. Essa aproximação é conseguida com o método dos mínimos quadrados, assim como na regressão linear.

Para as análises, usaram-se equações de $1^{\circ}$ (4.21) e 2ํㅜㄴ.22) graus.

$$
\begin{aligned}
& Y_{1}=\alpha_{0}+\alpha_{1} x_{1}+\alpha_{2} x_{2}+\varepsilon \\
& Y_{2}=\beta_{0}+\beta_{1} x_{1}+\beta_{2} x_{2}+\beta_{3} x_{1} x_{2}+\beta_{4} x_{1}^{2}+\beta_{5} x_{2}^{2}+\varepsilon
\end{aligned}
$$




\section{RESULTADOS E DISCUSSÃO}

Os resultados serão divididos em quatro partes:
a) Resultados dos experimentos exploratórios,
b) Resultados dos experimentos comparativos,
c) Modelo do fenômeno de separação.

\subsection{Experimentos exploratórios}

Considerando-se que o fluxo salino $\left(\mathrm{J}_{\mathrm{S}}\right)$ é o mais importante na eletrodiálise, analisou-se o comportamento desse fluxo diante dos fatores densidade de corrente elétrica (i), concentração inicial da alimentação (C) e vazão volumétrica das soluções (Q). Com propósito ilustrativo, a figura 5.1 apresenta o comportamento de um experimento qualquer.

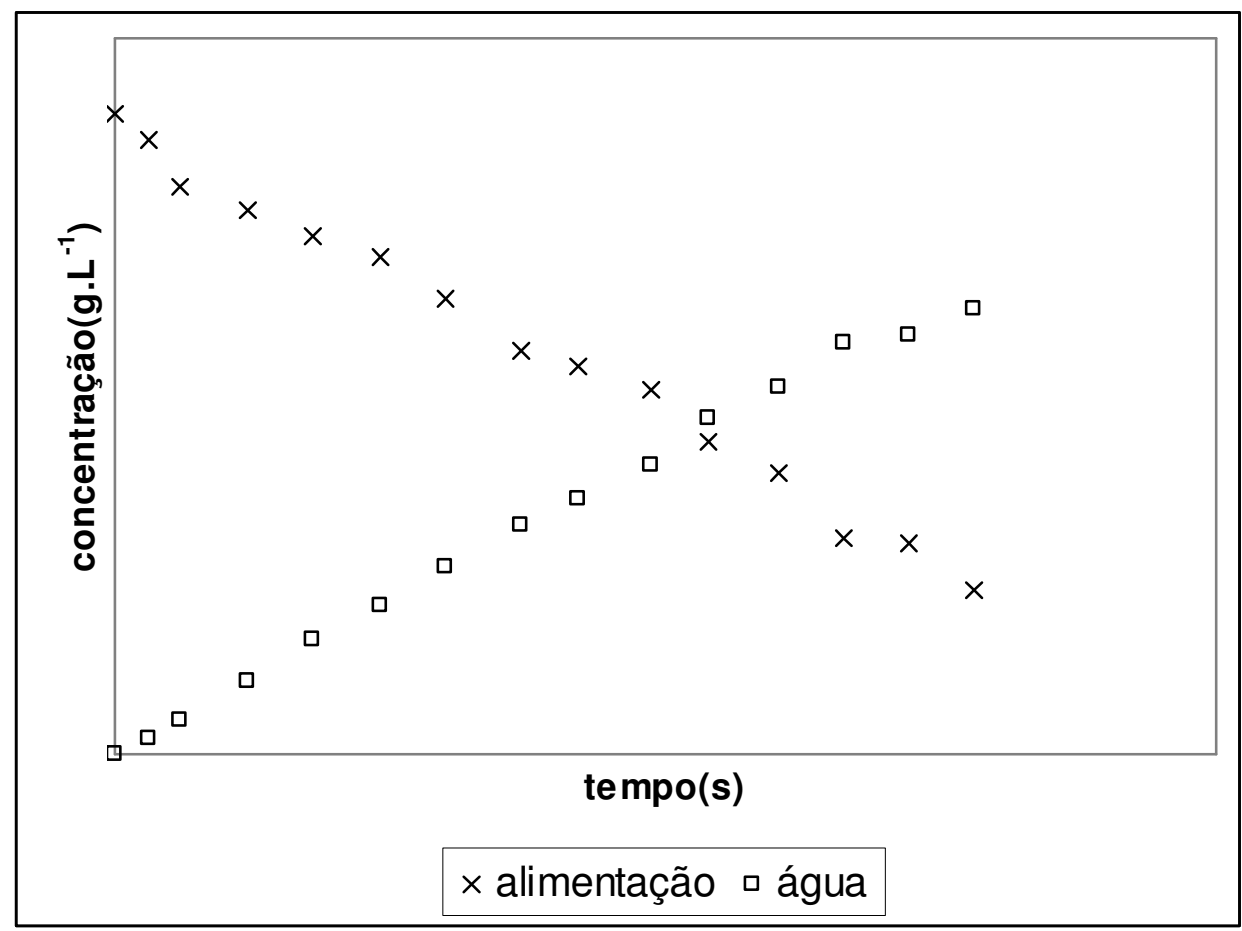

Figura 5.1.Evolução da condutividade dos tanques de alimentação e água obtidas em um experimento qualquer. 
Supõe-se que não houve variação na composição do cloreto de sódio que atravessa as membranas da alimentação para o água, ou seja, para cada íon $\mathrm{Na}^{+}$ que atravessou a membrana, um $\mathrm{Cl}^{-}$também atravessou. Caso houvesse diferença entre os fluxos de $\mathrm{Na}^{+}$e $\mathrm{Cl}^{-}$, haveria mudança de $\mathrm{pH}$ em ambos os tanques, pois os íons $\mathrm{H}^{+}$e $\mathrm{OH}^{-}$, substituiriam as duas primeiras espécies no transporte iônico.

Tabela 5.1.Fluxos médios de sal (Js) obtidos nos experimentos exploratórios

\begin{tabular}{|c|c|c|c|}
\hline $\begin{array}{c}\text { Diferença de } \\
\text { concentração } \\
\text { inicial }(\mathrm{C}) \\
{\left[\mathrm{g} \cdot \mathrm{L}^{-1}\right]}\end{array}$ & $\begin{array}{c}\text { Densidade de } \\
\text { corrente } \\
\text { elétrica (i) } \\
{\left[A \cdot \mathrm{m}^{-2}\right]}\end{array}$ & $\begin{array}{c}\text { Vazão de } \\
\text { soluções } \\
(\mathrm{V}) \\
{\left[\mathrm{L} \cdot \mathrm{h}^{-1}\right]}\end{array}$ & $\begin{array}{c}\mathrm{J}_{\mathrm{s}} \cdot 10^{3} \\
{\left[\mathrm{~kg} \cdot \mathrm{s}^{-1} \cdot \mathrm{m}^{-2}\right]}\end{array}$ \\
\hline 25 & 200 & 45 & 0.22 \\
\hline 45 & 200 & 45 & 0.28 \\
\hline 25 & 350 & 45 & 0.41 \\
\hline 45 & 350 & 45 & 0.39 \\
\hline 25 & 200 & 75 & 0.22 \\
\hline 45 & 200 & 75 & 0.26 \\
\hline 25 & 350 & 75 & 0.43 \\
\hline 45 & 350 & 75 & 0.35 \\
\hline 35 & 275 & 60 & 0.32 \\
\hline 35 & 275 & 60 & 0.32 \\
\hline 35 & 275 & 60 & 0.35 \\
\hline
\end{tabular}

Tabela 5.2.Análise de variância do fluxo de sal $\left(\mathrm{J}_{\mathrm{s}} \cdot 10^{3}\right)$ dos experimentos exploratório

\begin{tabular}{lcccccc}
\hline Fonte & $\mathrm{GL}$ & $\mathrm{SC}$ sec. & $\mathrm{SC}$ ajust. & $\mathrm{MC}$ ajust. & $\mathrm{F}$ & $\mathrm{P}$ \\
\hline Efeitos principais & 3 & 0.04567 & 0.04567 & 0.01522 & 80.18 & 0.002 \\
$\quad$ Interação de 2 fatores & 3 & 0.00645 & 0.00645 & 0.00215 & 11.34 & 0.038 \\
Interação de 3 fatores & 1 & 0.00027 & 0.00027 & 0.00027 & 1.46 & 0.313 \\
Erro residual & 3 & 0.00057 & 0.00057 & 0.00019 & & \\
$\quad$ Falta de ajuste & 1 & 0.00012 & 0.00012 & 0.00012 & 0.58 & 0.526 \\
$\quad$ Erro puro & 2 & 0.00044 & 0.00044 & 0.00022 & & \\
Total & 10 & 0.05298 & & & & \\
\hline
\end{tabular}

Os resultados apresentados referem-se aos experimentos exploratórios com soluções de $\mathrm{NaCl}$, conforme o planejamento fatorial completo mostrado na Tabela 4.3. 
Tabela 5.3.Análise de variância dos fatores sobre o fluxo de sal $\left(\mathrm{Js} .10^{3}\right)$ nos experimentos exploratórios

\begin{tabular}{lccccc}
\hline \multicolumn{1}{c}{ Termo } & Efeito & Coef & Coef. de EE & $\mathrm{T}$ & $\mathrm{P}$ \\
\hline Constante & & 0.32235 & 0.004155 & 77.58 & 0 \\
$\mathrm{C}$ & -0.00083 & -0.00042 & 0.004872 & -0.09 & 0.937 \\
$\mathrm{i}$ & 0.15064 & 0.07532 & 0.004872 & 15.46 & 0.001 \\
$\mathrm{~V}$ & -0.01204 & -0.00602 & 0.004872 & -1.24 & 0.305 \\
$\mathrm{C}{ }^{*} \mathrm{i}$ & -0.05224 & -0.02612 & 0.004872 & -5.36 & 0.013 \\
$\mathrm{C}^{*} \mathrm{~V}$ & -0.02235 & -0.01118 & 0.004872 & -2.29 & 0.106 \\
$\mathrm{i}^{*} \mathrm{~V}$ & 0.00069 & 0.00034 & 0.004872 & 0.07 & 0.948 \\
$\mathrm{C}^{*} \mathrm{i}^{*} \mathrm{~V}$ & -0.01178 & -0.00589 & 0.004872 & -1.21 & 0.313 \\
\hline
\end{tabular}

$$
J_{S}=\alpha_{0}+\alpha_{1} \cdot i+\alpha_{12} \cdot i \cdot C=-0.1125+0.0011 . i-0.0000034 . i . C
$$

A partir da tabela 5.2, consegue-se verificar que as interações entre 3 fatores não é significativa com $95 \%$ de confiança, pois tem valor $P[=0,313]$ maior que $5 \%$ [=1-0,95]. Assim, as interações entre 2 fatores e os efeitos principais são siginificativos com a mesma confiança. Parte-se, então, para análise discriminada apresentada na tabela 5.3. Nessa segunda tabela, observamos que "i" e "C*i" são significativos.

Dessa forma, não á nenhum fator relacionado com a vazão que seja significativo. Isso pode ser justificado pelo regime de turbulência em que ocorreram os experimentos, pois o menor valor de Reynolds [Re] é 2,6.10³.

$\mathrm{Na}$ sequência, os experimentos comparativos foram realizados sem o fator vazão, o que é apresentado na tabela 4.4. Essa é a principal conclusão retirada dos experimentos exploratórios.

\subsection{Densidade de corrente limite}

Antes dos experimentos comparativos foram realizados experimentos para determinar a corrente limite $\left(i_{\text {lim }}\right)$. Os resultados não são precisos, mas servem de indicativos para os valores de $i$ utilizados nos comparativos. Para cada sal escolheuse a condição de menor concentração inicial de alimentação $(C)$ e maior densidade 
de corrente ( $I)$, o que fornece o menor valor de $\mathrm{i}_{\mathrm{lim}}$, dentro no planejamento experimental.

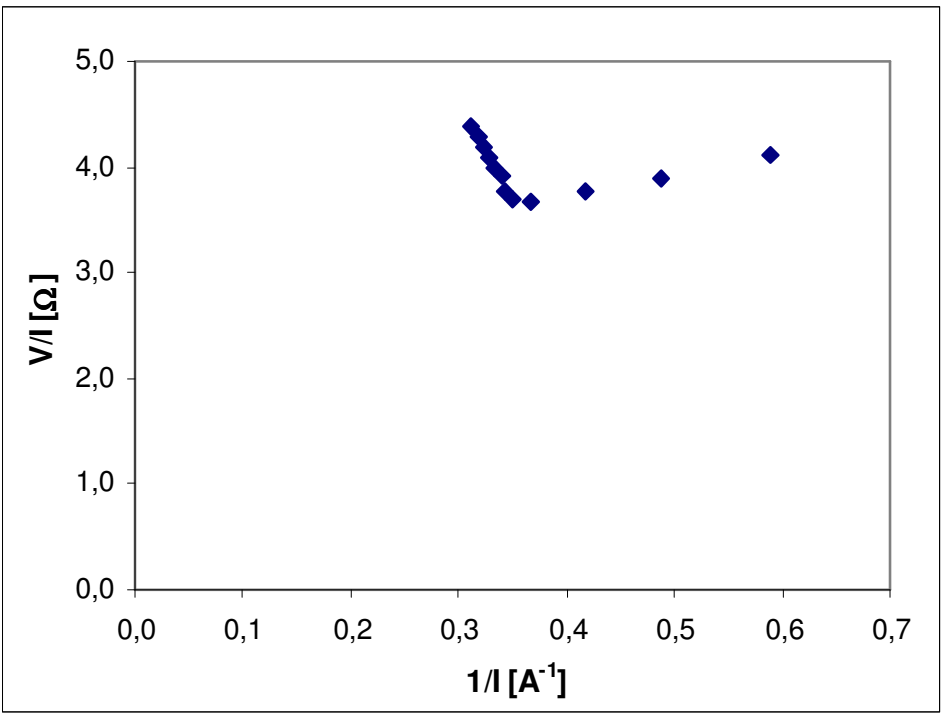

Figura 5.2 Curva obtida para solução de $\mathrm{NaCl}$ na aplicação do método de Cowan \& Brown, 1959.

Tabela 5.4. Densidade de corrente limit $\epsilon$

\begin{tabular}{|c|c|}
\hline Sal & $\mathrm{i}_{\mathrm{i} i m}\left[\mathrm{~A} \cdot \mathrm{m}^{-2}\right]$ \\
\hline $\mathrm{NaCl}$ & 460 \\
\hline $\mathrm{Na}_{2} \mathrm{SO}_{4}$ & 469 \\
\hline $\mathrm{MgCl}_{2}$ & 458 \\
\hline $\mathrm{KCl}$ & 465 \\
\hline
\end{tabular}

Os valores de $I_{\text {lim }}$ experimentais, para os quatro sais, ficaram em torno de 460A. $\mathrm{m}^{-2}$,conforme a tabela 5.4. o que é coerente com a igualdade de concentração de equivalentes químicos. Dessa forma, $0,8 . \mathrm{i}_{\lim }\left(=368 \mathrm{~A} \cdot \mathrm{m}^{-2}\right)$ está acima dos maiores valores de densidade de corrente utilizados nos experimentos (350 A.m.

\subsection{Experimentos comparativos}

A segunda etapa do trabalho consiste na comparação entre os fluxos de íons para as soluções de $\mathrm{NaCl}, \mathrm{Na}_{2} \mathrm{SO}_{4}, \mathrm{KCl}$ e $\mathrm{MgCl}_{2}$. Para efeito de comparação, o 
planejamento experimental baseou-se em soluções iguais em base de equivalentes químicos. O planejamento utilizado foi apresentado na tabela 4.4.

\subsubsection{Fluxos salinos $\left(\mathrm{J}_{\mathrm{S}}\right)$}

A determinação dos coeficientes dos modelos de fluxos salinos $\left(\mathrm{J}_{S}\right)$ foi feita por regressão linear pelo método dos mínimos quadrados, a partir dos valores da tabela 5.5 .

Tabela 5.5. Fluxos de sal $\left(\mathrm{J}_{\mathrm{S}}\right)$ obtidos nos experimento comparativos

\begin{tabular}{ccccccccc}
\hline \multicolumn{7}{c}{ Fatores } & \multicolumn{2}{c}{ Fatores não- } \\
Exp. & codificados & \multicolumn{2}{c}{ codificados } & & Js. $10^{3}$. eq.s ${ }^{-1} \cdot \mathrm{m}^{-2}$ & \\
& $\mathrm{i}$ & $\mathrm{C}$ & $\mathrm{i}$ & $\mathrm{C}$ & $\mathrm{NaCl}$ & $\mathrm{Na}_{2} \mathrm{SO}_{4}$ & $\mathrm{MgCl}_{2}$ & $\mathrm{KCl}$ \\
\hline 1 & 0 & 0 & 200 & 0,45 & 2,061 & 2,049 & 2,380 & 2,146 \\
2 & 1 & 0 & 300 & 0,45 & 2,967 & 2,845 & 3,351 & 3,035 \\
3 & 0,5 & 0,866 & 250 & 0,58 & 2,498 & 2,442 & 2,987 & 2,550 \\
4 & -1 & 0 & 100 & 0,45 & 0,950 & 0,922 & 1,100 & 0,995 \\
5 & $-0,5$ & $-0,866$ & 150 & 0,32 & 1,685 & 1,645 & 1,945 & 1,632 \\
6 & 0,5 & $-0,866$ & 250 & 0,32 & 2,480 & 2,383 & 2,758 & 2,448 \\
7 & $-0,5$ & 0,866 & 150 & 0,58 & 1,645 & 1,580 & 1,861 & 1,666 \\
\hline 8 & 0 & 0 & 200 & 0,45 & 2,091 & 2,054 & 2,330 & 2,139 \\
9 & 1 & 0 & 300 & 0,45 & 3,001 & 2,511 & 3,256 & 2,856 \\
10 & 0,5 & 0,866 & 250 & 0,58 & 3,183 & 2,545 & 2,994 & 2,573 \\
11 & -1 & 0 & 100 & 0,45 & 1,052 & 0,953 & 1,123 & 0,981 \\
12 & $-0,5$ & $-0,866$ & 150 & 0,32 & 1,665 & 1,661 & 1,916 & 1,642 \\
13 & 0,5 & $-0,866$ & 250 & 0,32 & 2,519 & 2,509 & 3,183 & 2,639 \\
14 & $-0,5$ & 0,866 & 150 & 0,58 & 1,686 & 1,625 & 1,908 & 1,697 \\
\hline & & & & & & & & \\
\hline
\end{tabular}

A análise de resíduos condiz com a hipótese de $\varepsilon$ nulo. A figura 5.3 mostra os resíduos aproximando-se de uma reta no gráfico de probabilidade normal. A figura 5.4 apresenta os resíduos bem distribuídos ao redor do zero. Isso confirma a hipótese de $\varepsilon=\left(0, \sigma^{2}\right)$. 

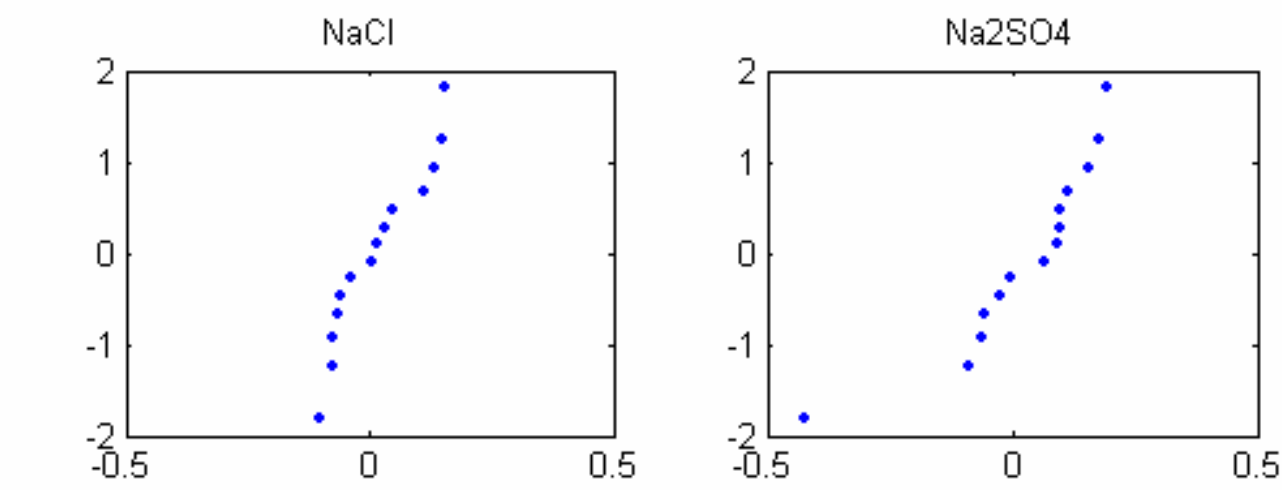

$M$
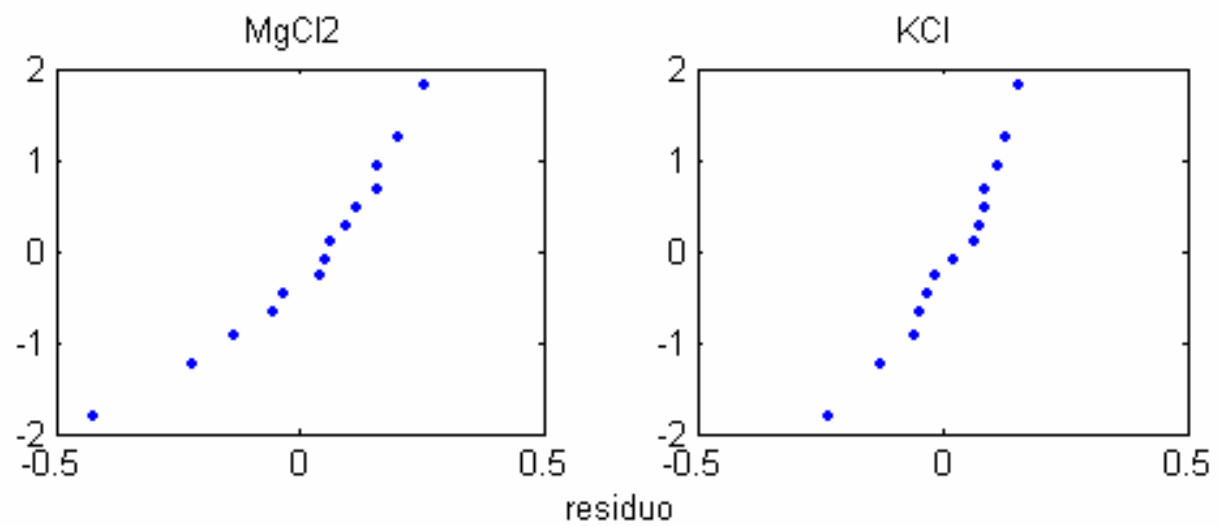

Figura 5.3.Gráfico do resíduo de $\mathrm{J}_{\mathrm{S}}$ para ajuste linear em papel de probabilidade normal

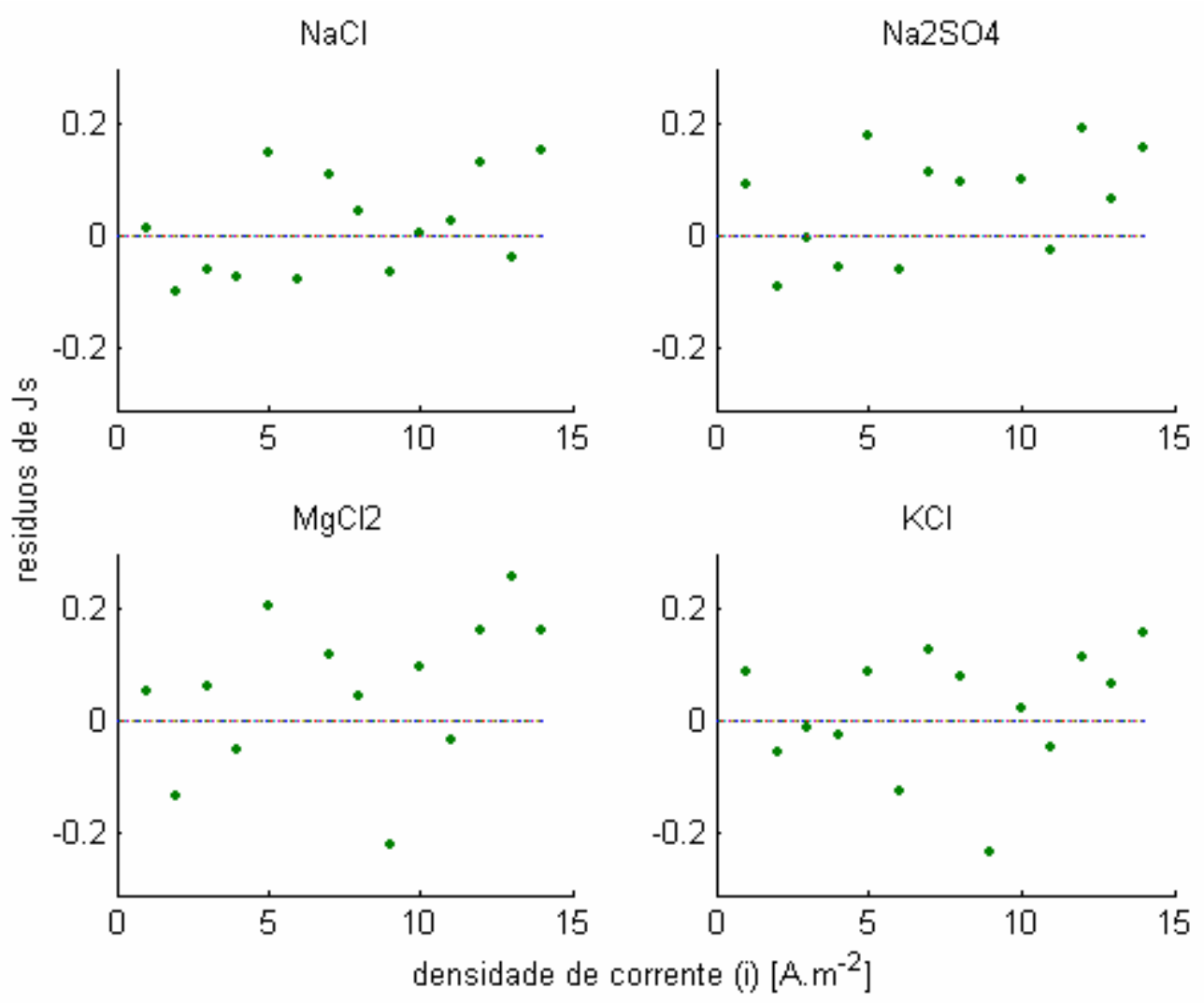

Figura 5.4.Gráfico da distribuição dos erros de $\mathrm{J}_{S}$ para os respectivos ajustes lineares 
Tabela 5.6. Análise de variância para o modelo de Js de $\mathrm{NaCl}$

\begin{tabular}{lcccc}
\hline Fator & $\mathrm{GL}$ & $\mathrm{SQ}$ & $\mathrm{MQ}$ & $\mathrm{F}$ \\
\hline Regressão & 4 & 6.249 & 1.562 & 128.3 \\
Erro & 9 & 0.110 & 0.012 & \\
Total & 13 & 6.359 & & \\
\hline
\end{tabular}

Tabela 5.7. Análise de variância para o modelo de Js de $\mathrm{Na}_{2} \mathrm{SO}_{4}$

\begin{tabular}{lcccc}
\hline Fator & $\mathrm{GL}$ & $\mathrm{SQ}$ & $\mathrm{MQ}$ & $\mathrm{F}$ \\
\hline Regressão & 4 & 5.326 & 1.331 & 12.96 \\
Erro & 9 & 0.925 & 0.103 & \\
Total & 13 & 6.250 & & \\
\hline
\end{tabular}

Tabela 5.8. Análise de variância para o modelo de Js de $\mathrm{MgCl}_{2}$

\begin{tabular}{lcccc}
\hline Fator & $\mathrm{GL}$ & $\mathrm{SQ}$ & $\mathrm{MQ}$ & $\mathrm{F}$ \\
\hline Regressão & 4 & 7.555 & 1.888 & 14.29 \\
Erro & 9 & 1.189 & 0.132 & \\
Total & 13 & 8.744 & & \\
\hline
\end{tabular}

Tabela 5.9. Análise de variância para o modelo de Js de $\mathrm{KCl}$

\begin{tabular}{lcccc}
\hline Fator & $\mathrm{GL}$ & $\mathrm{SQ}$ & $\mathrm{MQ}$ & $\mathrm{F}$ \\
\hline Regressão & 4 & 5.847 & 1.462 & 17.01 \\
Erro & 9 & 0.773 & 0.086 & \\
Total & 13 & 6.620 & & \\
\hline
\end{tabular}

A hipótese testada é $H_{0}: \beta_{1}=0$, ou seja, se o coeficiente angular é nulo. Todos os quatro $\mathrm{F}$ calculados são maiores que $\mathrm{F}_{0.95,4,9}=4.26$. Logo, as análises de variância de $J_{S}$ (tabelas 5.6 a 5.9) indicam que $H_{0}$ deve ser rejeitado. Portanto, os coeficientes $\beta_{1}$ ajustam-se aos dados empíricos, com 99\% de confiança. (Figura 5.5)

No planejamento experimental existem 7 experimentos diferentes combinando i e $\mathrm{C}$ em diferentes níveis. São 5 níveis de i e 3 de $C$. Ao desconsiderar $C$ na regressão linear, o planejamento fica todo em função de i. Por isso, as tabelas acima apresentam 4 graus de liberdade na regressão.

A análise da tabela 5.10 indica que os fluxos de sai semelhantes. Com exceção de $\mathrm{MgCl}_{2}$, todos os demais fluxos tem variação de, no máximo, $5 \%$ em relação ao melhor fluxo $\left(\mathrm{Na}_{2} \mathrm{SO}_{4}\right)$. 
Tabela 5.10. Equações obtidas para $\mathrm{J}_{\mathrm{S}}\left[10^{-3} \mathrm{eq} \cdot \mathrm{m}^{-2} \cdot \mathrm{s}^{-1}\right]$

\begin{tabular}{lc} 
Fator & equação \\
\hline $\mathrm{NaCl}$ & $J_{S}=0.0102 . i$ \\
$\mathrm{Na}_{2} \mathrm{SO}_{4}$ & $J_{S}=0.0098 . i$ \\
$\mathrm{MgCl}_{2}$ & $J_{S}=0.0117 . i$ \\
$\mathrm{KCl}$ & $J_{S}=0.0103 . i$ \\
\hline
\end{tabular}

Levantaram-se as curvas com a presença dos pontos experimentais (figura 5.5) e a representação dos intervalos de confiança de $95 \%$. Com ela é notável que as a aproximação dos modelos por retas em função da densidade de corrente, passando pela origem, representa os sistemas de fluxo sal $\left(\mathrm{J}_{\mathrm{s}}\right)$.

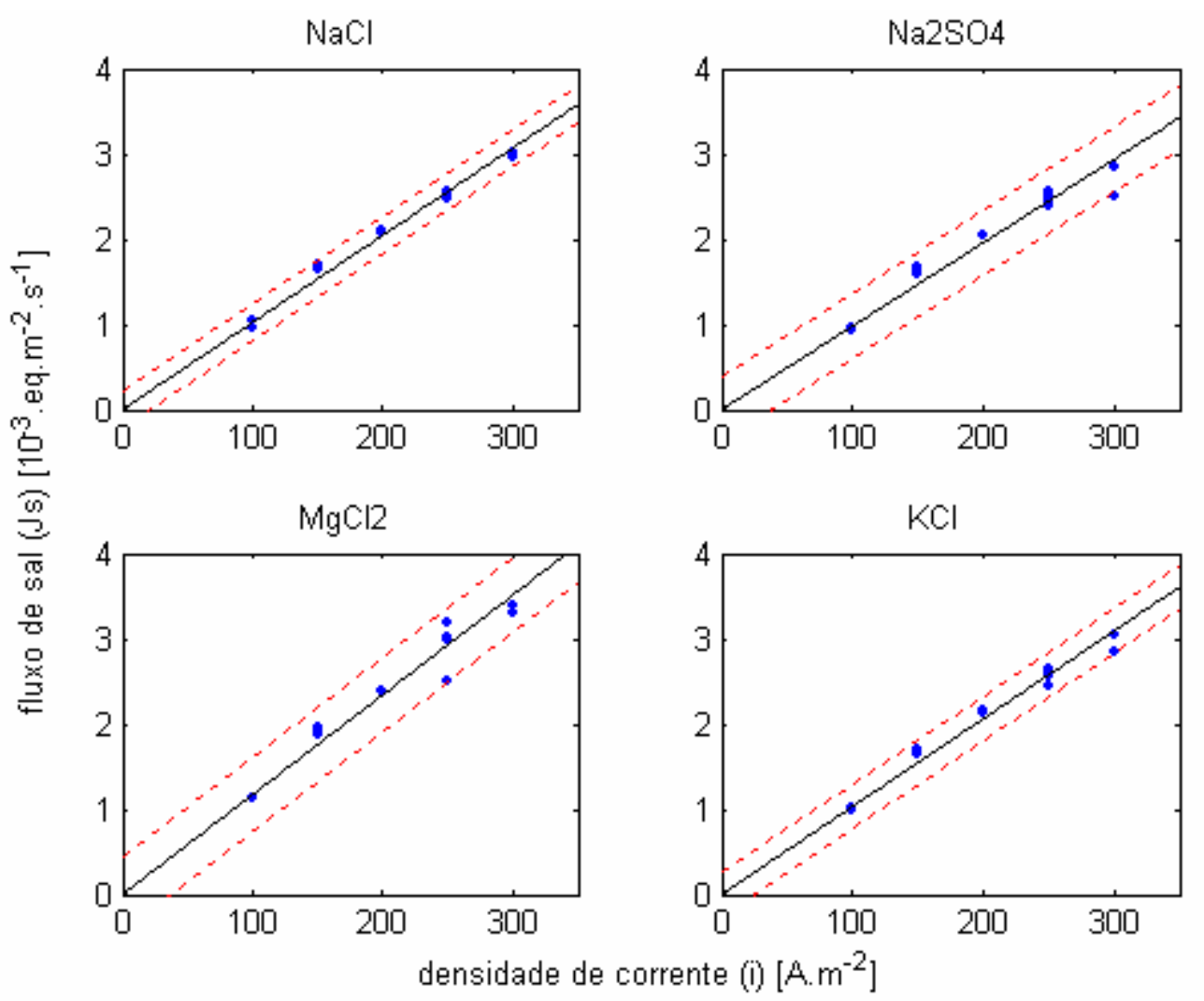

Figura 5.5.Pontos experimentais e modelo da regressão com bandas de confiança (95\%).

Portanto, a aproximação por uma reta passando pela origem é adequada para o modelo de $\mathrm{J}_{\mathrm{S}}$, como pode ser visualizado na figura 5.5 . 


\subsubsection{Fluxo de água $\left(J_{V}\right)$}

A regressão linear aplicada para $J_{V}$ não pode ser feita da mesma forma que $J_{S}$, pois $J_{V}$ é variável durante os experimentos. A variação na diferença de concentração entre os tanques $(\Delta \mathrm{C})$ altera o transporte por osmose $\left(\mathrm{J}_{\mathrm{V}}\right)$. A diferença é dada por 5.2.

$$
\Delta C=C_{D}-C_{C}
$$

Durante os experimentos, i foi considerada constante. Supõe-se que $\Delta \mathrm{C}$ é constante entre duas medidas. Com essa suposição, foi calculado o valor médio de $J_{V}$ nos intervalos de medição ao longo de cada experimento.

Juntaram-se os valores numa única tabela para todos os experimentos com determinado sal. A partir dessa tabela compilada, foi feita a análise estatística mostrada a seguir.

As figuras 5.6, 5.8, 5.10 e 5.12 confirmam a hipótese de erro nulo com distribuição normal. Em todos os casos, os erros estão distribuídos em torno de zero. Os gráficos de distribuição normal (figuras 5.7, 5.9, 5.11 e 5.13) aproximam-se por retas, o que confirma a normalidade de distribuição.

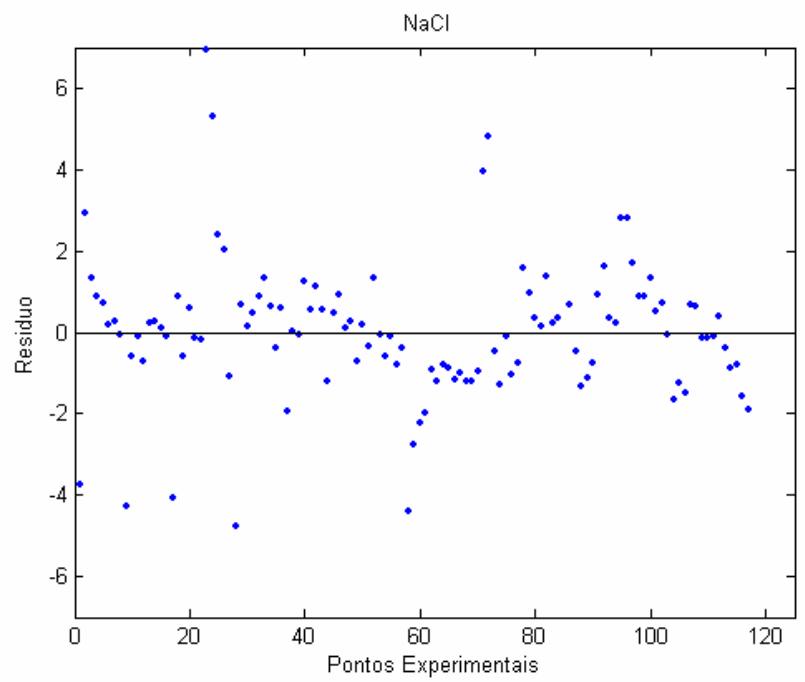

Figura 5.6.Distribuição dos resíduos de $\mathrm{J}_{v}$ de $\mathrm{NaCl}$ 


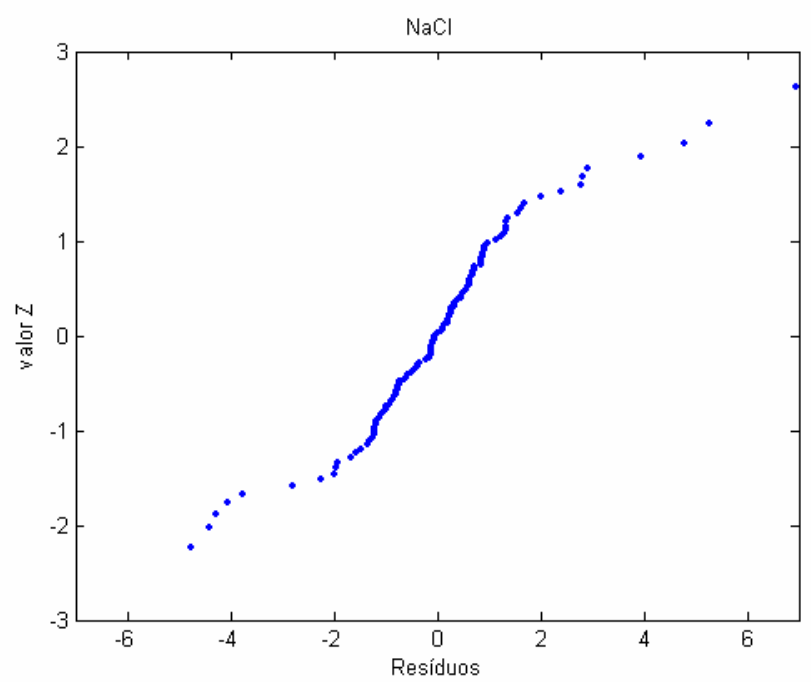

Figura 5.7.Distribuição dos resíduos de $\mathrm{J}_{V}$ de $\mathrm{NaCl}$ no gráfico de probabilidade normal

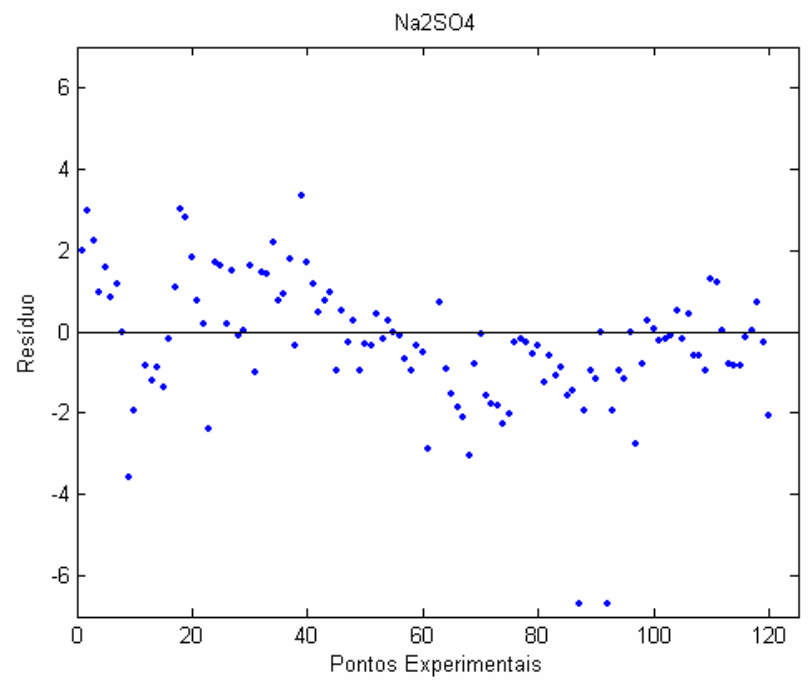

Figura 5.8.Distribuição dos resíduos de $\mathrm{J}_{V}$ de $\mathrm{Na}_{2} \mathrm{SO}_{4}$

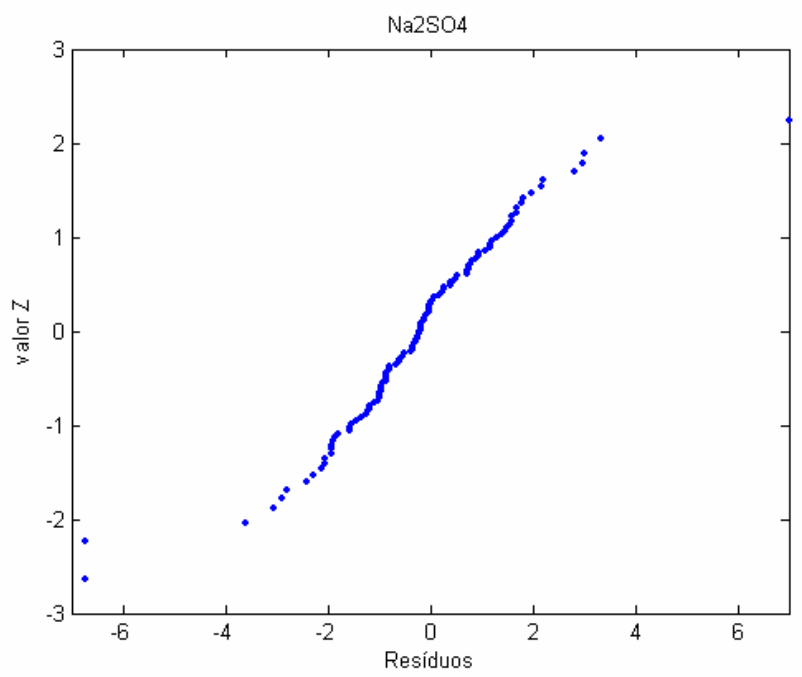

Figura 5.9.Distribuição dos resíduos de $\mathrm{J}_{V}$ de $\mathrm{Na}_{2} \mathrm{SO}_{4}$ no gráfico de probabilidade normal 


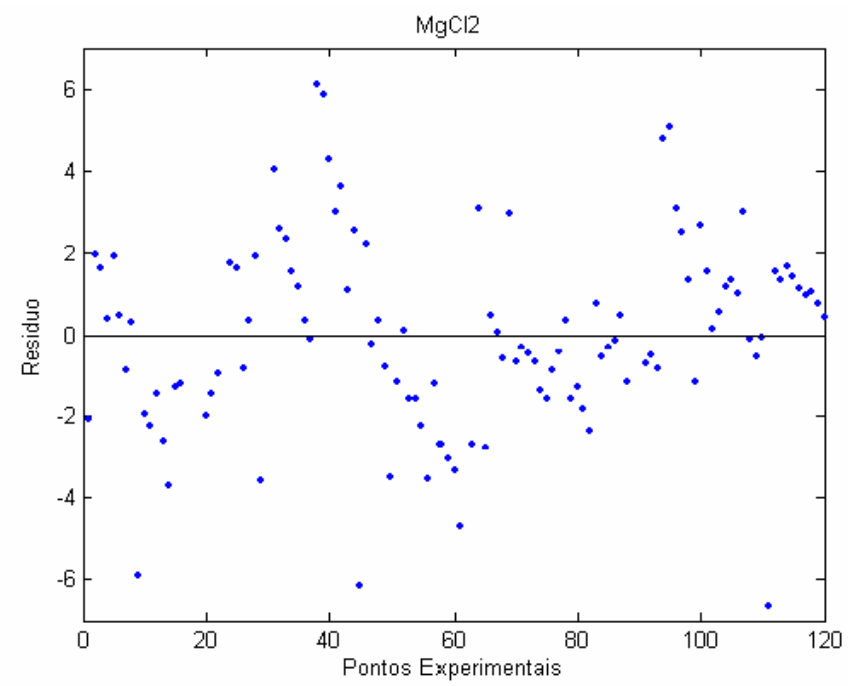

Figura 5.10. Distribuição dos resíduos de $\mathrm{J}_{\mathrm{V}}$ de $\mathrm{MgCl}_{2}$

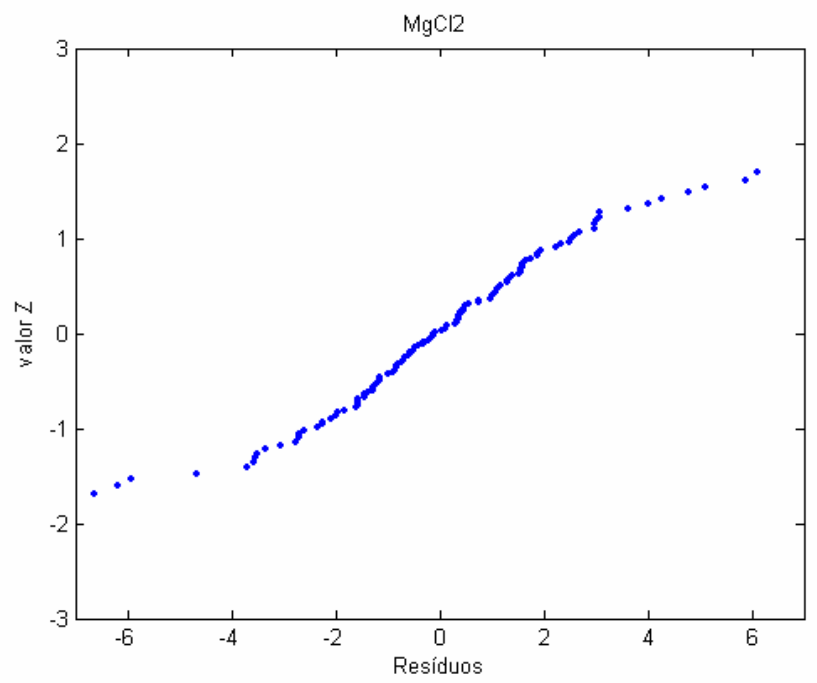

Figura 5.11.Distribuição dos resíduos de $\mathrm{J}_{\mathrm{v}}$ de $\mathrm{MgCl}_{2}$ no gráfico de probabilidade normal

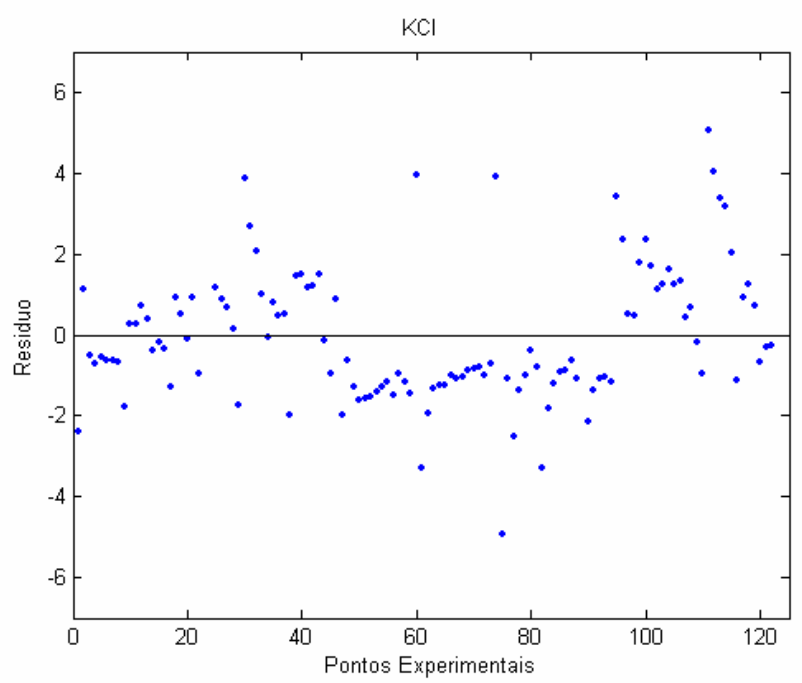

Figura 5.12.Distribuição dos resíduos de $J_{v}$ de $\mathrm{KCl}$ 


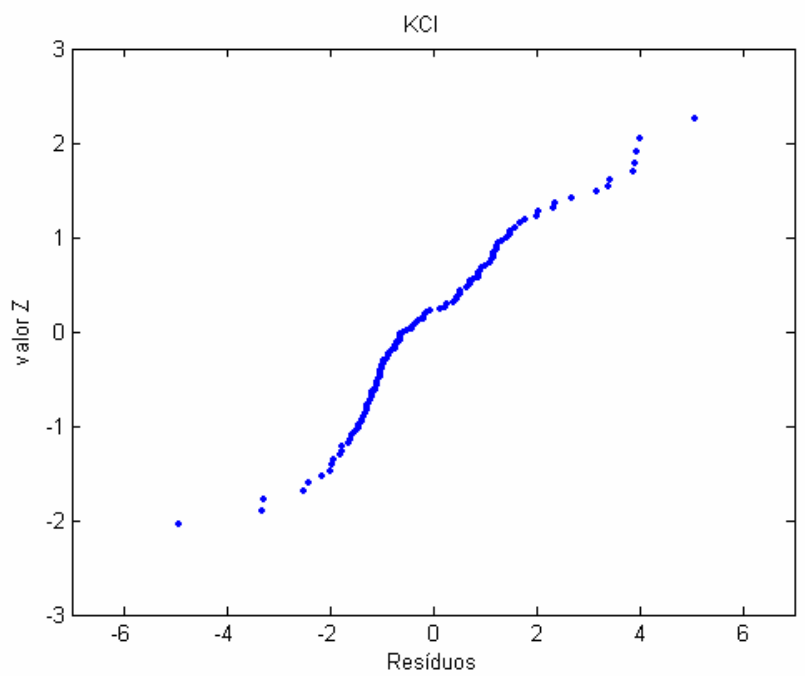

Figura 5.13.Distribuição dos resíduos de $J_{V}$ de $\mathrm{KCl}$ no gráfico de probabilidade normal

Foi realizada uma ANOVA a fim de verificar a adequação da regressão. Os graus de liberdade $(\mathrm{GL})$ da regressão são dados por $(p-1)$, onde $p$ são os parâmetros estimados. Os $\mathrm{GL}$ do erro, por $(n-p)$, onde $n$ são os pontos experimentais obtidos.

Realizaram-se os experimentos com $i$ constante. Porém, no início do experimento, há uma elevação de $i$ até que atinja o valor a ser operado em cada experimento. Isso é devido à variação da condutividade das soluções. Apenas os pontos com $i$ constante foram usados na regressão. Sendo assim, há diferença entre a quantidade de pontos usados nas regressões de $\mathrm{J}_{\mathrm{V}}$.

As tabelas abaixo indicam que os valores de $\mathrm{F}$ calculados são muito maiores que $F_{0.95 ; 1 ; 120}=3.92$. Logo, os coeficientes são adequados aos pontos experimentais.

Por esses resultados pode-se inferir que os modelos matemáticos obtidos (tabela 5.15) adequam os pontos experimentais com 95\% de confiança. Logo, tanto densidade de corrente como diferença de concentração (osmose) influem no fluxo de água através das membranas.

Tabela 5.11. Análise de variância para o modelo de $\mathrm{J}_{V}$ de $\mathrm{NaCl}$

\begin{tabular}{lcccc}
\hline Fator & $\mathrm{GL}$ & $\mathrm{SQ}$ & $\mathrm{MQ}$ & $\mathrm{F}$ \\
\hline Regressão & 1 & 1.008 & 1.008 & 742 \\
Erro & 115 & 0.155 & 0.001 & \\
Total & 116 & 1.163 & & \\
\hline
\end{tabular}


Tabela 5.12. Análise de variância para o modelo de $\mathrm{JV}_{V}$ de $\mathrm{Na}_{2} \mathrm{SO}_{4}$

\begin{tabular}{lcccc}
\hline Fator & $\mathrm{GL}$ & $\mathrm{SQ}$ & $\mathrm{MQ}$ & $\mathrm{F}$ \\
\hline Regressão & 1 & 0.747 & 0.747 & 747 \\
Erro & 118 & 0.133 & 0.001 & \\
Total & 119 & 0.880 & & \\
\hline
\end{tabular}

Tabela 5.13. Análise de variância para o modelo de $\mathrm{JV}_{\mathrm{V}}$ de $\mathrm{MgCl}_{2}$

\begin{tabular}{lcccc}
\hline Fator & $\mathrm{GL}$ & $\mathrm{SQ}$ & $\mathrm{MQ}$ & $\mathrm{F}$ \\
\hline Regressão & 1 & 1.223 & 1.223 & 244 \\
Erro & 120 & 0.611 & 0.005 & \\
Total & 121 & 1.8434 & & \\
\hline
\end{tabular}

Tabela 5.14. Análise de variância para o modelo de $\mathrm{J}_{V}$ de $\mathrm{KCl}$

\begin{tabular}{lcccc}
\hline Fator & $\mathrm{GL}$ & $\mathrm{SQ}$ & $\mathrm{MQ}$ & $\mathrm{F}$ \\
\hline Regressão & 1 & 0.994 & 0.994 & 56.2 \\
Erro & 120 & 2.123 & 0.018 & \\
Total & 121 & 3.117 & & \\
\hline
\end{tabular}

$\mathrm{Na}$ sequência são expostas as figuras (5.14 a 5.17) com os pontos experimentais em comparação aos modelos matemáticos (superfície de resposta). No caso dos íons monovalentes, as superfícies têm menor inclinação em relação aos dois fatores.

Tal fato pode significar que os íons bivalentes possuam maiores valores de número de hidratação $\left(T_{w}\right)$, isto é, possuirem mais moléculas de água solvatadas a eles.

Há, também, o fato de liberarem mais íons quando dissolvidos, ou melhor, os sais divalentes liberam três íons e os monovalentes, dois. Isso acarreta em maior pressão osmótica entre as membranas, já que a pressão depende do número de partículas dissolvidas.

Os fluxos de água negativos são resultado de fluxos osmóticos superiores aos fluxos por solvatação, por isso aparecem nas figuras nas regiões de menores $\Delta C$ (valor negativos) e menores densidades de corrente. 


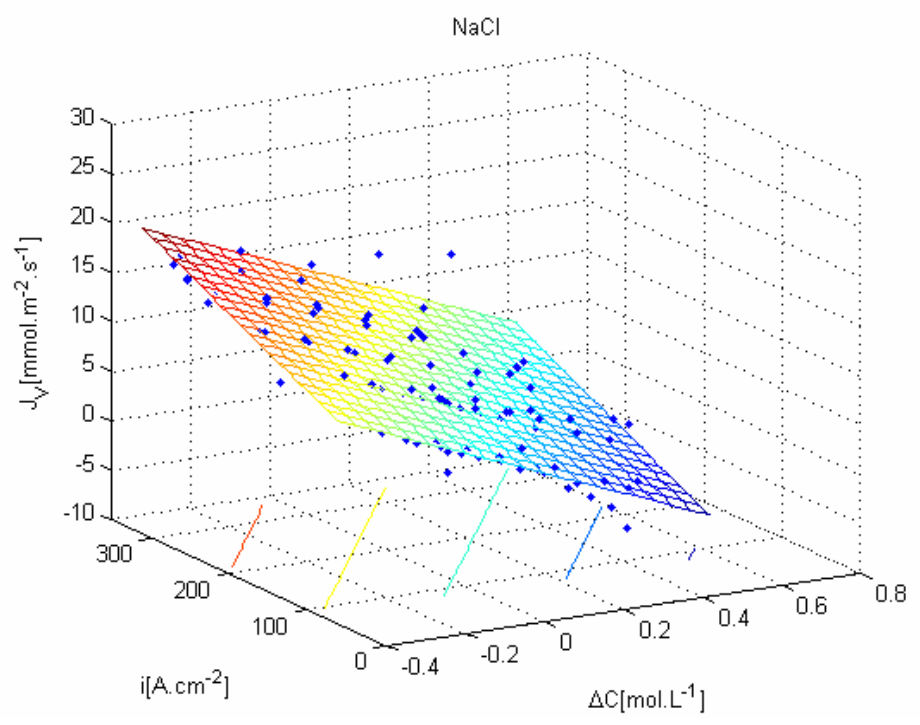

Figura 5.14.Superfície de resposta e pontos experimentais para $\mathrm{J}_{v}$ de $\mathrm{NaCl}$

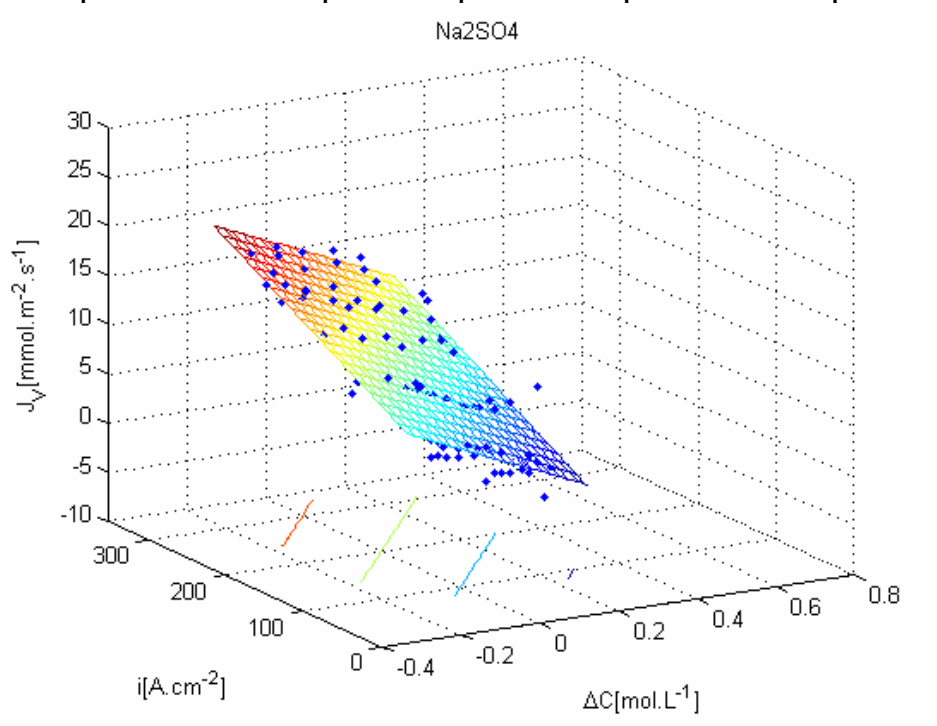

Figura 5.15.Superfície de resposta e pontos experimentais para $\mathrm{J}_{\mathrm{V}}$ de $\mathrm{Na}_{2} \mathrm{SO}_{4}$ $\mathrm{MgCl} 2$

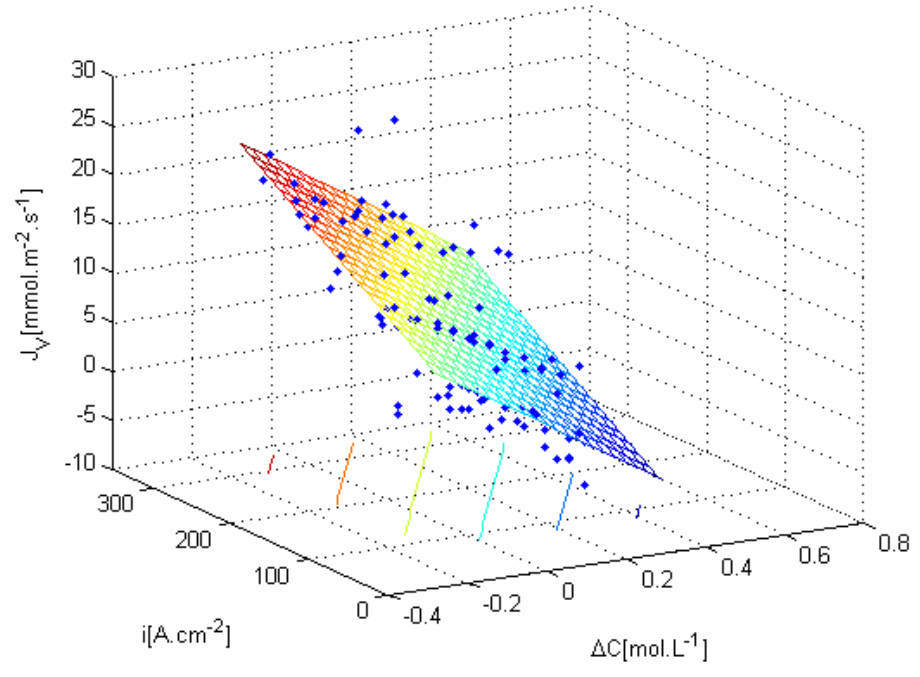

Figura 5.16.Superfície de resposta e pontos experimentais para $\mathrm{Jv}_{\mathrm{V}}$ de $\mathrm{MgCl}_{2}$ 


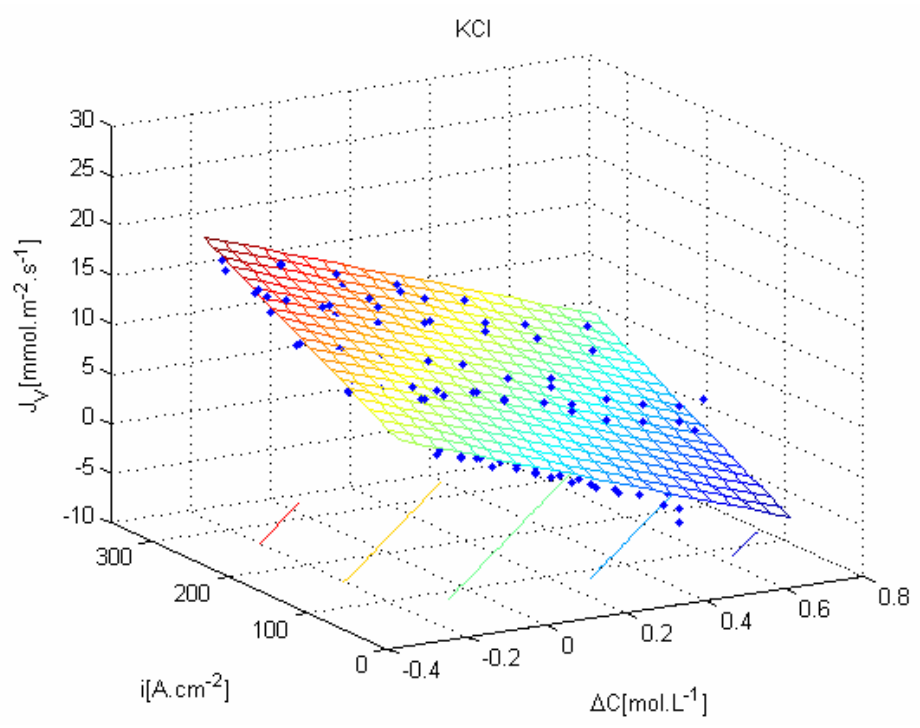

Figura 5.17.Superfície de resposta e pontos experimentais para $\mathrm{J}_{V}$ de $\mathrm{KCl}$

Em seguida, os coeficientes da equação geral (3.10) foram calculados com auxílio do software MATLAB. A tabela 5.15 apresenta as equações obtidas.

\begin{tabular}{lc}
\multicolumn{2}{c}{ Tabela 5.15. Equações obtidas para $J_{V}\left[\mathrm{mmol} \cdot \mathrm{m}^{-2} \cdot \mathrm{s}^{-1}\right]$} \\
\hline $\mathrm{Sal}$ & equação \\
\hline $\mathrm{NaCl}$ & $J_{V}=0.0424 . i-16.14 . \Delta \mathrm{C}$ \\
$\mathrm{Na}_{2} \mathrm{SO}_{4}$ & $J_{v}=0.0494 . i-17.34 . \Delta \mathrm{C}$ \\
$\mathrm{MgCl}_{2}$ & $J_{V}=0.0579 . i-25.09 . \Delta \mathrm{C}$ \\
$\mathrm{KCl}$ & $J_{v}=0.0466 . i-13.96 . \Delta \mathrm{C}$ \\
\hline
\end{tabular}

A primeira vista, os resultados aparentam ser dominado pela osmose devido aos coeficientes das equações da tabela 5.15. No entanto, há de se verificar que a ordem de grandeza da densidade de corrente é cerca de 1000 vezes maior. assim, o fluxo de água é, predominantemente, consequência da densidade de corrente.

Partindo das hipóteses apresentadas na seção 3.4.1.1, os resultados confirmam que há transporte de água por solvatação de íons e por osmose, representados pelos coeficientes de i e $\Delta \mathrm{C}$, respectivamente. Embora não seja simples separar quantitativamente cada um dos mecanismos.

Por tanto, há osmose e eletro-osmose causando o transporte de água através das membranas. 


\subsubsection{Número de hidratação ( $\left.\mathrm{T}_{\mathrm{W}}\right)$}

Com as equações de $J_{V}$ e $J_{S}$ calcularam-se valores de $T_{W}$. Foram fixadas

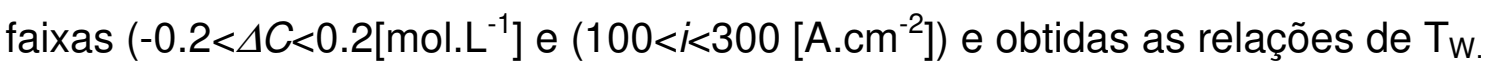

$\mathrm{Na}$ figura 5.18 mostra os pontos calculados para o número de hidratação. Verificam-se três regiões de Tw:

Para $\Delta \mathrm{C}>0$ (alimentação mais concentrada), Tw diminui com o aumento de $\mathrm{i}$, isto é, há uma parcela de fluxo osmótico contrário ao fluxo de íons.

Para $\Delta \mathrm{C}<0$, Tw aumenta com a diminuição de $\mathrm{i}$, isto é, a osmose e o fluxo de íons somam-se.

Em $\Delta \mathrm{C}=0$, Tw não se altera. Logo, a osmose é desprezível em relação ao fluxo salino.

Isso reforça a participação da osmose no fluxo de água. Dessa forma, os valores de $T w$ apresentados na tabela 5.16 são para $\Delta C=0$, buscando retirar a participação da osmose. Os íons monovalentes apresentaram valores maiores que os bivalentes, em base molar. 

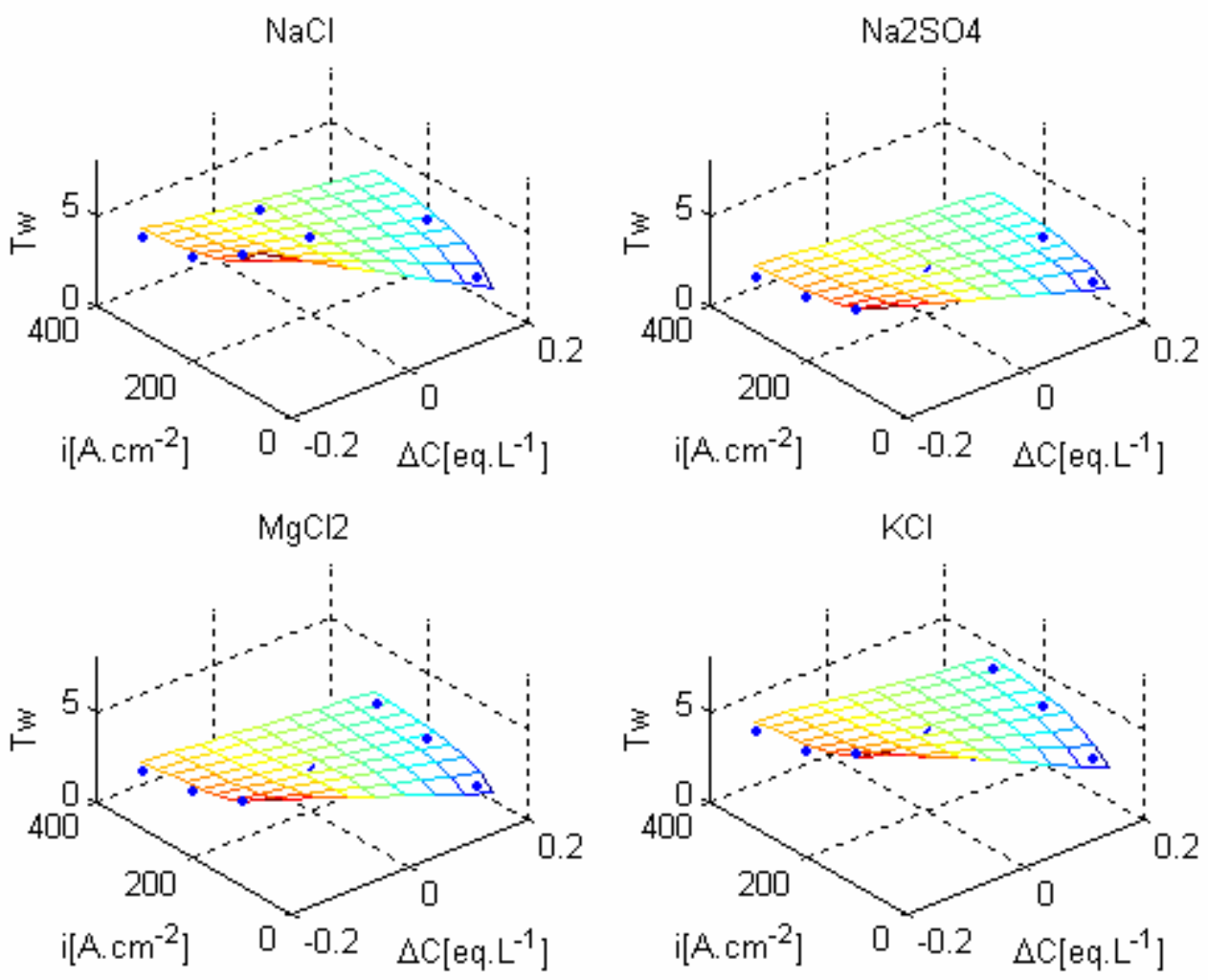

Figura 5.18.Pontos calculados para Tw $\left[\mathrm{molH}_{2} \mathrm{O} . \mathrm{molSal}^{-1}\right]$

Tabela 5.16. Valores de $T_{W}$ para $\Delta C=0$ na faixa de

\begin{tabular}{lc} 
& $100<i<300[$ A.cm \\
\hline Sal & $T_{W}\left[\mathrm{~mol}_{\mathrm{H} 2 \mathrm{O}} \cdot \mathrm{mol}_{\mathrm{Sal}^{-1}}\right]$ \\
\hline $\mathrm{NaCl}$ & 4.16 \\
$\mathrm{Na}_{2} \mathrm{SO}_{4}$ & 2.52 \\
$\mathrm{MgCl}_{2}$ & 2.47 \\
$\mathrm{KCl}$ & 4.52 \\
\hline
\end{tabular}

Dessa tabela, extrai-se que os sais monovalente transportam mais água por mol que os bivalentes. É importante destacar que, matematicamente, não é possível quantificar quanto cada espécie, isoladamente, transporta.

\subsubsection{Consumo de energia}

O consumo energético envolvido na eletrodiálise engloba a energia do bombeamento e a energia associada à separação, propriamente dita, calculada a 
partir da densidade de corrente contínua aplicada sobre o empilhamento de células. Considerou-se apenas a energia envolvida na aplicação de corrente contínua para remoção de íons.

O cálculo da energia consumida pela fonte elétrica foi feito pela integração da curva de potência elétrica ao longo do tempo. A energia consumida dividida pela massa de sal removida da alimentação resultou na tabela 5.17. A tabela 5.18 apresenta a energia por equivalente removido.

Tabela 5.17. Consumo energético por massa removida

\begin{tabular}{ccccccc}
\hline \multicolumn{7}{c}{ Fatores } \\
Exp. & não-codificados & \multicolumn{5}{c}{$\begin{array}{c}\text { Energia por massa } \\
{[\mathrm{Wh} / \mathrm{g}]}\end{array}$} \\
& $\mathrm{i}$ & $\mathrm{C}$ & $\mathrm{NaCl}$ & $\mathrm{Na}_{2} \mathrm{SO}_{4}$ & $\mathrm{KCl}$ & $\mathrm{MgCl}_{2}$ \\
& {$\left[\right.$ A.m $\left.{ }^{-2}\right]$} & {$\left[\right.$ eq. $\left.\mathrm{L}^{-1}\right]$} & & & & \\
\hline 1 & 200 & 0,45 & $0,41 / 0,40$ & $0,39 / 0,39$ & $0,31 / 0,30$ & $0,58 / 0,55$ \\
2 & 300 & 0,45 & $0,58 / 0,58$ & $0,54 / 0,54$ & $0,41 / 0,38$ & $0,84 / 0,80$ \\
3 & 250 & 0,58 & $0,44 / 0,38$ & $0,47 / 0,44$ & $0,31 / 0,31$ & $0,64 / 0,60$ \\
4 & 100 & 0,45 & $0,26 / 0,27$ & $0,25 / 0,25$ & $0,16 / 0,17$ & $0,26 / 0,28$ \\
5 & 150 & 0,32 & $0,36 / 0,37$ & $0,37 / 0,38$ & $0,31 / 0,31$ & $0,54 / 0,49$ \\
6 & 250 & 0,32 & $0,52 / 0,52$ & $0,54 / 0,52$ & $0,42 / 0,39$ & $0,77 / 0,71$ \\
7 & 150 & 0,58 & $0,32 / 0,33$ & $0,32 / 0,30$ & $0,21 / 0,21$ & $0,41 / 0,38$ \\
\hline
\end{tabular}

Tabela 5.18. Consumo energético por equivalente químico

Fatores Energia por massa

Exp. não-codificados [Wh/eq]

\begin{tabular}{ccccccc} 
Exp. & $\mathrm{i}$ & $\mathrm{C}$ & $\mathrm{NaCl}$ & $\mathrm{Na}_{2} \mathrm{SO}_{4}$ & $\mathrm{KCl}$ & $\mathrm{MgCl}_{2}$ \\
& {$\left[\right.$ A.m $\left.{ }^{-2}\right]$} & {$\left[\right.$ eq. $\left.\mathrm{L}^{-1}\right]$} & & & & \\
\hline 1 & 200 & 0,45 & $24,2 / 23,1$ & $27,9 / 27,5$ & $22,8 / 22,2$ & $27,7 / 26,4$ \\
2 & 300 & 0,45 & $33,9 / 34,0$ & $38,2 / 38,2$ & $30,4 / 28,5$ & $39,9 / 38,0$ \\
3 & 250 & 0,58 & $25,7 / 23,5$ & $33,0 / 31,5$ & $23,3 / 23,3$ & $30,4 / 28,6$ \\
4 & 100 & 0,45 & $15,6 / 15,7$ & $17,7 / 18,2$ & $11,8 / 12,8$ & $12,4 / 13,2$ \\
5 & 150 & 0,32 & $21,3 / 21,9$ & $26,4 / 26,8$ & $22,8 / 23,1$ & $25,7 / 23,3$ \\
6 & 250 & 0,32 & $31,1 / 30,3$ & $38,6 / 37,1$ & $31,1 / 29,3$ & $36,6 / 33,7$ \\
7 & 150 & 0,58 & $18,5 / 19,3$ & $21,3 / 21,7$ & $15,7 / 15,3$ & $19,7 / 18,3$ \\
\hline
\end{tabular}

Na literatura, num sistema em escala de laboratório, encontram-se valores de 0,59 kWh/kg (Chen, X; Chen, P.; Tan, Y., 1995) e em plantas industriais de 0,155 kWh/kg (Turek, 2002). Os resultados apresentados estão coerentes com a literatura.

As equações de previsão de consumo de energia resultaram dos dados da tabela 5.17. Primeiro, os dois fatores foram considerados numa regressão linear, conforme visto na figura 5.19. Nota-se que as curvas de nível projetadas no plano 
Oxy são paralelas ao eixo de concentração inicial de alimentação (C). Em razão disso, fez-se nova regressão apenas com o termo em densidade de corrente (i).

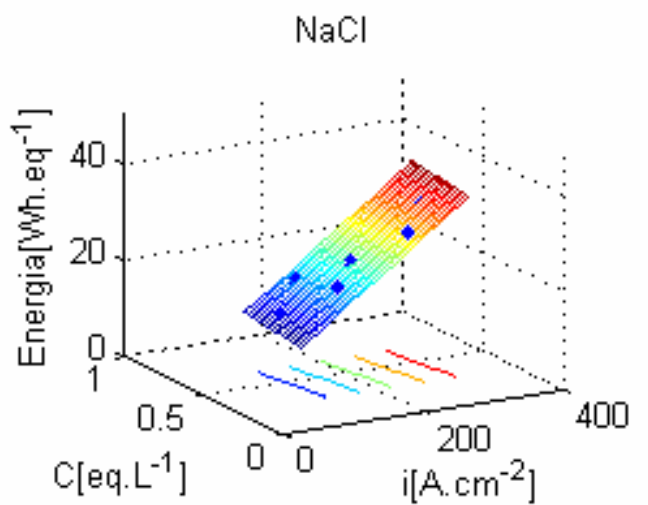

$\mathrm{MgCl} 2$

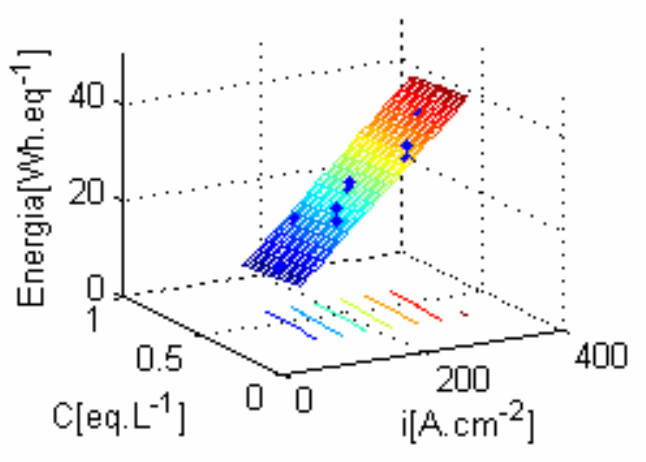

$\mathrm{Na} 2 \mathrm{SO} 4$

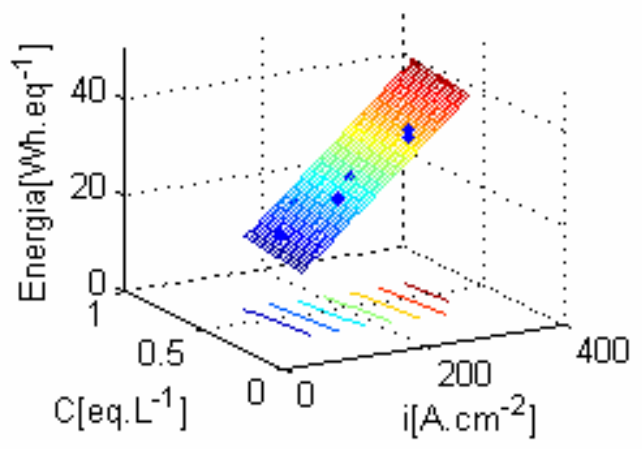

$\mathrm{KCl}$

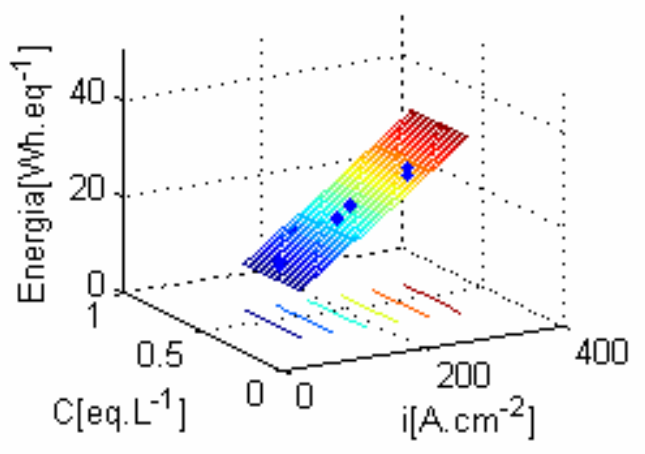

Figura 5.19. Superfície de resposta do consumo energético na remoção de sais
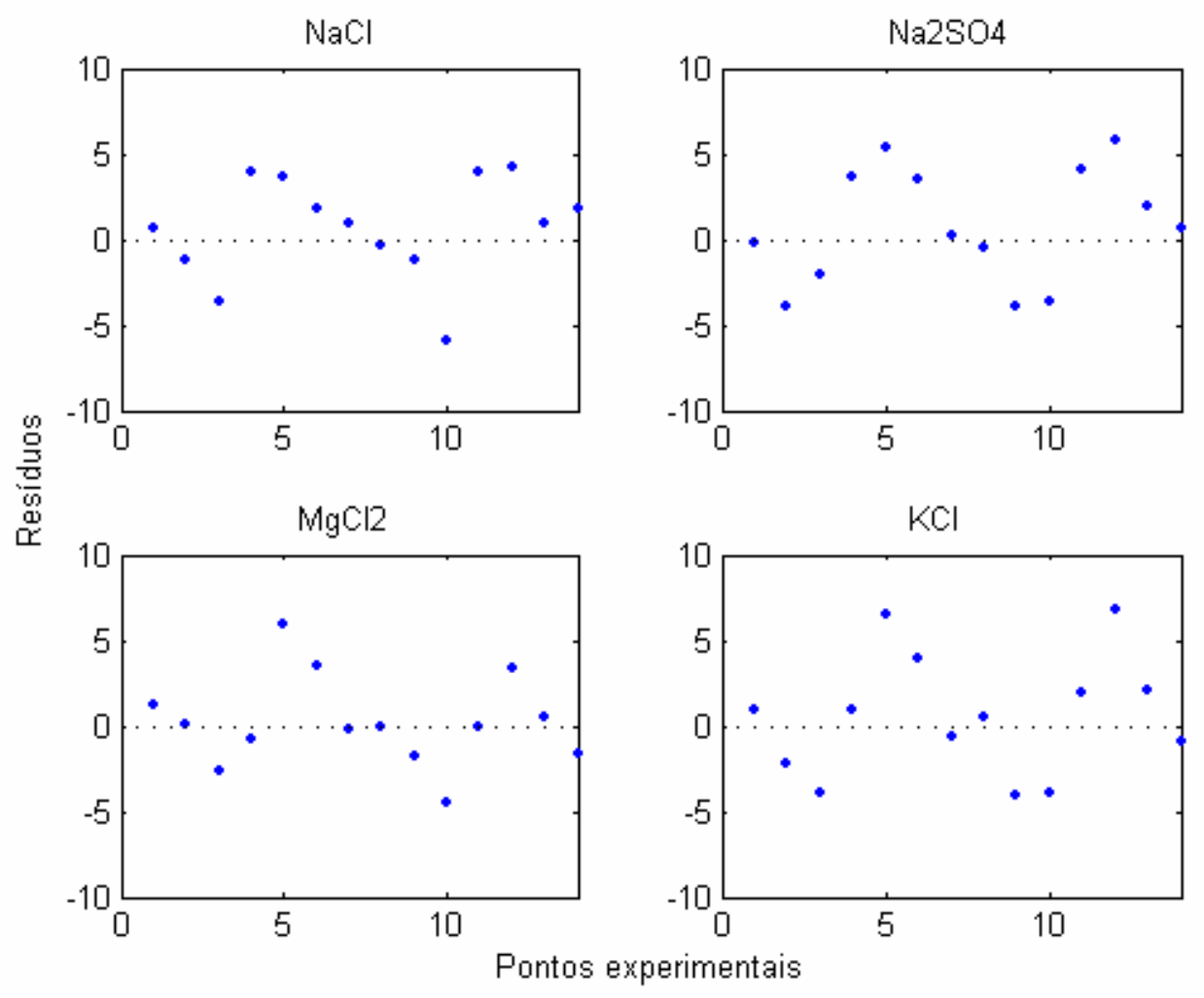

Figura 5.20. Distribuição dos resíduos de energia consumida por equivalente removido 


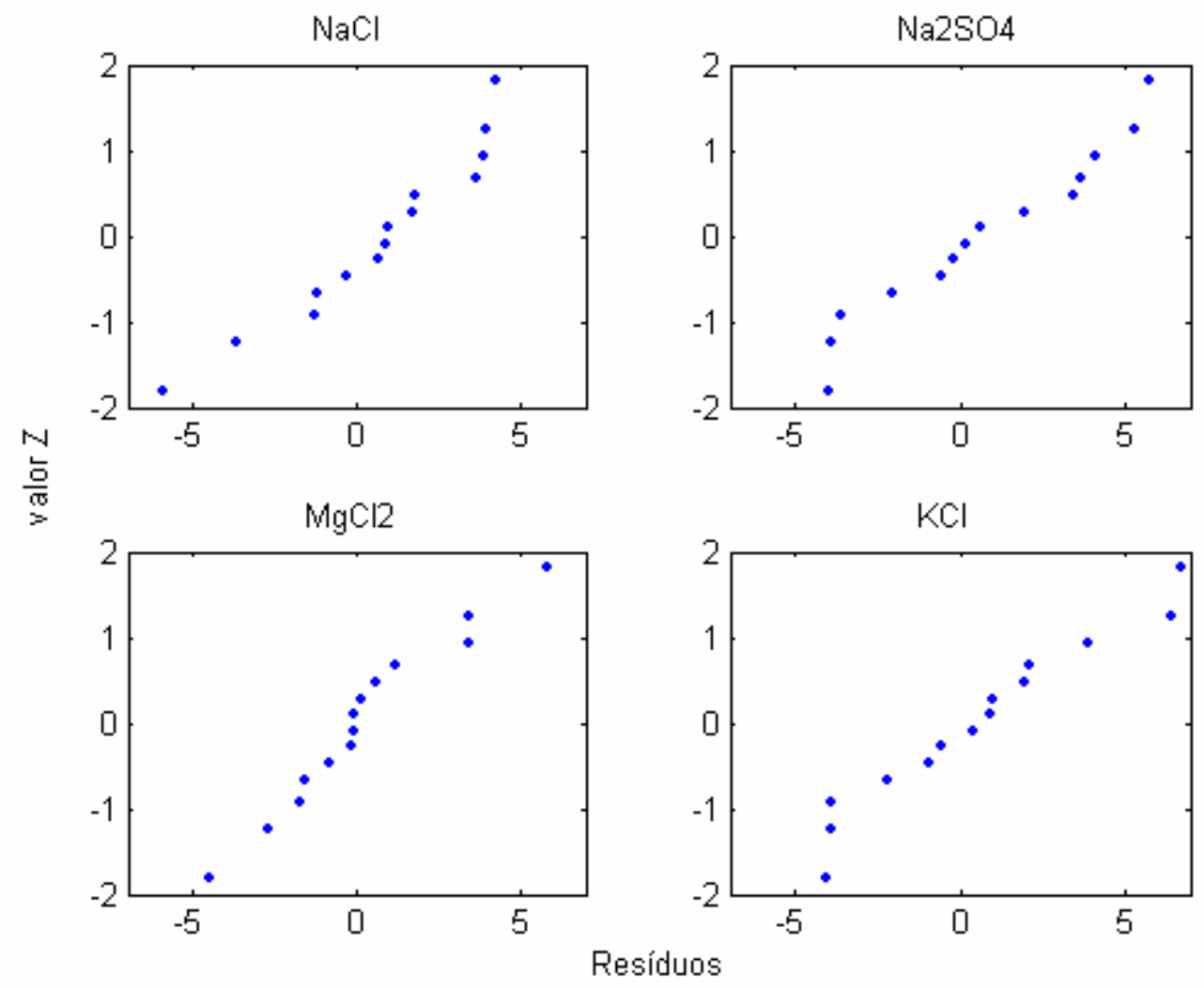

Figura 5.21. Gráfico de probabilidade normal dos resíduos de energia consumida por equivalente removido

Verifica-se que o ajuste é bom, pois os resíduos das equações estão bem distribuídos ao redor de zero (figura 5.20). Esses mesmos resíduos aproximam-se de uma reta no gráfico de probabilidade normal (figura 5.21). As retas obtidas são apresentadas na figura 5.22. As linhas pontilhadas são as bandas de confiança com $95 \%$ de confiança.

Tabela 5.19. Equações obtidas para consumo de energia [Wh.eq ${ }^{-1}$ ]

\begin{tabular}{ll}
\hline Fator & equação \\
\hline $\mathrm{NaCl}$ & $E=0.1174 . i$ \\
$\mathrm{Na}_{2} \mathrm{SO}_{4}$ & $E=0.1404 . i$ \\
$\mathrm{MgCl}_{2}$ & $E=0.1324 . i$ \\
$\mathrm{KCl}$ & $E=0.1088 . i$ \\
\hline
\end{tabular}



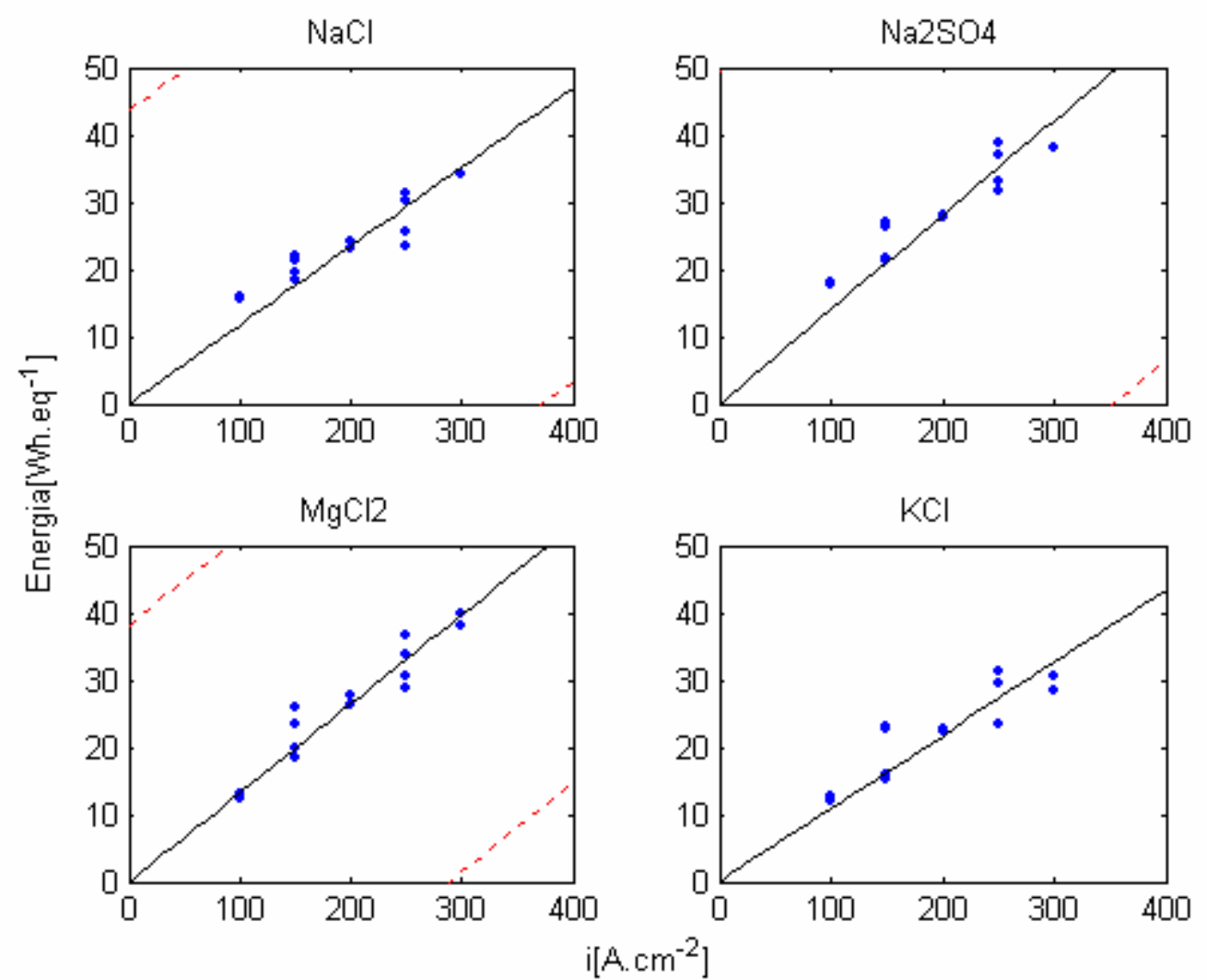

Figura 5.22. Pontos experimentais e curvas obtidas com as bandas de confiança em $95 \%$ para consumo energético para remoção de sais.

Partindo dos resultados, compararam-se os modelos em pares a partir da tabela 5.19.

A primeira conclusão é que a energia necessária é proporcional à densidade de corrente.

Supondo que a energia para remover um equivalente de $\mathrm{Cl}^{-}$é a mesma independente do cátion do sal. A energia necessária para remover um equivalentegrama de $\mathrm{KCl}$ é a menor das quatro. Logo a remoção de $\mathrm{K}^{+}$é mais fácil que $\mathrm{Na}^{+}$. Já o $\mathrm{Mg}^{2+}$ exige maior energia para se remover um equivalente-grama. Dessa forma, a energia necessária para remoção dos cátions é $\mathrm{K}^{+}<\mathrm{Na}^{+}<\mathrm{Mg}^{2+}$.

Fazendo o mesmo raciocínio com $\mathrm{Na}^{+}$, a energia de remoção dos ânions é $\mathrm{SO}_{4}{ }^{2-}>\mathrm{Cl}^{-}$.

Pode-se entender a menor energia para remoção pela maior mobilidade do íon na solução. Quanto mais móvel, mais fácil transportar. 


\section{CONCLUSÕES}

Tendo em vista os objetivos estabelecidos para o trabalho, os resultados possibilitaram obter as seguintes conclusões.

Quanto à montagem do sistema de eletrodiálise, chegou-se ao objetivo pretendido. Nessa etapa do trabalho, foram encontradas dificuldades práticas, principalmente quanto ao dimensionamento, instalação e funcionamento das bombas.

A maior dificuldade foi encontrar bombas que atendessem à demanda energética e resistissem ao meio agressivo. As bombas com partes metálicas enferrujam com pouco tempo de uso e perdem capacidade de bombeamento. Essas bombas utilizadas no processo requerem características específicas. Por esses motivos, as bombas escolhidas são do tipo magnético com rotor de plástico.

Como foi exposto, a corrosão atacou válvulas e manômetro utilizados no início dos trabalhos. Todos os componentes metálicos foram substituídos por plástico ou materiais de aço inox 316 tipo.

Portanto, conclui-se dessas observações que estudos de viabilidade de unidades de eletrodiálise em escala industrial devem considerar o fator de material, o qual encarece os custos de investimento e de manutenção.

Os experimentos exploratórios indicaram que, na faixa de operação, não há influência da vazão no fluxo salino. A partir daí, os experimentos comparativos foram realizados com os outros dois fatores.

O fluxo de sal $\left(J_{S}\right)$ demonstrou-se dependente da densidade de corrente aplicada sobre o empilhamento. Assim como o consumo energético para remoção de íons. Ambos são relacionados apenas com a densidade de corrente com boa aproximação dos valores experimentais

No estudo de transporte de água, observou-se a influência da osmose (diferença de concentração) e da densidade de corrente como principais fatores responsáveis por este fluxo. Dependendo da faixa de diferença de concentração entre os compartimentos, há influência positiva ou negativa sobre o transporte de água. 
Os resultados e conclusões apresentados representam um conjunto importante de informações sobre o processo de dessalinização de soluções aquosas de sais por eletrodiálise.

A partir desses resultados, sugere-se, em futuros trabalhos, a realização de estudos com abordagens: experimental e computacional. A primeira com 0 tratamento de soluções compostas por maior diversidade de íons. A última, no desenvolvimento de modelos de sistemas de eletrodiálise acoplados a outras unidades de processamento em processos, visando seu equacionamento, modelagem e otimização.

Em suma, a pesquisa realizada buscou conhecer melhor o sistema de dessalinização por eletrodiálise. Essa tecnologia ainda é pouco difundida no Brasil, apesar de já ter algumas plantas em funcionamento. 


\section{REFERÊNCIAS}

ATKINS, P.W. Physical chemistry, 6.ed. Oxford, Oxford University Press, New York, 1999.

BAKER, Richard W.; Membrane technology and applications. 2nd ed. Chichester, England: Wiley, 2004.

BORGES, F.J. Integração dos processos de eletrodiálise de degradação fotoquímica para o tratamento de efluentes salinos contendo fenol. 134p. Tese de Doutorado - Programa de Pós-Graduação em Engenharia Química. Escola Politécnica, Universidade de São Paulo, São Paulo, 2009

BOX, G.E.P ; HUNTER, W.G. ; HUNTER, J.S. Statistics for experimenters: An introduction o design, data analysis and model building. John Wiey \& Sons, 1978

CHEN, X.; CHEN, P; TAN, Y.. Electrodialysis for the desalination of seawater and high strength brackish water. Desalination \& Water Reuse Quaterly. v.4, pp. 16-22, 1995.

COMPANHIA DE SANEAMENTO BÁSICO DO ESTADO DE SÃO PAULO. www.sabesp.com.br. Acessado em 01/06/2010.

COWAN, D.A.; BROWN,J.H. Effect of turbulence on limiting current in electrodialysis cells. Industrial Engineering Chemistry Research, [S.I], v.51, p. 1445,1959

DEMIRCIOGLU, M. Demineralization by electrodialysis (ED) - separation performance and cost comparison for monovalente salts. Desalination, v.153, p.329-333, 2002. 
DOEHLERT, David. H. Uniform Shell Designs. Applied Statistics, [S.I], v. 19, n. 3, p. 231-239, 1970.

KUTNER, M. H,; NACHTSHEIM, C. J.; NETER, J. Applied Linear Regression Models. McGraw-Hill Irwin, Boston, 2004.

LIDE, David R. (org.). CRC Handbook of Chemistry and Physics. 86th ed. Boca Raton, Fla; London: Taylor \& Francis, 2005.

MACHULEK, A. Jr. Estudos Mecanísticos da Origem da Inibição da Reação Foto-Fenton por Íons Cloreto. 123p. Tese de Doutorado - Programa de Pós-Graduação em Química (Físico-Química). Instituto de Química, Universidade de São Paulo, São Paulo, 2007.

MONTGOMERY, Douglas C. Applied Statistics and probabilities for engineers. 3rd ed. New York: Wiley, 2003

ODA,Y.; YAWATAYA,T. Neutrality-disturbance phenomenon of membranesolution systems. Desalination. Amsterdam: Elsevier, 1967

RAUTENBACH, R; ALBRECHT, R. Membrane Processes.1st ed. Bath, England: Wiley, 1989.

ROSENBERG, N. W., TIRREL, C. E. Limiting currents in membrane cells. Industrial Engineering Chemical, 49(4), 780-784, 1957.

ROUX-de BALMANN, Hélène, CASADEMONT, Ernest. Électrodialyse. Toulouse. Apostila de disciplina.

STRATHMANN, H. Ion-exchange membrane separation processes. Membrane Science and Technology Series. 1st ed. Amsterdam: Elsevier, v.9, 2004. 
TAKY, M. et al. Polarization phenomena at the interfaces between an electrolyte solution and an ion exchange membrane. Journal Electroanalytical Chemistry, v. 336, pp 171-194, 1992.

TANAKA,Y. Irreversible thermodynamics and overall mass transport. Journal of Membrane Science, n. 281, 517-531. 2006.

TUREK, Marian. Cost effective electrodialytic seawater desalination. Desalination, v.153, pp 371-376, 2002.

VAN DER BRUGGEN, B. Separation of monovalent and divalent ions from aqueous solution by electrodialysis and nanofiltration. Water Researcher, v.38, pp 1347-1353, 2004.

WANGNICK, K. 1990 Worldwide desalting plants inventory: The development of the desalination market. Desalination, v. 81, pp 19-37, 1991.

WITTHOLZ, Michelle K. Estimating the cost of desalination plants using a cost database. Desalination, v. 229, pp 10 - 20, 2008.

ZANG, Y. et al. Separation of nutrient ions and organic componds from salts in RO concentrates by standard na monovalent selective ion-exchange membrane used in electrodialysis. Journal of Membrane Science, v.332, pp 104-112, 2009. 


\section{ANEXO A. CURVAS DE CALIBRAÇÃO DE CONDUTIVIDADE DAS SOLUÇÕES}

As curva de calibração $\left[\mathrm{NaCl}, \mathrm{Na}_{2} \mathrm{SO}_{4}, \mathrm{KCl}\right.$ e $\left.\mathrm{MgCl}_{2}\right]$ foram levantadas na faixa de 0 a 60 g. $\mathrm{L}^{-1}$ que envolve a faixa de concentração usada.

Utilizou-se o Medidor “Accumet $\circledast$ excel', modelo XL 50 da Fischer Scientific.

Para efeito de comparação, as curvas (gráficos A.1 e A.2) apresentam os valores encontrados na literatura (Lide, 2005).

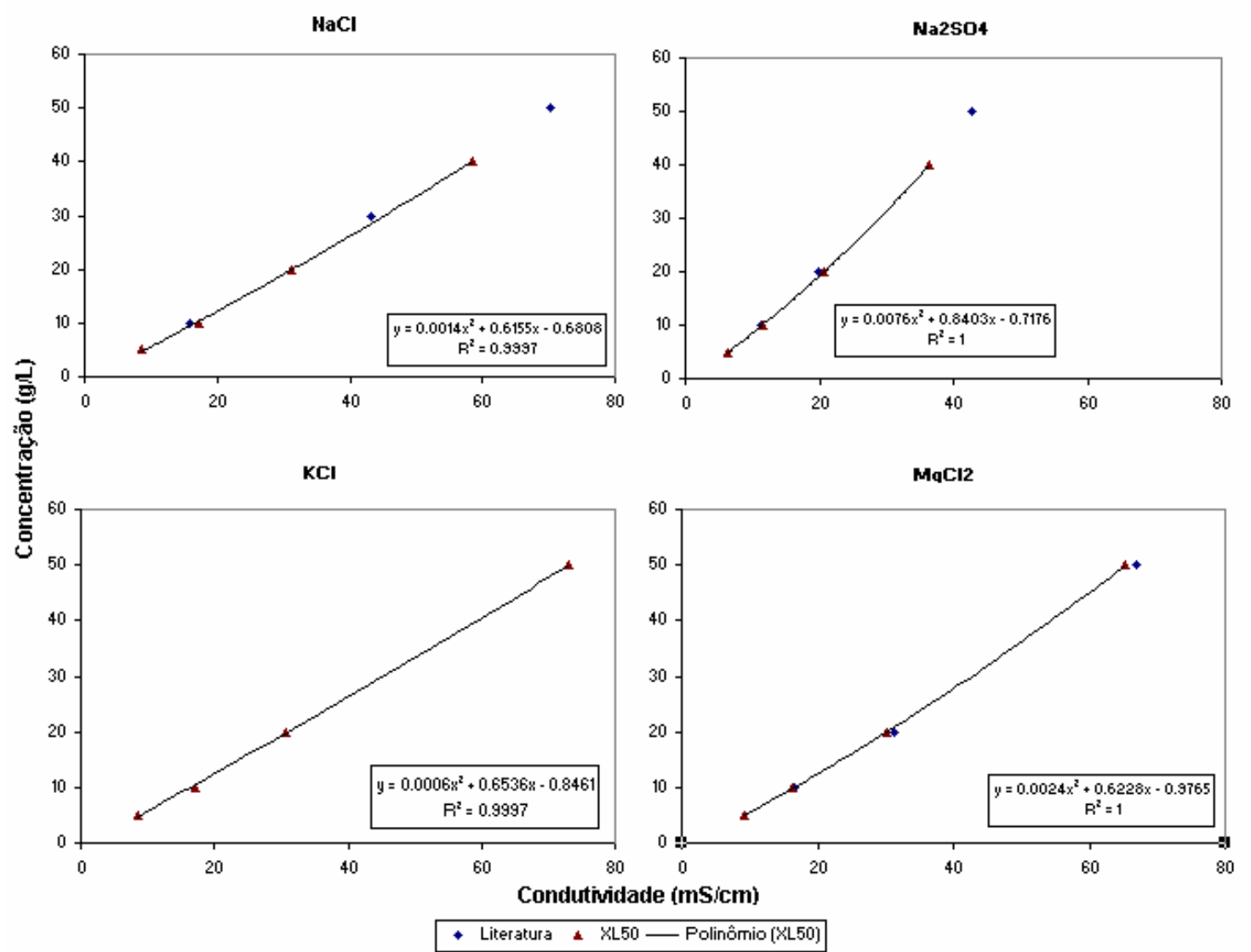

Figura A.1. Curvas de calibração dos sais.

As parábolas obtidas pelo Excel foram usadas para obtenção das concentrações dos sais nos tanques durante os experimentos. 
Tabela A.1 Equações das curvas de calibração

\begin{tabular}{ll}
\hline Sal & \multicolumn{1}{c}{ Equação } \\
\hline $\mathrm{NaCl}$ & $\mathrm{C}_{\mathrm{NaCl}}=0,0014 \cdot \Lambda_{\mathrm{NaCl}}{ }^{2}+0,6155 \cdot \Lambda_{\mathrm{NaCl}}-0,6808$ \\
$\mathrm{Na} 2 \mathrm{SO} 4$ & $\mathrm{C}_{\mathrm{Na} 2 \mathrm{SO} 4}=0,0076 \cdot \Lambda_{\mathrm{Na} 2 \mathrm{SO} 4}{ }^{2}+0,8403 \cdot \Lambda_{\mathrm{Na} 2 \mathrm{SO} 4}-0,7176$ \\
$\mathrm{KCl}$ & $\mathrm{C}_{\mathrm{KCl}}=0,0006 \cdot \Lambda_{\mathrm{KCl}}{ }^{2}+0,6563 \cdot \Lambda_{\mathrm{KCl}}-0,8461$ \\
$\mathrm{MgCl} 2$ & $\mathrm{C}_{\mathrm{MgCl} 2}=0,0024 \cdot \Lambda_{\mathrm{MgCl} 2}{ }^{2}+0,6228 \cdot \Lambda_{\mathrm{MgCl} 2}-0,9765$ \\
\hline
\end{tabular}

As equações da Tabela A.1 foram usadas para converter as condutividades medidas em concentração. 